\title{
MINERALIZAÇÃO, ABSORÇÃO E LIXIVIAÇÃO DE NITROGÊNIO EM POVOAMENTOS DE Eucalyptus grandis SOB CULTIVO MÍNIMO E INTENSIVO DO SOLO
}

\author{
MARIA IZABEL PIRES SERRANO \\ Bióloga
}

Orientador: Prof. Dr. José LEONARDO DE MORAES GONÇALVES

Dissertação apresentada à Escola
Superior de Agricultura "Luiz de
Queiroz", Universidade de são
Paulo, para obtenção do título de
Mestre em Ciências - Área de
Concentração: Ciências Florestais.

PIRACICABA

Estado de São Paulo - Brasil

Setembro - 1997 
Dados Internacionais de Catalogação na Publicação (CIP) DIVISĀo DE BIBLIOTECA E DOCUMENTAÇĀO - Campus "Luiz de Queiroz"/USP

Serrano, Maria lzabel Pires

Mineraçãa, absorção e lixiviação de nitrogênio em povoamentos de Eucalyptus grandis sob cultivo mínimo e intensivo do solo / Maria lzabel Pires Serrano. - Piracicaba, 1997.

$86 \mathrm{p}$.

Dissertaçāo (mestrado) - - Escola Superior de Agricultura Luiz de Queiroz, 1997. Bibliografia.

1. Absorção 2. Cultivo 3. Eucalipto 4. Lixiviação 5. Manejo florestal 6. Mineração 7. Nitrogênio 8. Nutrição 9. Solo florestal ? 


\section{MINERALIZAÇÃO, ABSORÇÃO E LIXIVIAÇÃO DE NITROGÊNIO EM POVOAMENTOS DE Eucalyptus grandis SOB CULTIVO MINIMO E INTENSIVO DO SOLO}

Aprovada em: 17/11/97

Comissão julgadora:

Prof. Dr. Fabio Poggiani

ESALQ/USP

Prof. Dr. José Leonardo de Moraes Gonçalves ESALQ/USP

Prof ${ }^{\text {. }}$ Dra. Marisa de Cassia Piccolo

CENAIUSP

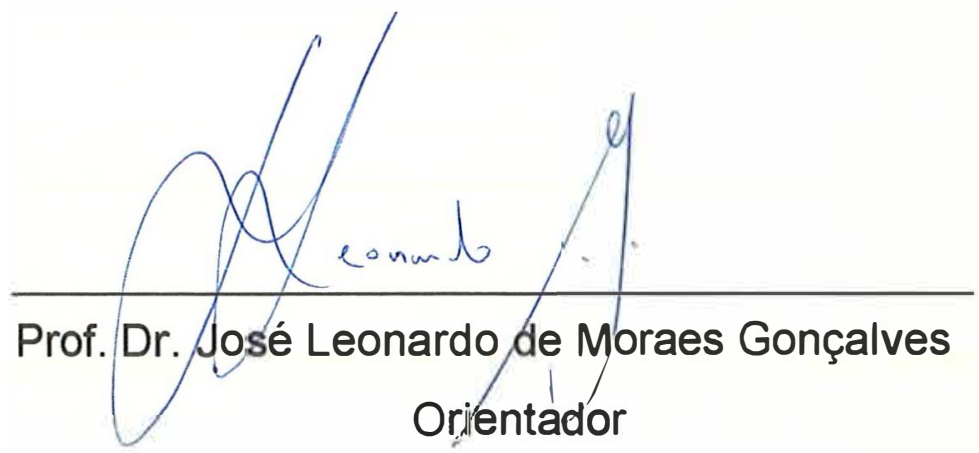




\section{OIDERECO}

LOB meur pais, Laura e Eerrano, irmãos: Carloe Elberto (Beto), Bilmia Helema (EII), Mlademir Ricardo (Mlade) e Endré Luir, Bobrinhol: Rodrigo, Manrioio, Maroela, Maupioio Felis e Dominit Rafael, por exibtirem em minha pida ... Por farerem-me euportar a dor da aubênola, apenaß, pela alegria de nobBo reencontro... "Na Baudade dercobrinos una colisa entranha: denejamos encontrar no futuro, aquilo que já experimentamos como alegria no pareado"

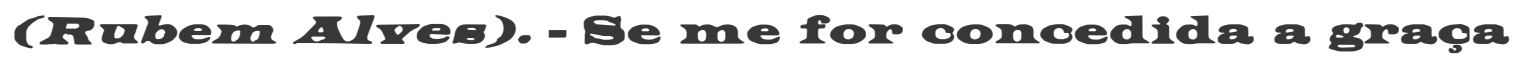
de escolher de noro minha familia, quero rocể nowamente :!!

DIDICO

Eo meu pai, José Plres Eerramo Filho (in memorian)

De quem guardo o Eapirito, GaudadeB... Maria Trabel Piren Serpano 


\section{JOSÉ PIRES SERRANO FILHO}

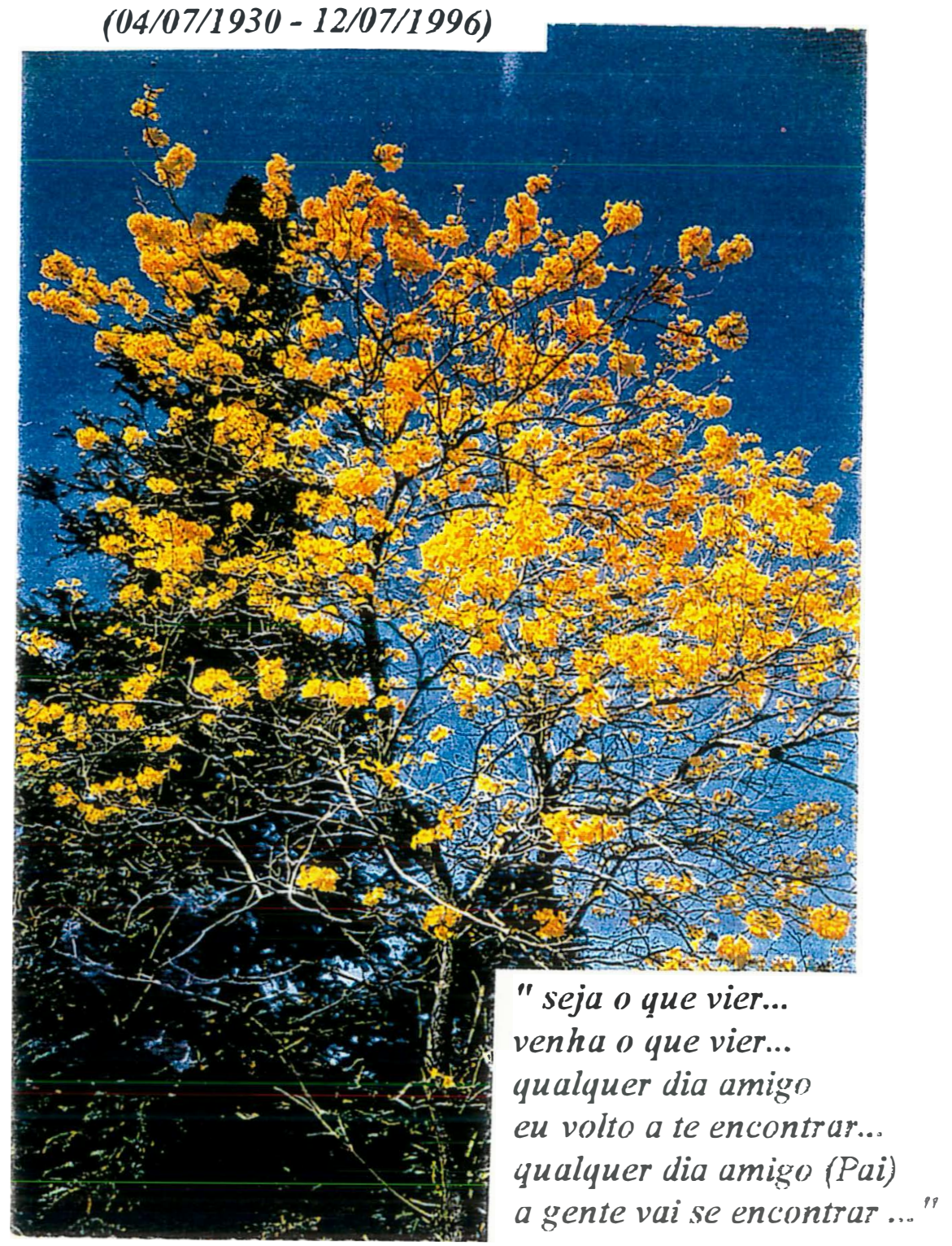


Ao Prof. José Leonardo de M. Goncalyes Meu orientador, na Pós-Graduação

\&

\begin{abstract}
ì Prof Maria Therezinha Martins Minha orientadora, na graduação (in memorian)
\end{abstract}

Aepero é o caminho do aprendizado. Muitas vezes, a única colea que mantém o discípulo animado é a fé no Mestre ... Até onde o discípulo chegará é coisa que não preocupa o Mestre. ale apenas the ensina 0 caminho, delxando percorrê-lo por ei meemo ... A fim de que o aluno eupere a prova de solidão, Mestre eepara-se dele, exortandoo cordialmente a proserguir mais longe do que ele e a se"elevar acima dos ombros do Mestre".

Para onde quer que o caminho escondido leve 0 discipulo, ele pode perder o Meetre de pieta, mas Jamaie esquecê-1o (...) !!!!!

por Dugen fierrigel 


\section{AGRADECIMENTOS}

À Escola Superior de Agricultura "Luiz de Queiroz" da Universidade de São Paulo, pela oportunidade de aperfeiçoamento profissional e pessoal;

Ao Professor José Leonardo de Moraes Gonçalves, pela confiança em mim depositada, pela orientação e amizade;

Ao Professor Boaventura Freire dos Reis, pelos ensinamentos transmitidos, pelo apoio logístico e pessoal, pelo seu espírito, enfim...por tudo...

Ao Professor Antonio Natal Gonçalves, por todo o apoio técnico e pessoal concedido;

A COMPANHIA SUZANO CELULOSE E PAPEL, na pessoa do Eng..$^{\circ}$ Florestal José Luiz Gava, pela concessão da área para instalação do experimento e, pelo apoio técnico da equipe de pesquisa (Adilson, Carlos, Freitas e Gilson);

À CAPES pela concessão da bolsa de estudos durante o período de Mar/94 a Set/96;

Aos funcionários do Departamento de Ciéncias Florestais e do IPEF, Alba V. Masseto, Antonio L. de Oliveira, Antonio Celso Gonçalves, Antonio Roberto Cicolim, Bianca R. Moura, Claudio R. Silva, Creisa A. Rodrigues, Davi I. Das Neves, Edward Fagundes Branco, Elza Martins Ferraz, Flávio Bertim G. Mendes, Israel G. Vieira, Jeferson L. Polizel, José Amarildo da Fonseca, José Francisco Teixeira, José Martins de Oliveira, Luís Eduardo Facco, Magali R. S. Martin, Margarete A. Z. Pinese, Maria A. R. C. Bermudez, Maria de Fátima D. Juliane, Marialice M. Poggiani, Maria Regina Buch, Milton C. Ribeiro, Paulo S. Beraldo, Pedro dos Santos Souza, Reinaldo Manoel Alcarde, Rogerio O. Naressi, Sueli Dressano e Udemilson Luiz Ceribelli,Vanda M Zambello, Valdomiro Benzato, por toda colaboração e convívio durante o curso de Pós-Graduação;

Aos funcionários da Seção de Transporte da ESALQ/USP por todo o auxílio nas saídas de campo, em especial, ao Sr. Usiel Marques da Silva (in memorian) e à Sandra, Araújo, Adilson, Darci, Geraldo, José Roberto e Lima;

Ao Vitor José Moretti de Oliveira (Vitor's Design) e ao Geraldo do CPD do CENA ("Gera"), pelo auxílio na editoração de figuras, pela atenção e pela amizade;

Ao Sérgio Ricardo Portes Bentivenha (Areião) estudante do Curso de Engenharia Florestal e estagiário do Projeto (Iniciação Científica/FAPESP) por toda colaboração, pelas sugestões e críticas, pelas conversas e, acima de tudo, pela amizade;

Ao Estudante do Curso de Engenharia Florestal, Luís Eugénio Gonçalves de Oliveira (Tédio), ao Pós-Graduando Sérgio Luís de Miranda Mello e ao técnico Peterson Roberto Daroz, colegas de equipe desde o início do projeto, pelo apoio, auxílio, amizade e companheirismo;

À todos os pesquisadores, funcionários, alunos e estagiários da Seção de Química Analítica do Centro de Energia Nuclear na Agricultura (CENA/USP), pelo apoio e convívio tão gratificantes, em especial, à Aparecida de Fátima Patreve, Yolanda Aparecida Rufini, Sheila Roberta Wenzel Perdigão, Valdemir Aparecido Fernandes; 
Ao Professor Carlos Clementi Cerri e toda sua equipe, em especial, à Antonia Mara P. Casarin, ao Sr. Darcir Bortoleto, José Roberto Martins, à Sandra Maria G. Nicolete por todo apoio técnico e pessoal;

Ao Professor Fábio Poggiani, pelas valiosas contribuiçōes no início e no decorrer do desenvolvimento do projeto;

Ao Professor José Luís Stape, pelas valiosas contribuições, atenção e pela amizade;

Ao Professor Jorge de Castro Kiehl, pelos ensinamentos transmitidos, por toda atenção, colaboração e pela amizade;

Ao Professor Takashi Muraoka, e à sua equipe, em especial, à Marileuza Aparecida B. Elias, à Sandra Teresa Pereira e ao Reimar Padovani por toda a ajuda concedida, e atenção;

Aos funcionários e estágiários da Biblioteca Central da ESALQ/USP, em especial, ao Airton Luís Barbosa, Àlvaro Sobreiro, Eliana M. G. Sabino, Fábio Marin, Kátia P. Andrade Ferraz, Luzia Fátima dos S.Possato, Ronaldo Capreci, Roseli T. de Barros, Silvana C. N. de Oliveira por toda colaboração e carinho;

À Marília R. G. Henyei, Elsie H. Mathes, Raquel C. T. de Carvalho e Cleide A. Ferraz da Biblioteca do CENAUSP por toda colaboração e carinho;

A todos os funcionários da Seção de Pós-Graduação da ESALQ, em especial, à Lia P. Moretti, por toda atenção e carinho,

Aos colegas da Graduação e da Pós- Graduação, em especial, ao André Cesar Vitti, Beatriz Machado Gomes, Claudio de Barros (Xerox do CALQ), Celso Ribeiro de Almeida, Cristián A Carranza, Fernando Flávio Bernardes, Inés C. M. Galina, José Erivaldo Pereira, Lothar Schacht, Marciano de M. P. Brito, Marlene Dietrich (IQ/USP), Maria Paula D. A. Marques (Xerox do CALQ), Natália Frutuoso Gonçalves, Natália M. Ivanauskas, Martial Bemoux, Paulo Maurício L. de A. Graça, Ronaldo Luis V. A. Silveira, Sebastião Pires de M. Neto, Silvana A. Pavan Fernandes, Vicente Xavier Compte, Walkyria B. Scivittaro pelo convívio, estímulo, colaboração e amizade.

A todos os fucionários do SAMD pela solidariedade e carinho, em especial, à Cecília M.Coelho Bezerra, Elis Neila N. Torres, Valquiria A. O Souza, Olga M. C. Oka e ao Ricardo Blasquez.

À Dra. Iva Moscatti Milstein e aos Drs. Geraldo Perez, Paulo Sérgio B. Perez e Alberto B. Mendes, não apenas pelo extremo profissionalismo, mas acima de tudo pela grandiosidade de suas almas!

Ao Eduardo Pereira-Cabral Gomes (Edu) e à Senhora Helena Gomes Pereira-Cabral por toda atenção, compreensão, colaboração e amor!

Enfim, a todos que, em algum momento, participaram de minha vida e contribuiram para a realização desse trabalho, o meu

E(TERNO) 


\section{SUMÁRIO}

Página

LISTA DE FIGURAS.

LISTA DE TABELAS.

xiii

RESUMO. XV

SUMMARY.

xviii

1 INTRODUÇÃO.

2 REVISÃO DE LITERATURA.

2.1 Reservas de N no solo.

2.2 Fontes de $\mathrm{N}$

2.3 Ciclo do N.

2.4 Mineralização de N

2.5 Mineralização versus imobilização de $\mathrm{N}$

2.6 Fatores que afetam os processos de mineralização de $\mathrm{N}$ 
Página

2.6.2 Umidade.

2.6.3 Acidez.

2.6.4 Aeração

2.6.5 Textura.

2.7 Modelos sazonais de mineralização e absorção de N

2.8 Reservas de $\mathrm{N}$ nos povoamentos florestais

2.9 Efeitos das práticas silviculturais na mineralização e lixiviação de $\mathrm{N}$

2.10 Métodos de avaliação da disponibilidade de $\mathrm{N}$ no solo.

2.11 Utilização de ${ }^{15} \mathrm{~N}$.

2.12 Comparação de métodos.

3. MATERIAL E MÉTODOS

3.1 Área de estudo.

3.2 Sistemas de preparo do solo. 
3.5 Inventário de fitomassa e do estoque de nutrientes nos diferentes compartimentos do povoamento de Eucalyptus grandis

3.6 Caracterização química e física do solo.

3.7 Caracterização química da serapilheira acumulada.

3.8 Mineralização, absorção e lixiviação de $\mathrm{N}$ no solo.

3.9 Demonstração dos cálculos para a obtenção das quantidades de $\mathrm{N}$ mineralizadas, lixiviadas e absorvidas (Raison et al., 1987)

3.10 Análises estatísticas

4. RESULTADOS E DISCUSSÃO.

4.1 Efeitos do preparo do solo em sua fertilidade.

4.2 Índices de crescimento e estoque de biomassa e nutrientes no povoamento de Eucalyptus grandis.

4.3 Efeitos das práticas de manejo sobre a temperatura e umidade do solo. 
Página

4.5 Mineralização de N.

4.6. Lixiviação e absorção de $\mathrm{N}$

63

4.7. Balanço das quantidades de $\mathrm{N}$ mineralizadas, absorvidas e lixiviadas.

69

5. CONCLUSÕES

6. APLICAÇÕES PRÁTICAS.

7. REFERÊNCIAS BIBLIOGRÁFICAS. 


\section{LISTA DE FIGURAS}

Página

1 Esquema do ciclo do nitrogênio na natureza, segundo Stevenson (modificado) em Fassbender \& Bornemisza, 1987.

2 Balanço hídrico, segundo Thornthwaite \& Matter, 1955, considerando $125 \mathrm{~mm}$ de capacidade de armazenamento de água do solo.

3 Esquema da área experimental.

4 Esquema da instalação dos tubos no campo (Raison et al., 1987).

5 Variação das temperaturas máximas e mínimas do ar e do solo na profundidade $2,5 \mathrm{~cm}$.

6 Precipitação média mensal $(\mathrm{mm})$ entre os meses de setembro de 1995 e março de 1996.

7 Umidade média da serapilheira e do solo entre os meses de setembro de 1995 e março de 1996.

8 Concentração de $\mathrm{N}-\mathrm{NH}_{4}^{+}$no solo.

9 Concentração de $\mathrm{N}-\mathrm{NO}_{3}^{-}$no solo.

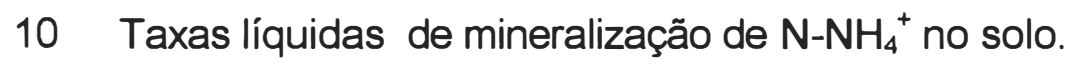

11 Taxas líqidas de mineralização de $\mathrm{N}^{-\mathrm{NO}_{3}}{ }^{-}$no solo...

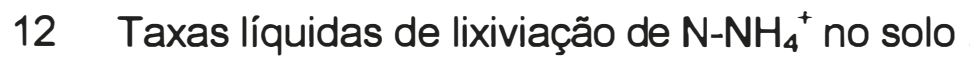

13 Taxas de líquidas de lixiviação de $\mathrm{N}^{-} \mathrm{NO}_{3}{ }^{-}$de no solo.

14 Taxas líquidas de absorção de $\mathrm{N}_{-} \mathrm{NH}_{4}{ }^{+}$no solo

15 Taxas de líquidas absorção de $\mathrm{N}_{-} \mathrm{NO}_{3}^{-}$no solo 


\section{LISTA DE TABELAS}

página

1 Características químicas do solo, 34 dias após a aplicação dos tratamentos experimentais.

2 Características químicas do solo, nos tratamentos $A, F$ e G, 173 dias após a aplicação dos tratamentos experimentais e, após 216 dias para os tratamentos $\mathrm{C}$ e $\mathrm{E}$.

3 Características físicas do solo sob povoamento de Eucalyptus grandis com 7 anos de idade (Tratamento A)......

4 Composição química da serapilheira acumulada amostrada no tratamento $\mathrm{A}$.

5 Avaliações de crescimento das árvores do povoamento de E. grandis (7 anos de idade).

6 Altura média das árvores e ocorrência de falhas,aos 6 meses de idade $^{(1)}$, nos diferentes tratamentos,

7 Composição química dos diferentes compartimentos das árvores do povoamento de $E$. grandis (7 anos). 
8 Estoque de biomassa e nutrientes nos diferentes compartimentos do povoamento de Eucalyptus grandis.

9 Médias das temperaturas $\left({ }^{\circ} \mathrm{C}\right)$ máximas e mínimas do ar e do solo, na profundidade de $2,5 \mathrm{~cm}$ e, indices pluviométricos $(\mathrm{mm})$ nos tratamentos A, C, E, F e G entre os meses de Setembro de 1995 e Março de 1996.

10 Quantidades de $\mathrm{N}^{-} \mathrm{NH}_{4}{ }^{+}$e de $\mathrm{N}-\mathrm{NO}_{3}{ }^{-}$mineralizadas, lixiviadas e absorvidas, na profundidade de 0-30 $\mathrm{cm}$ do solo $\left(\mathrm{kg} \mathrm{ha}^{-1}\right)$, nos 4 períodos de incubação compreendidos entre os meses de Setembro de 1995 e Março de 1996.

11. Quantidades de $\mathrm{N}$ mineralizadas, lixiviadas e absorvidas ( $\mathrm{kg} \mathrm{ha}^{-1}$ ) no solo sob povamento de Eucalyptus grandis (7 anos), entre os meses de setembro de 1995 e março de 1996, nas profundidades de $0-5,5-15$ e $15-30 \mathrm{~cm}$

12. Balanço parcial das quantidades de $\mathrm{N}\left(\mathrm{NH}_{4}^{+}\right.$e $\left.\mathrm{NO}_{3}{ }^{-}\right)$ mineralizadas, lixiviadas e absorvidas $\left(\mathrm{kg} \mathrm{ha}^{-1}\right)$ na profundidade de 0-30 cm, entre os meses de setembro de 1995 e março de 1996. 


\title{
MINERALIZAÇÃO, ABSORÇÃO E LIXIVIAÇÃO DE NITROGÊNIO EM POVOAMENTOS DE Eucalyptus grandis SOB CULTIVO MÍNIMO E INTENSIVO DO SOLO
}

\author{
Autora: Maria Izabel Pires Serrano \\ Orientador: José Leonardo de Moraes Gonçalves
}

\section{RESUMO}

O presente trabalho teve como objetivos principais: (i) estimar as quantidades de nitrogênio mineralizadas, lixiviadas e absorvidas no solo por povoamentos de Eucalyptus grandis submetidos a diferentes sistemas de manejo dos resíduos florestais e do solo, e (ii) verificar como as práticas de preparo do solo afetam o teor de água e a temperatura do solo. O experimento foi instalado (agosto/95) em uma área de plantio comercial de Eucalyptus grandis Hill Ex Maiden, em Itatinga-SP. Por ocasião do início do estudo o povoamento estava com 7 anos de idade. Os tratamentos experimentais consistiram em práticas operacionais que contemplaram distúrbios de diferentes magnitudes dos resíduos e do solo, a saber: A) manutenção do povoamento de Eucalyptus grandis intacto, B) corte raso do povoamento, os restos culturais e serapilheira foram mantidos sobre o solo, condução da rebrota, C) corte raso do povoamento, restos culturais e serapilheira mantidos 
sobre o solo, d) corte raso do povoamento, seguido da remoção dos restos da colheita florestal, mantendo-se apenas a serapilheira, e) corte raso do povoamento, remoção de todos resíduos culturais, f) corte raso do povoamento e incorporação de todos os resíduos culturais com grade pesada, e g) corte raso do povoamento, seguido da queima de todos resíduos culturais. Nos tratamentos $\mathbf{C}$ a $\mathbf{G}$ foi estabelecido um novo plantio de Eucalyptus grandis.

Verificou-se que cerca de 25 a $40 \mathrm{Kg} \mathrm{ha}^{-1}$ de $\mathrm{N}$, dependendo do tratamento, foram mineralizados em seis meses de incubação. Estas altas taxas de mineralização de $\mathrm{N}$ permitiram inferir que, a falta ou a pequena ocorrência de resposta à adubação nitrogenada resulta das grandes quantidades de $\mathrm{N}$ mineralizadas, as quais superam a demanda média de $\mathrm{N}$ em povoamentos de eucaliptos (20 a $40 \mathrm{Kg} \mathrm{ha}^{-1} \mathrm{ano}^{-1}$ ). No tratamento onde foi realizada a queima dos resíduos foram verificadas as menores quantidades de $\mathrm{N}$ mineralizadas durante o estudo $\left(16,4 \mathrm{Kg} \mathrm{ha}^{-1}\right)$, indicando a provável perda de quantidades apreciáveis de $\mathrm{N}$ por volatilização e por fluxo de massa junto com as cinzas em suspensão no ar. Além disso, a queima deve ter prejudicado a comunidade do solo, responsável pela mineralização de $\mathrm{N}$. O corte raso do povoamento favoreceu a nitrificação, independentemente do manejo dado aos resíduos e do preparo de solo. As maiores quantidades de $\mathrm{N}$ lixiviadas foram na forma nítrica. No povoamento adulto de Eucalyptus grandis a forma predominante e mais absorvida de $\mathrm{N}$ foi a amoniacal. A manutenção dos resíduos sobre o solo reduziu as oscilações térmicas e hídricas do solo em 
relação às observadas nos tratamentos, onde os resíduos foram queimados, removidos ou incorporados. Nos tratamentos em que a infestação por plantas invasoras foi favorecida (tratamentos $\mathrm{E}, \mathrm{F}$ e G), as taxas de lixiviação de $\mathrm{N}$ foram menores, evidenciando a importância dessas plantas na retenção de nutrientes em áreas descobertas. 


\title{
MINERALIZATION, UPTAKE AND LEACHING OF NITROGEN IN Eucalyptus grandis PLANTATION UNDER MINIMUM AND INTENSIVE SITE PREPARATION
}

\author{
Author: Maria Izabel Pires Serrano \\ Adviser: Prof. Dr. José Leonardo de Moraes Gonçalves
}

SUMMARY

The aims of this work were: (i) to estimate the quantities of $\mathrm{N}$ mineralized, leached and taken up from the litter and soil in $E$. grandis plantations under different practices of site cultivation, and (ii) to verify how these practices affect soil moisture and temperature. The experiment was set up (Aug/95) in commercial plantation of E. grandis Hill Ex Maiden (7 years-old), in Itatinga county, São Paulo State.

The experimental treatments were: a) preservation of the $E$. grandis stand undisturbed, covering the soil, b) clear-felling of the E. grandis stand, slash and litter retained, and kept the sprouting, c) clear-felling of the $E$. grandis stand, slash and litter retained, d) clear-felling ofthe E. grandis stand, litter retained and slash removed, e) clear-felling of the $E$. grandis stand, litter and slash removed, f) clear-felling of the E. grandis stand, litter and slash harrowed, andg) clear-felling of the E. grandis stand, litter and slash burned. It was established a new $\mathbf{E}$. grandis plantation at treatments $\mathbf{C}$ to $\mathbf{G}$.

Over six months 25 to $40 \mathrm{~kg} \mathrm{ha}^{-1}$ of $\mathrm{N}$ were mineralized depending on treatment. These data point out that the lack or small response to $N$ fertilization in Brazilian eucalypt plantation may be a consequence of the high rates of $\mathrm{N}$ mineralization, which exceed the average nutritional demand of the stand (20 to $40 \mathrm{~kg} \mathrm{ha}$ year $^{-1}$ ). The smallest amount of mineralized $\mathrm{N}$ $\left(16,4 \mathrm{~kg} \mathrm{ha}^{-1}\right)$ was found at burned residues treatment, showing likely loss of meaningful quantities of $\mathrm{N}$ by volatilization and mass flux of ashes in 
suspension in the air. More likely the burning reduced the soil community responsible by $\mathrm{N}$ mineralization.

Spite of site cultivation practice, the clear-felling of E. grandis stand enhanced the nitrification. Nitrate was the main leached form of $\mathrm{N}$. Ammonium was the main uptake form of $\mathrm{N}$ in adult stand of eucalypt. The soil temperature and moisture oscillations were smaller when the residues were kept undisturbed on soil. Lower $\mathrm{N}$ leaching was observed at the treatments where weed proliferation was higher (treatments $E, F$ e $G$ ), showing the importance of these plants to nutrient retention in exposed soils. 


\section{INTRODUÇÃO}

A crescente demanda por produtos florestais, a nível nacional e mundial, registrada nos últimos 50 anos, bem como a intensa pressão exploratória sobre as matas nativas brasileiras, têm levado a iniciativa pública e privada a estimular e implantar extensas áreas de povoamentos florestais com espécies de rápido crescimento. O Brasil possui mais de 6 milhões de hectares reflorestados com povoamentos homogêneos, predominando as espécies dos genêros Eucalyptus (52\%) e Pinus (30\%) - (Sociedade Brasileira de Silvicultura, 1990).

Ao lado da crescente relevância do setor florestal para o país, frequentemente se questiona, nos mais variados meios acadêmicos e técnicos, sobre a sustentabilidade da produção das florestas plantadas, a médio e a longo prazo, tendo em vista que a grande maioria dessas florestas foram plantadas em solos com baixa fertilidade natural. Além disso, para elevar os índices de produtividade, os sistemas silviculturais utilizados no Brasil têm sido muito intensivos contemplando, inclusive, o plantio de espécies florestais de rápido crescimento com grande capacidade de extração e exportação de nutrientes.

Nos últimos 10 anos, tem se difundido pelo setor florestal brasileiro o sistema de cultivo mínimo, baseado no preparo de solo restrito às linhas ou covas de plantio, mantendo os resíduos culturais sobre o terreno (Gonçalves, 1995c). Por se tratar de um sistema de cultivo muito recente, ainda 
inexistem pesquisas que têm como objetivos estudar a ciclagem de nutrientes e, particularmente, a mineralização, lixiviação e absorção de $\mathrm{N}$, neste sistema.

Apesar do reconhecimento de que a conservação da matéria orgânica é fundamental para a manutenção da produtividade a longo prazo particularmente, em solos de baixa fertilidade natural (Flinn et al., 1980), ainda são poucos, em nosso país, os estudos sistemáticos visando quantificar as relações entre a matéria orgânica, as reservas de nitrogênio e a mineralização de $\mathrm{N}$ sob diferentes práticas de manejo dos resíduos e do solo, destacando-se os trabalhos realizados por Cerri et al. (1991); Luizão et al. (1992); Martins et al. (1991); Piccolo et al. (1994); Feigl et al. (1995); Neill et al. (1995) e Neil et al. (1997), cujos estudos foram realizados em floresta natural e de pastagens.

Estudos sobre a decomposição da matéria orgânica e a mineralização de $\mathrm{N}$ em solos sob plantações homogêneas de Eucalyptus e Pinus, submetidos a diferentes práticas de manejo, ainda são necessários em nosso país. Em outros países, destacam-se os estudos realizados por Adams \& Attwill (1986a,b; 1991) em florestas de Eucalyptus e os de Vitousek \& Matson (1985), Smethurst \& Nambiar (1990a,b), Whynot \& Weetman (1991) em florestas de Pinus, os quais constataram acentuados efeitos das práticas de manejo de resíduos culturais, da sazonalidade e do tipo de solo sobre as quantidades e a forma de $\mathrm{N}$ mineralizadas.

No presente estudo, procurou-se obter respostas para várias questões relativas aos efeitos dos diversos sistemas de cultivo sobre a fertilidade do solo e a ciclagem de nutrientes, em especial, sobre a mineralização, lixiviação e absorção de $\mathrm{N}$, tais como:

- Qual a relação entre o grau de cobertura do solo pelos resíduos culturais e plantaçoes de eucalipto $e$, as taxas líquidas de mineralização do nitrogênio? 
* Qual a relação entre as taxas líquidas de mineralização do nitrogênio e as perdas por lixiviação?

* Existe um comportamento sazonal das taxas líquidas de mineralização e lixiviação do nitrogênio?

* Como a intensidade de preparo do solo e o manejo dos resíduos florestais influencia as taxas líquidas de mineralização do nitrogênio e a lixiviação do mesmo?

* Qual a relação entre o crescimento das árvores e as quantidades de $\mathrm{N}$ mineralizadas no sistema solo-serapilheira?

* Qual o efeito da queima dos resíduos culturais sobre as quantidades de $\mathrm{N}$ mineralizáveis no sistema solo-serapilheira?

Respostas a essas questões são fundamentais para tomadas de decisões apropriadas para o manejo dos resíduos culturais e do solo, com enormes reflexos sobre a sustentabilidade econômica e técnica da produção florestal por várias rotações de cultivo.

Diversos métodos têm sido utilizados para quantificar as taxas de amonificação e nitrificação de N (Cameron \& Kowalenko, 1976; Westermann \& Crothers, 1980; Nadelhoffer et al., 1983; Hart \& Binkley, 1985; Vitousek \& Matson, 1985; Adams \& Attiwill, 1986b; Smethurst \& Nambiar, 1989; Raison et al., 1987; Piccolo, 1994), mas nenhum método fornece um índice seguro das mesmas, por diferentes razões. Incubações aeróbicas e anaeróbicas em laboratório sob condições controladas, fornecem uma estimativa das quantidades de nitrogênio mineralizável presentes no tempo de amostragem e, permitem estabelecer comparações entre os sítios, porém não refletem as 
flutuações naturais que ocorrem sob condições de campo (Lamb, 1980; Hart \& Binkley, 1985).

Entre os vários métodos de avaliação da mineralização do nitrogênio, sob condições de campo, a incubação sequencial de colunas de solo pouco pertubadas tem sido indicada como o método mais adequado devido ao menor distúrbio no solo, sendo sensivel às variações ambientais (Nadelhoffer et. al., 1983; Binkley \& Hart, 1989; Raison et al.,1990), sendo a técnica adotada nesse estudo. Dentro desse contexto, o presente estudo teve como objetivos:

( $\mathrm{i}$ ) estimar as quantidades de $\mathrm{N}$ mineralizadas, lixiviadas $\mathrm{e}$ absorvidas no solo de povoamentos de Eucalyptus grandis submetidos a diferentes sistemas de manejo dos resíduos e do solo;

( ii ) verificar como as práticas de preparo do sítio que envolvem manipulações dos restos culturais e da serapilheira afetam o teor de água e a temperatura do solo. 


\section{REVISÃO DE LITERATURA}

\subsection{Reservas de $\mathbf{N}$ no solo}

Em solos das regiões tropicais, a grande reserva de nitrogênio para as plantas reside na fração orgânica, uma vez que a maioria desses solos apresenta predominantemente argilas do tipo 1:1, óxidos de ferro e de alumínio, quartzo e materiais amorfos, com baixos valores de CTC, sendo a fixação de $\mathrm{N}-\mathrm{NH}_{4}{ }^{+}$por argilas do tipo 2:1 de pouca expressão (Sanches, 1976).

Apenas uma pequena fração do nitrogênio total encontra-se prontamente disponivel para as plantas, sendo o nitrogênio na forma de nitrato $\left(\mathrm{N}-\mathrm{NO}_{3}{ }^{-}\right)$e de amônio $\left(\mathrm{N}_{-} \mathrm{NH}_{4}^{+}\right)$trocáveis, as formas inorgânicas mais importantes do ponto de vista da nutrição mineral. As concentrações dessas formas de $\mathrm{N}$ no solo variam muito ao longo do ano em função do regime de chuvas e das oscilações na temperatura.

\subsection{Fontes de $\mathbf{N}$}

A precipitação pluviométrica e a fixação biológica do $\mathrm{N}_{2}$ atmosférico constituem os principais processos naturais responsáveis pelas entradas de $\mathrm{N}$ nos solos. A fixação biológica do nitrogênio consiste no processo através do qual o $\mathrm{N}_{2}$ atmosférico é reduzido a $\mathrm{NH}_{3}$ pelo complexo enzimático nitrogenase presente em microrganismos diazotróficos (Alexander, 1977).

\subsection{Ciclo do N}

$\mathrm{O}$ ciclo do nitrogênio no solo constitui parte do ciclo mais amplo do $\mathrm{N}$ na natureza. Os processos químicos e bioquímicos desse ciclo envolvem a participação de todas as formas de $\mathrm{N}$, resultando assim em um ciclo muito complexo e peculiar. $\mathrm{O}$ ciclo do $\mathrm{N}$ na natureza é ilustrado na Figura 1 , sendo a seguir comentadas as principais transformações de $\mathrm{N}$ no solo. 


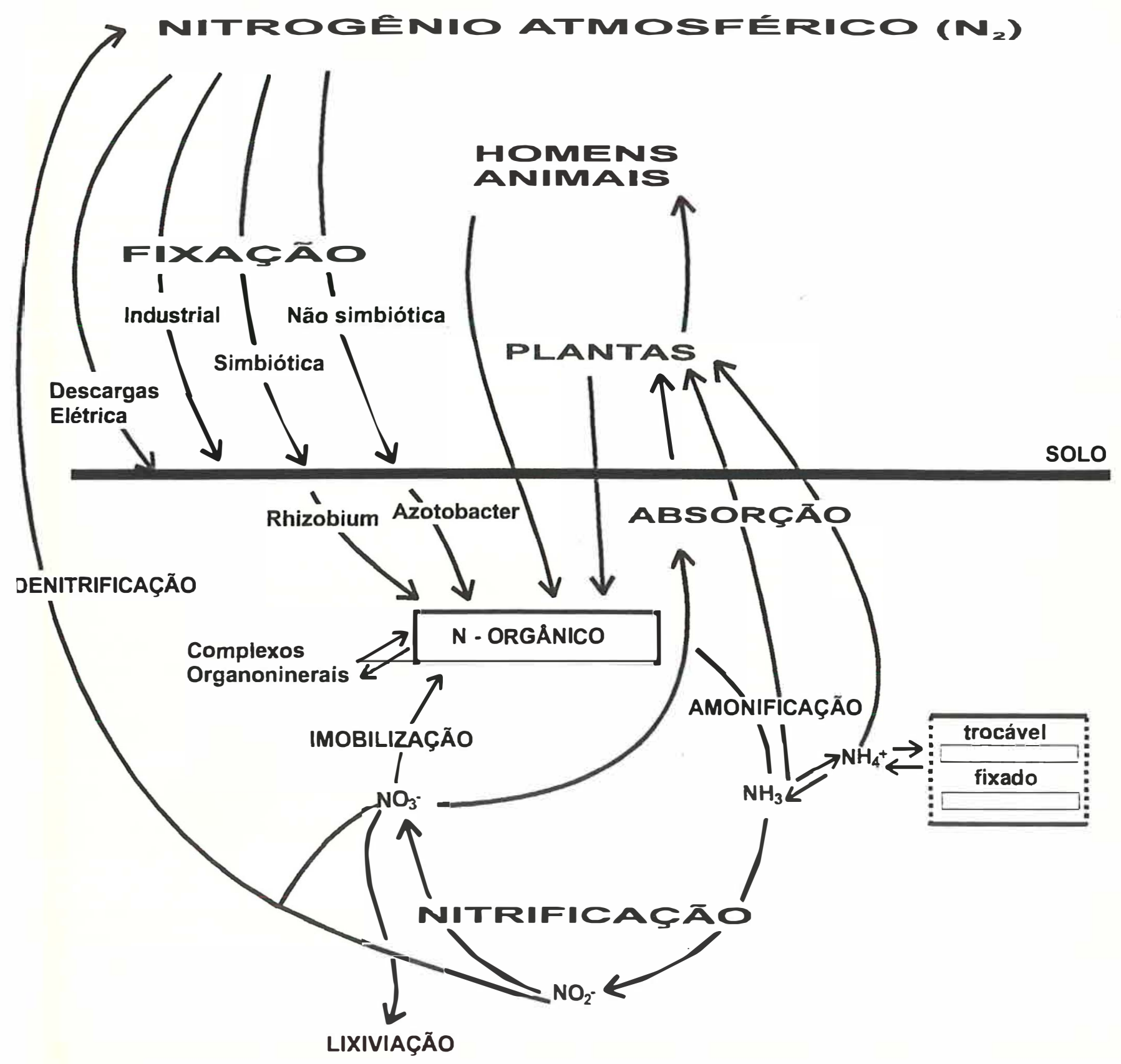

Figura 1. Esquema do ciclo do Nitrogênio na natureza, segundo Stevenson (modificado) em Fassbender \& Bornemisza, 1987. 


\subsection{Mineralização de N}

A conversão do nitrogênio organico em formas inorgânicas disponíveis $\left(\mathrm{N}^{-\mathrm{NH}_{4}}{ }^{+}, \mathrm{N}-\mathrm{NO}_{3}{ }^{-}\right)$ocorre através de várias transformações bioquímicas mediadas por microrganismos, constituindo o processo de mineralização do qual participam bactérias, fungos, actinomicetos $e$ protozoários. O processo de mineralização é influenciado pela temperatura, umidade, $\mathrm{pH}$, pressão parcial de oxigênio e qualidade do substrato, os quais afetam a atividade microbiana. A etapa inicial da mineralização é denominada amonificação e, envolve a conversão de $\mathrm{N}$ orgânico em $\mathrm{NH}_{3}$, sendo realizada exclusivamente por microrganismos heterotróficos, aeróbicos e/ou anaeróbicos.

Segundo Alexander (1977), entre $10^{5}$ a $10^{7}$ organismos por grama de solo são amonificadores, mas a definição das populações presentes no meio depende basicamente da natureza do substrato. Em geral, as bactérias predominam em ambientes neutros ou alcalinos, os fungos em ambientes ácidos e as bactérias anaeróbicas em ambientes com reduzida pressão parcial de oxigênio.

A transformação subsequente de $\mathrm{NH}_{3}$ a $\mathrm{NO}_{3}^{-}$é realizada basicamente por dois grupos de bactérias quimioautotróficas e aeróbicas estritas - Nitrosomonas, a qual converte $\mathrm{NH}_{3}$ a $\mathrm{NO}_{2}^{-}$e, Nitrobacter, a qual converte $\mathrm{NO}_{2}^{-}$a $\mathrm{NO}_{3}^{-}$. Essas duas últimas etapas são conhecidas como nitritação e nitratação, respectivamente.

A mineralização é sempre acompanhada pelo processo inverso de imobilização, ou seja, a tranformação de $N$ inorgânico em $N$ orgânico pela microbiota. Trabalhando em direções opostas, esses dois processos são responsáveis pela decomposição e formação da matéria orgânica do solo, resultando na mineralização ou imobilização dos nutrientes. Da dinâmica e da intensidade relativa desses dois processos opostos, tem-se a mineralização ou imobilização líquida de $\mathrm{N}$ que, determinam a disponibilidade de nutrientes do 
solo. Segundo Campbell (1978), cerca de 1 a $5 \%$ do $N$ orgânico do solo estabilizado é anualmente mineralizado.

\subsection{Mineralização versus imobilização de $\mathrm{N}$}

A composição básica do substrato no qual os microrganismos se desenvolvem constitui o fator determinante do balanço líquido entre os processos de mineralização e imobilização. Quando o substrato apresenta um teor de $\mathrm{N}$ baixo, a demanda microbiana pelo mesmo ocasiona uma redução das concentrações de $\mathrm{N}$ inorgânico na solução do solo, resultando em uma imobilização de N. Ao contrário, quando o substrato apresenta teor elevado de $\mathrm{N}$ ocorre o predomínio da mineralização sobre a imobilização. Dessa forma, a relação $\mathrm{C}: \mathrm{N}$ têm sido muito utilizada na avaliação da disponibilidade de $\mathrm{N}$ no solo. Entretanto, a avaliação dos teores de $\mathrm{C}$ e $\mathrm{N}$ do substrato nem sempre reflete o efeito da decomposição da matéria orgânica sobre a disponibilidade de $\mathrm{N}$ no solo, sendo necessário considerar os fatores de ordem climática, edáfica e química bem como os efeitos das interações entre os mesmos na avaliação da disponibilidade de N no solo (Alves, 1992).

\subsection{Fatores que afetam os processos de mineralização de $\mathrm{N}$}

\subsubsection{Temperatura}

A taxa de mineralização de $\mathrm{N}$ é influenciada pela temperatura. De modo geral, o aumento de temperatura acelera as reações químicas e o metabolismo dos organismos. O acúmulo de matéria orgânica em regiões de clima frio ou em locais de altitudes elevadas é comum devido à redução nas taxas de mineralização. Stanford et al. (1973) verificaram que, em solos com teor de umidade próximo à capacidade de campo, a taxa de mineralização é função da temperatura, obtendo um coeficiente de temperatura $\left(Q_{10}\right)$ de 
aproximadamente 2,0 , ou seja, a taxa de mineralização dobra com um aumento de $10^{\circ} \mathrm{C}$ na temperatura.

\subsubsection{Umidade}

A taxa de mineralização de $\mathrm{N}$ também é muito influenciada pelo teor de água do solo. Stanford \& Epstein (1974), mostraram que a mineralização de $\mathrm{N}$, à temperatura constante, diminui com a redução do teor de água do solo. Os ciclos na umidade do solo também são importantes, pois causam um aumento do fluxo de $\mathrm{N}$ mineral (Birch, 1960), sendo que cada ciclo sucessivo resulta em um fluxo levemente menor. A magnitude do fluxo encontra-se relacionada ao conteúdo de matéria orgânica do solo e ao tempo em que o solo permaneceu seco. Segundo Stevenson (1986), as possiveis explicações para esse fluxo de $\mathrm{N}$ mineral seriam: * os microrganismos são mortos pela secagem (esterilização parcial) e o $\mathrm{N}$ é liberado quando as células mortas sofrem autólise e são decompostas; * a secagem leva à conversão de $\mathrm{N}$ orgânico a compostos mais solúveis, os quais são atacados pelos microrganismos com a liberação de $\mathrm{N}$ mineral; * o umedecimento e a secagem levam à quebra de agregados estáveis com a exposição de superfícies novas para $o$ ataque microbiano.

$\mathrm{O}$ congelamento e o descongelamento do solo poderiam afetar a mineralização do nitrogênio do mesmo modo que o umedecimento e a secagem, mas em menor grau (Stevenson, 1986).

Hopmans et al. (1980), estudando a mineralização de $\mathrm{N}$ em um ensaio sob condições controladas com uma ampla faixa de umidade e de períodos de incubação, mostraram que as taxas de amonificação na superfície de um solo arenoso sob pinheiro ou eucalipto foram relativamente altas para um solo florestal, sendo fortemente dependentes do conteúdo de umidade. Esses autores encontraram uma maior amonificação em solos sob eucalipto do que em solos sob pinheiro independente do teor de água do solo ou do tempo 
de incubação, atribuindo a mesma à maior diversidade de microrganismos e/ou às mais altas populações nos solos sob eucalipto.

\subsubsection{Acidez}

$\mathrm{O} \mathrm{pH}$ é um dos principais fatores a atuar sobre a microbiota do solo, principalmente, sobre os microrganismos nitrificadores, mais sensíveis e exigentes, cujo $\mathrm{pH}$ ideal encontra-se próximo à faixa da neutralidade. Segundo Campbell (1978), as taxas de mineralização em solos ácidos são baixas, aumentando com a elevação do pH. Além de afetar diretamente a microbiota determinando as populações de microrganismos presentes no meio, $\mathrm{opH}$ controla a solubilidade dos nutrientes e ao disponibilizá-los estimula a microbiota aumentando por conseguinte, a mineralização do $\mathrm{N}$ do solo.

\subsubsection{Aeração}

A aeração é o fator determinante do tipo de população de microrganismos (aeróbicos ou anaeróbicos) que atuará na decomposição da matéria orgânica do solo e, portanto, determina a extensão de sua oxidação. Em solos de textura fina, o maior teor de umidade e a menor disponibilidade de oxigênio para o desenvolvimento microbiano podem afetar a microbiota, principalmente, os microrganismos aeróbios estritos. $O$ alagamento temporário ou permanente do solo suprime os microrganismos aeróbicos estritos, bem como a maioria dos animais e fungos, sendo os microrganismos anaeróbicos, persistentes nessas condições, pouco eficientes na decomposição dos resíduos. A oxidação incompleta da matéria orgânica em condições de anaerobiose, resulta em uma baixa produção de energia e menor síntese de células microbianas por unidade de $C$ degradado, implicando em uma maior liberação de $\mathrm{N}^{-\mathrm{NH}_{4}}{ }^{+}$para o solo (Campbell, 1978). A condição de anaerobiose pode surgir não apenas pela saturação do solo, mas também devido às 
grandes adições de material orgânico de fácil decomposição, acelerando o crescimento microbiano e levando ao esgotamento do oxigênio do solo.

\subsubsection{Textura}

A interação dos compostos orgânicos com a fração mineral do solo constitui um importante mecanismo para a conservação da matéria orgânica do solo. A destruição dos agregados do solo expõe a sua biomassa, ocasionando um aumento na mineralização do N. A agregação do solo determina o grau de infiltração da água, o teor de umidade, a temperatura do mesmo, bem como a facilidade ou não de penetração das raízes influenciando, indiretamente, a mineralização do N (Alisson, 1973).

\subsection{Modelos sazonais de mineralização e absorção de N}

Nadelhoffer \& Aber (1984) em um estudo sobre a mineralização de $\mathrm{N}$ em nove povoamentos florestais (Madison, EUA), verificaram uma variação sazonal pronunciada nos modelos de mineralização líquida de $\mathrm{N}$ com os valores máximos de mineralização ocorrendo no mês de junho e, ocasionalmente, em maio. $\mathrm{O}$ nitrato foi a forma de $\mathrm{N}$ predominantemente absorvida nesses povoamentos. Independente das osilações mensais nas taxas de mineralização de $\mathrm{N}$, o nitrato foi fornecido e absorvido de forma equilibrada durante toda a estação de crescimento.

Em florestas de clima temperado, as mais altas taxas de mineralização líquida de $\mathrm{N}$, utilizando a técnica de incubações sequenciais do solo in situ, ocorrem tipicamente na primavera ou no início do verão, apresentando picos secundários durante a estação de crescimento. No entanto, a forma de $\mathrm{N}$ disponível às árvores pode contrabalancear os efeitos dos modelos sazonais de mineralização líquida, pois se as quantidades de $\mathrm{N}$ $\mathrm{NH}_{4}^{+}$são suficientemente grandes, a nitrificação e a absorção do nitrato podem 
ocorrer mesmo em períodos em que a mineralização líquida de $\mathrm{N}$ seja próxima de zero (Nadelhoffer et al., 1983).

Smethurst \& Nambiar (1990b) em um estudo de três anos de duração envolvendo os fluxos de $\mathrm{N}$ mineral em um povoamento de Pinus radiata, no sudeste da Austrália, verificaram baixas taxas de mineralização de $\mathrm{N}$ na serapilheira do povoamento $\left(<1,0 \mathrm{~kg} \mathrm{ha}{ }^{-1} \mathrm{mês}^{-1}\right)$, excetuando-se a avaliação feita no mês de dezembro. Os autores testaram os efeitos do corte raso do povoamento e de diferentes manejos dos resíduos sobre os fluxos de $\mathrm{N}$ mineral e verificaram que, independentemente do tratamento aplicado aos resíduos após o corte raso, as taxas de mineralização foram mais altas entre fim da primavera e início do verão e, mais baixas no outono. Além disso, esses autores verificaram que o único tratamento onde as taxas de mineralização permaneceram altas, independentemente da estação do ano, foi o tratamento onde os resíduos foram mantidos sobre o solo.

Adams \& Attiwill (1986b) também estudaram a ciclagem de nutrientes e a mineralização de $\mathrm{N}$ em oito florestas de eucalipto no sudeste da Austrália. Os autores trabalharam com povoamentos florestais cobrindo uma ampla faixa de clima e de tipos de solos, realizando incubações de solo em laboratório (aeróbicas e anaeróbicas) e in situ. As mais altas taxas de mineralização de $\mathrm{N}$ nas incubações em laboratório foram obtidas para os solos coletados no verão, sendo as taxas obtidas para os solos em outras estações do ano, em geral, menores. Em contraste com os dados encontrados nas incubações em laboratório, as taxas de minéralização de $\mathrm{N}$ obtidas nas incubações in situ (aeróbicas e anaeróbicas) variaram significativamente com o mês de amostragem. Provavelmente, as condições ótimas utilizadas para as incubações em laboratório não permitiram que os autores observassem, nos resultados obtidos, a variação que ocorre no campo.

Theodorou \& Bowen (1983) estudaram as transformações de $N$ em solos sob povoamentos de Pinus radiata de $1^{a}$ e $2^{a}$ rotação e verificaram 
que a disponibilidade de $\mathrm{N}$ mineral foi fortemente influenciada pela estação em ambos os solos. As maiores quantidades de $\mathrm{N}$ mineral no campo foram verificadas durante o verão e no começo do outono, sendo de 3 a 10 vezes mais altas nesse período do que no meio do inverno e na primavera. Resultados similares foram obtidos por Ellis (1974) em solos sob florestas e pastagens no Canadá. Entretanto, dentro de uma mesma estação, Theodorou \& Bowen (1983) constataram diferenças significativas entre os solos de $1^{\text {a }}$ e de $2^{\mathrm{a}}$ rotação. Os solos de $1^{\mathrm{a}}$ rotação continham até cerca de $36 \%$ mais $\mathrm{N}$ mineral do que o solo de $2^{\mathrm{a}}$ rotação até $\circ 1^{\circ}$ mês após o corte raso e o preparo do solo. Após os 15 meses iniciais, os solos de $2^{a}$ rotação frequentemente continham mais $\mathrm{N}$ mineral do que os solos de $1^{\text {a }}$ rotação. Os autores verificaram uma tendência similar da disponibilidade de $\mathrm{N}$ mineral em incubações em laboratório, sendo o teor máximo de $\mathrm{N}$ mineral verificado na amostragem de verão e outono e o teor mínimo no inverno e na primavera.

Segundo Theodorou \& Bowen (1981), as flutuações sazonais na disponibilidade de $\mathrm{N}$ mineral estão relacionadas com flutuações no número de microrganismos e portanto, com a influência dos fatores ambientais na atividade dos mesmos, bem como com as perdas de $\mathrm{N}$ mineral por lixiviação durante períodos com precipitações elevadas. Os autores verificaram grandes flutuações sazonais nas populações de microrganismos, sendo as maiores quantidades observadas no outono e as menores na primavera.

\subsection{Reservas de $\mathbf{N}$ nos povoamentos florestais}

A importância dos restos culturais e da serapilheira como reservas de $\mathrm{N}$ é evidenciada quando $\mathrm{o} \mathrm{N}$ destes componentes é considerado em relação ao estoque de $\mathrm{N}$ do solo. Flinn et al. (1979) verificaram que os restos culturais e a serapilheira de povoamentos de Pinus radiata combinados continham cerca de $424 \mathrm{~kg} \mathrm{ha}^{-1}$ de $\mathrm{N}$, representando $21 \%$ da reserva de $\mathrm{N}$ do sítio para uma profundidade de $50 \mathrm{~cm}$. Em contraste, Hall (1984) encontrou que, em 
plantações de Pinus radiata, estes componentes continham apenas 5\% das reservas de $\mathrm{N}$ do sítio, indicando a mais alta reserva de $\mathrm{N}$ no solo.

Smethurst \& Nambiar (1990a) encontraram que, em povoamentos de Pinus radiata com 37 anos de idade, os restos culturais, a serapilheira e os $30 \mathrm{~cm}$ superiores do solo combinados continham $1957 \mathrm{Kg} \mathrm{ha}^{-1}$ de $\mathrm{N}$ dos quais, os restos culturais e a serapilheira continham aproximadamente, 235 e $489 \mathrm{Kg} \mathrm{ha}^{-1}$, respectivamente.

\subsection{Efeitos das práticas silviculturais na mineralização e lixiviação de $\mathrm{N}$}

A taxa de decomposição da matéria orgânica pode ser alterada em função das mudanças nos regimes de temperatura e umidade provocadas pelo desbaste e pela deposição dos resíduos sobre o solo, refletindo na atividade da microbiota. É possível também um aumento na imobilização de $\mathrm{N}$ durante a decomposição caso os resíduos apresentem alta relação $\mathrm{C}: \mathrm{N}$. Carlyle (1995) verificou em povoamentos de Pinus radiata de $2^{\mathrm{a}}$ rotação que, quando o desbaste é de baixa intensidade, os efeitos sobre a mineralização do $\mathrm{N}$ são pequenos quando comparados aos efeitos do corte raso, onde as taxas de mineralização são elevadas por um fator de 2 ou 3 vezes mesmo quando os resíduos são removidos. O autor encontrou que a manutenção dos resíduos teve uma maior influência sobre a mineralização de $\mathrm{N}$ na serapilheira do que o desbaste propriamente, sendo que a quantidade de $\mathrm{N}$ mineralizado aumentou com a quantidade do resíduo retido.

É de conhecimento geral que o corte raso de florestas aumenta as taxas de mineralização de $\mathrm{N}$, levando a um aumento na concentração de $\mathrm{N}$ mineral na serapilheira e no solo, particularmente na ausência de vegetação. $O$ aumento das taxas de mineralização após o corte raso é usualmente atribuído à elevação do teor de água e da temperatura do solo (Borman et al. , 1968; Marks \& Bormann,1972; Burger \& Pritchet, 1984). 
Vitousek \& Matson (1985), em estudo realizado em um povoamento de Pinus taeda, durante a $2^{\mathrm{a}}$ estação de crescimento, encontraram que, após o corte raso do povoamento, cerca de $94 \mathrm{Kg} \mathrm{ha}^{-1}$ de $\mathrm{N}$ foram mineralizados contra somente $22 \mathrm{~kg} \mathrm{ha}^{-1}$ de $\mathrm{N}$ mineralizados em um povoamento intacto. As concentrações e os conteúdos de $\mathrm{N}$ mineral na serapilheira e no solo sob o povamento intacto foram baixos, apesar das acentuadas variações nas taxas de mineralização de $\mathrm{N}$ e, de nenhuma lixiviação. Evidentemente a absorção de $\mathrm{N}$ pelo povoamento foi praticamente igual à sua mineralização. Entretanto, os autores verificaram que esse balanço nos fluxos de $\mathrm{N}$ foi perturbado na área com corte raso, onde as taxas aumentadas de mineralização e, a absorção muito baixa durante o primeiro ano após o plantio, resultaram na acumulação de $\mathrm{N}$ mineral.

O corte raso de povoamentos florestais pode ocasionar um aumento nas perdas de $\mathrm{N}^{-\mathrm{NO}_{3}}{ }^{-}$para cursos de água. Segundo Vitousek \& Matson (1985), as perdas de $\mathrm{N}-\mathrm{NO}_{3}{ }^{-}$dos sítios são reguladas pela:

* quantidade de nitrogênio mineralizado anualmente antes do corte raso e a extensão na qual a mineralização é aumentada pelo mesmo;

* imobilização de $\mathrm{N}$ pelos microrganismos, mantendo o nitrogênio em formas relativamente imóveis;

* rebrota da vegetação e presença de plantas invasoras, restabelecendo o processo de absorção no sítio;

* disponibilidade de $\mathrm{N}$ antes do distúrbio, pois a relação $\mathrm{C}: \mathrm{N}$ dos resíduos vegetais, produzidos em sítios onde o $\mathrm{N}$ é limitante, é relativamente alta e os microrganismos podem imobilizar grandes quantidades de $\mathrm{N}$. Além disso, os microrganismos heterotróficos, presentes nesses sítios, podem competir com os microrganismos autotróficos nitrificadores, pelo amônio, reduzindo a população de nitrificadores e com isto reduzindo a produção de nitrato. 
Smethurst \& Nambiar (1990a) observaram um aumento nas taxas de mineralização de $\mathrm{N}$ após o corte raso de um povoamento de Pinus radiata, bem como uma elevação das concentrações de $\mathbf{N}$ mineral na serapilheira e no solo devido à ausência das árvores. Segundo esses autores, cerca de 64 a $76 \%$ desse $\mathrm{N}$ mineral disponível foi lixiviado abaixo de $30 \mathrm{~cm}$ de profundidade antes do replantio. $\mathrm{Na}$ área onde o povoamento foi mantido intacto, foram verificadas apenas pequenas flutuações nas concentrações de $\mathrm{N}$ mineral na serapilheira e no solo. Entretanto, esses autores verificaram que o aumento nas taxas de mineralização de $\mathrm{N}$ foi mais evidente apenas 18 meses após 0 corte raso do povoamento, quando não havia nenhuma diferença no conteúdo de umidade do solo entre o tratamento onde o povoamento foi mantido e aqueles onde houve o corte raso, de forma que diferenças na taxas de mineralização entre as áreas onde foi realizado o corte raso e aquelas onde o povoamento foi mantido não seriam atribuídas à diferenças no conteúdo de água do solo.

Vitousek \& Matson (1985), verificaram que a colheita de árvores inteiras em povoamentos de pinheiros levou a uma redução da mineralização líquida de $\mathbf{N}$ quando comparada com a mineralização obtida após a colheita apenas do tronco. Os autores encontraram que essa diferença foi significativa durante vários meses. As quantidades de $\mathrm{N}-\mathrm{NO}_{3}{ }^{-}$verificadas nas áreas onde a colheita foi total também foram menores do que as encontradas onde a colheita foi restrita ao tronco, embora essas diferenças não tenham sido significativas. Os autores concluiram que a remoção dos resíduos reduz as quantidades de $\mathrm{N}$ potencialmente mineralizáveis no ano seguinte à colheita das árvores.

O fogo pode causar grandes e rápidas mudanças em solos florestais. Essas mudanças podem ser benéficas ou destrutivas dependendo do tipo e da intensidade do fogo (Raison, 1979). A queima destrói uma quantidade variável de resíduos não incorporados. Entretanto, uma queima moderada não chega a causar uma redução da matéria orgânica e do $\mathrm{N}$ total no solo, podendo 
inclusive provocar uma elevação deste através da adição de material parcialmente queimado. $\mathrm{O}$ aumento na disponibilidade de $\mathrm{N}$ após $\circ$ fogo é frequente. Wagle \& Kitchen (1972) encontraram cerca de $33 \mathrm{ppm}$ de $\mathrm{N}$ na profundidade de $0-15 \mathrm{~cm}$ em solos florestais recentemente queimados e apenas $12 \mathrm{ppm}$ em áreas protegidas, porém essa disponibidade foi apenas temporária. Theodorou \& Bowen (1982), estudando os efeitos do fogo na microbiologia de um planossolo distrófico sob florestas de eucalipto, encontraram uma mineralização de $\mathrm{N}$ significativamente maior na área queimada do que não queimada na profundidade de 0-2 cm do solo.

\subsection{Métodos de avaliação da disponibilidade de $\mathrm{N}$ no solo}

Tendo em vista que o $\mathrm{N}$ apresenta uma dinâmica extremamente alta nos ecossistemas, estando constantemente sendo convertido em formas inorgânicas (via mineralização) e orgânicas (via imobilização) deve-se considerar como $\mathrm{N}$ disponivel não apenas $\circ \mathrm{N}-\mathrm{NH}_{4}^{+}$e $\circ \mathrm{N}-\mathrm{NO}_{3}^{-}$trocável, mas também a fração lábil da matéria orgânica (fração facilmente mineralizada pelos microrganismos).

Os métodos de avaliação do suprimento de $\mathrm{N}$ do solo através do $\mathrm{N}$ absorvido pelas plantas, em casa de vegetação ou no campo, fornecem resultados mais próximos do real, porém tornam-se inviáveis na análise de rotina ficando restritos à calibração de outros métodos (Alisson, 1973). Têm sido propostos então, métodos baseados na oxidação biológica ou química da matéria orgânica.

Os métodos biológicos são baseados na estimativa do $\mathrm{N}$ mineral produzido com a incubação do solo sob condições favoráveis à mineralização do $N$, enquanto que os métodos químicos procuram simular a ação dos microrganismos sobre a matéria orgânica mediante o emprego de agentes oxidantes e extratores. 
O desenvolvimento de um método quımıco que permita a obtenção de um bom índice da disponibilidade de $\mathrm{N}$ é muito desejável do ponto de vista prático, pois as análises químicas, em geral, são mais rápidas e precisas que os ensaios biológicos. Entretanto, são poucos os métodos químicos encontrados na literatura que apresentam uma boa correlação entre as suas estimativas de disponibilidade de $\mathrm{N}$ e as estimativas de $\mathrm{N}$ mineralizado por métodos biológicos (Métodos de Incubação) ou de $\mathrm{N}$ absorvido pelas plantas.

Tendo em vista que a disponibilidade de $\mathrm{N}$ do solo depende diretamente da ação dos microrganismos sobre a sua matéria organıca (reserva de $\mathrm{N}$ ) são esperadas correlações altas entre $\mathrm{o} \mathrm{N}$ mineralizado após a incubação do solo e o $\mathrm{N}$ absorvido pelas plantas. Os primeiros métodos basearam-se em incubações aeróbicas ou anaeróbicas, em laboratório, sob condições controladas de temperatura e umidade (Keeney \& Bremner, 1966; Waring \& Bremner, 1964).

Os resultados obtidos com os métodos acima foram satisfatórios, indicando que tanto a incubação aeróbica quanto a anaeróbica possuem potencial para avaliar a disponibilidade de $\mathrm{N}$ no solo sob condições padrões. Entretanto, estes métodos não permitem avaliar o efeito das condições ambientais na disponibidade de $\mathrm{N}$, sendo a falta de representatividade das condições de campo a principal crítica feita aos mesmos. Todavia, as condições padronizadas mesmo sendo artificiais, propiciam uma oportunidade para que sejam estabelecidas comparaçōes entre diversos locais e estudos, as quais não seriam possíveis sob condições ambientais variáveis (Binkley \& Hart, 1989).

Uma vez que a mineralização do nitrogênio é fortemente afetada pelas condições microambientais vários métodos têm sido desenvolvidos para incluir os fatores ambientais nas avaliações (incubações in situ). Esses métodos podem fornecer melhores estimativas da mineralização (mais 
proxımas dos valores reais), mas em contrapartida podem apresentar uma variabilidade muito maior ao longo do período de amostragem, quando comparados com os métodos de incubação em laboratório sob temperatura e umidade constantes.

Vários métodos de incubação in situ têm sido utilizados para estimar as taxas líquidas de mineralização de $\mathrm{N}$ do solo sob povoamentos florestais (Nadelhoffer \& Aber, 1984; Vitousek \& Matson, 1985; Adams \& Attiwill, 1986b; Raison et al., 1987). Esses métodos visam a manutenção das características físicas e químicas do solo durante a incubação, de modo que o mesmo esteja sujeito às variações naturais de umidade e temperatura no campo.

O método mais amplamente empregado em avaliações de disponibidade de $\mathrm{N}$ sob codições de campo tem sido o de incubações de solo em sacos plásticos (Matson \& Vitousek, 1981; Mellilo, 1981; Nadelhoffer \& Aber, 1984). As amostras de solo são coletadas com trados e colocadas em sacos plásticos com o mínimo de distúrbio, os quais são enterrados na camada superficial sob a serapilheira. O método permite as trocas gasosas e variação de temperatura, mas evita a perda de água. As principais desvantagens do método acima residem no fato do mesmo, necessariamente, ser restrito à camada superficial do solo e sua sensibilidade restrita aos regimes de temperatura.

Nadelhoffer \& Aber (1984) utilizaram a metodologia acima, na avaliação da mineralização de $\mathrm{N}$ e de sua extração pelas árvores, estabelecendo modelos sazonais de mineralização de $\mathrm{N}$ e de absorção de $\mathrm{N}-\mathrm{NH}_{4}{ }^{+}$e de $\mathrm{N}-\mathrm{NO}_{3}{ }^{-}$em nove ecossistemas florestais. Os autores obtiveram alta correlação entre as taxas de mineralização de $\mathrm{N}$ e $\circ \mathrm{N}$ extraído pelas árvores $\left(r^{2}=0,90\right)$.

Outro método utilizado na avaliação da disponibilidade de $N$, sob condições de campo, consiste no emprego de bolsas com resinas de troca 
iônica (Binkley \& Matson, 1983), as quais também são enterradas na camada superficial do solo sob a serapilheira.

Segundo Binkley (1984), as acumulações de íns nas bolsas com resinas dependem fortemente das taxas de mineralização do nitrogênio, do transporte dos íons para as bolsas e da competição pelos nutrientes com microrganismos e as raízes das plantas. Entretanto, o método parece adequado para indicar diferenças na disponibilidade de $\mathrm{N}$ entre ecossistemas $\mathrm{e}$ entre tratamentos. A principal desvantagem do método é não possibilitar a identificação dos componentes responsáveis pelas diferenças observadas, tais como: a mineralização, a absorção pelas plantas e microrganismos e a mobilidade dos íons (Binkley \& Hart, 1989).

Di Stefano \& Gholz (1986) desenvolveram uma metodologia para avaliação da disponibilidade de $\mathrm{N}$, in situ, também utilizando resinas de troca iônica. Entretanto, nesse método os tubos de PVC são inseridos no solo e retirados imediatamente, sendo colocadas nas extremidades dos mesmos bolsas contendo a resina. Os tubos retornam ao mesmo local de amostragem, sendo incubados por um determinado período. A principal vantagem, em relação ao método anterior, consiste em eliminar a competição entre as resinas e as raízes pelo nitrogênio. No final do período de incubação, o $\mathrm{N}$ mineral do solo no interior dos tubos e nas resinas é determinado. $\mathrm{O} \mathrm{N}$ mineral determinado na resina localizada na base do tubo corresponde ao $\mathrm{N}$ lixiviado durante o período de incubação e, o $\mathrm{N}$ mineral determinado na resina, localizada na extremidade superior do tubo, corresponde às entradas de $\mathrm{N}$ no sistema. O N mineralizado, durante o período de incubação é dado então, pela

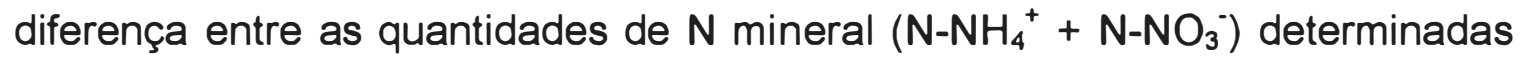
no final da incubação (solo + resinas) e as quantidades iniciais (determinadas no solo antes da incubação). Entretanto, a metodologia de Di Stephano \& Gholz (1986) aplica-se apenas a solos bem drenados ou em locais com altos índices pluviométricos (Binkley \& Hart, 1989). 


\subsection{Utilização de ${ }^{15} \mathrm{~N}$}

O nitrogênio na atmosfera constitui-se de 99,63 átomos $\%$ de ${ }^{14} \mathrm{~N}$ e 0,3663 átomos $\%$ de ${ }^{15} \mathrm{~N}$. No solo, a percentagem de átomos de ${ }^{15} \mathrm{~N}$ comumente varia de 0,3653 a $0,3673 \%$. A adição de fertilizantes nitrogenados enriquecidos com átomos de ${ }^{15} \mathrm{~N}$, isto é, com um teor de ${ }^{15} \mathrm{~N}$ superior a 0,3663 átomos \%, resultará em um excesso de ${ }^{15} \mathrm{~N}$ na solução do solo em relação à marcação natural, o qual dependerá da forma e concentração do fertilizante aplicado bem como do tempo decorrido para a determinação do ${ }^{15} \mathrm{~N}$ na solução. A mineralização do $\mathrm{N}$ orgânico do solo (com composição isotópica natural) libera $\mathrm{N}$ mineral para a solução do solo com a marcação natural de ${ }^{15} \mathrm{~N}(0,3663$ átomos $\%$ de ${ }^{15} \mathrm{~N}$ ), resultando em uma diminuição no teor de ${ }^{15} \mathrm{~N}$ do nitrogênio disponível do solo. A partir da diluição isotópica de ${ }^{15} \mathrm{~N}$ torna-se possível estimar a mineralização do nitrogênio do solo.

\subsection{Comparação de métodos}

Recentemente, foi desenvolvida uma técnica de incubação sequencial de colunas de solo in situ, por Raison et al. (1987) e Adams \& Attiwill (1986b), a qual permite avaliar simultaneamente as taxas de mineralização, lixiviação e absorção de $\mathrm{N}$. Essa técnica tem se mostrado promissora e segundo Whynot \& Weetman (1991) oferece ainda, as seguintes vantagens: a) os distúrbios no solo e a compactação são mínimos; b) as quantidades de $\mathrm{N}$ orgânico são reabastecidas por entradas de $\mathrm{N}$ orgânico das raízes danificadas nos tubos cobertos e de entradas de raízes e de serapilheira nos tubos abertos; c) o método é aplicável a solos florestais nos quais há um marcado desenvolvimento de um gradiente de matéria orgânica acima e no solo; d) os solos incubados, apesar de conterem mais altos conteúdos de umidade, em geral, apresentaram flutuações no teor de umidade em resposta às condições locais; e) devido a técnica estimar as taxas relativas de nitrificação e absorção de $\mathrm{N}-\mathrm{NO}_{3}{ }^{-}$, bem como as taxas de amonificação e de 
absorção de $\mathrm{N}-\mathrm{NH}_{4}^{+}$pode-se avaliar a preferência das plantas pelo $\mathrm{N}-\mathrm{NH}_{4}{ }^{+}$ou pelo $\mathrm{N}^{-\mathrm{NO}_{3}}{ }_{3}^{-}$bem como as condições que propiciam a nitrificação; f) os resultados obtidos com a técnica de incubação sequencial de colunas de solo podem ser comparados aos resultados obtidos em outros locais desde que os fluxos efetivos sejam calculados ou, pelo menos, as estimativas dos mesmos, ao contrário, dos índices medidos por outras técnicas (Hart \& Firestone, 1989).

Segundo Binkley \& Hart (1989), as incubações de laboratório permitem comparar diferentes locais quanto à qualidade do substrato, mas não com relação às taxas reais de mineralização. As incubações em laboratório devem ser modificadas para refletirem as condições de campo ou calibradas para tipos florestais específicos (Powers, 1980). Entretanto, Whynot \& Weetman (1991), ressaltam que a técnica de incubação in situ, proposta por Raison et al. (1987), oferece também algumas desvantagens, a saber: a) pode ser difícil encontrar efeitos significativos de tratamentos dentro de um sítio por causa dos grandes erros padrões. Os erros podem ser calculados, mas não podem ser explicitamente incluídos em uma análise de variância; b) por causa das estimativas de fluxo serem calculadas baseadas em diferenças entre médias, a técnica é muito cara para ser incluída em rotina como um índice da disponibilidade de $\mathrm{N}$ para recomendações de adubação nitrogenada; c) como em outras técnicas de campo, determinar o período de exposição apropriado pode ser problemático especialmente no caso de se trabalhar com diferentes tratamentos; d) quando comparados com outras técnicas, os valores estimados para as taxas de absorção podem não refletir a absorção real caso as plantas assimilem certas formas solúveis de $\mathrm{N}$ orgânico; e) por último, a técnica de incubação sequencial in situ pode oferecer problemas em solos pedregosos ou em solos com abundância de raízes grossas em que a inserção dos tubos torna-se difícil.

Em geral, a ausência de correlação entre os vários índices de disponibilidade de $\mathrm{N}$, provavelmente, resulta de diferenças nos componentes 
do ciclo do $\mathrm{N}$ avaliados em cada método (Hart \& Firestone, 1989; Binkley \& Hart, 1989) bem como da variação temporal e espacial no solo. Nenhum método fornece um índice inequívoco da disponibilidade de $\mathrm{N}$ em solos florestais (Hart \& Binkley, 1985), mas o método da incubação sequencial de colunas de solo oferece mais vantagens do que desvantagens, comparado com outras técnicas de incubação em campo e no laboratório para avaliar a capacidade de suprimento de $\mathrm{N}$ de um solo. A aplicação da técnica de incubação de colunas de solo in situ na análise de rotina para prescrições e recomendações de adubação não é viável, pois os trabalhos de campo e de laboratório são muito intensos. Entretanto, por constituir-se em um método sensivel às variações dos fatores ambientais e por causar menores distúrbios ao solo, pesquisas utilizando a mesma são importantes para aumentar a compreensão sobre a dinâmica que controla a disponibilidade de $\mathrm{N}$ para as árvores, os efeitos dos diferentes manejos sobre a qualidade do sítio e ainda, para elaboração de modelos de simulação da mineralização de $\mathrm{N}$ que permitam predizer as possíveis respostas das florestas à fertilização nitrogenada. 


\section{MATERIAL E MÉTODOS}

\section{1 Área de estudo}

O estudo foi realizado em uma área de plantio comercial de Eucalyptus grandis Hill Ex Maiden, pertencente à COMPANHIA SUZANO CELULOSE E PAPEL, associada ao Instituto de Pesquisas e Estudos Florestais (IPEF). A área experimental localiza-se na Fazenda Entre-Rios, no município de Itatinga, distando cerca de 200 Km da cidade de Piracicaba, São Paulo. As coordenadas geográficas da sede da fazenda Entre-Rios são: $23^{\circ} 17^{\prime}$ 'S e $48^{\circ} 28^{\prime} \mathrm{O}$.

A área experimental encontra-se a uma altitude de $649 \mathrm{~m}$, sendo o clima da região classificado como $\mathrm{Cwa}$, segundo a classificação de Köppen, ou seja, mesotérmico de inverno seco com a temperatura média do mês mais frio (julho) inferior a $18^{\circ} \mathrm{C}$ e a média do mês mais quente (janeiro) superior a $22^{\circ} \mathrm{C}$. O total de chuvas do mês mais seco não ultrapassa $30 \mathrm{~mm}$. A precipitação média anual da área é de, aproximadamente, $1579 \mathrm{~mm}$, com $57 \%$ concentrada nos meses de dezembro a março. $O$ balanço hídrico do solo encontra-se na Figura 2.

O relevo é plano a suave ondulado e o tipo de solo é caracterizado como um latossolo vermelho-amarelo, textura média e distrófico.

A vegetação natural da região é o cerrado, sendo as condições edafoclimáticas e florísticas da mesma representativas de extensos blocos de povoamentos de eucaliptos. 
Balanço hídrico

Fazenda Entre-Rios

- - precipitação

Itatinga - SP

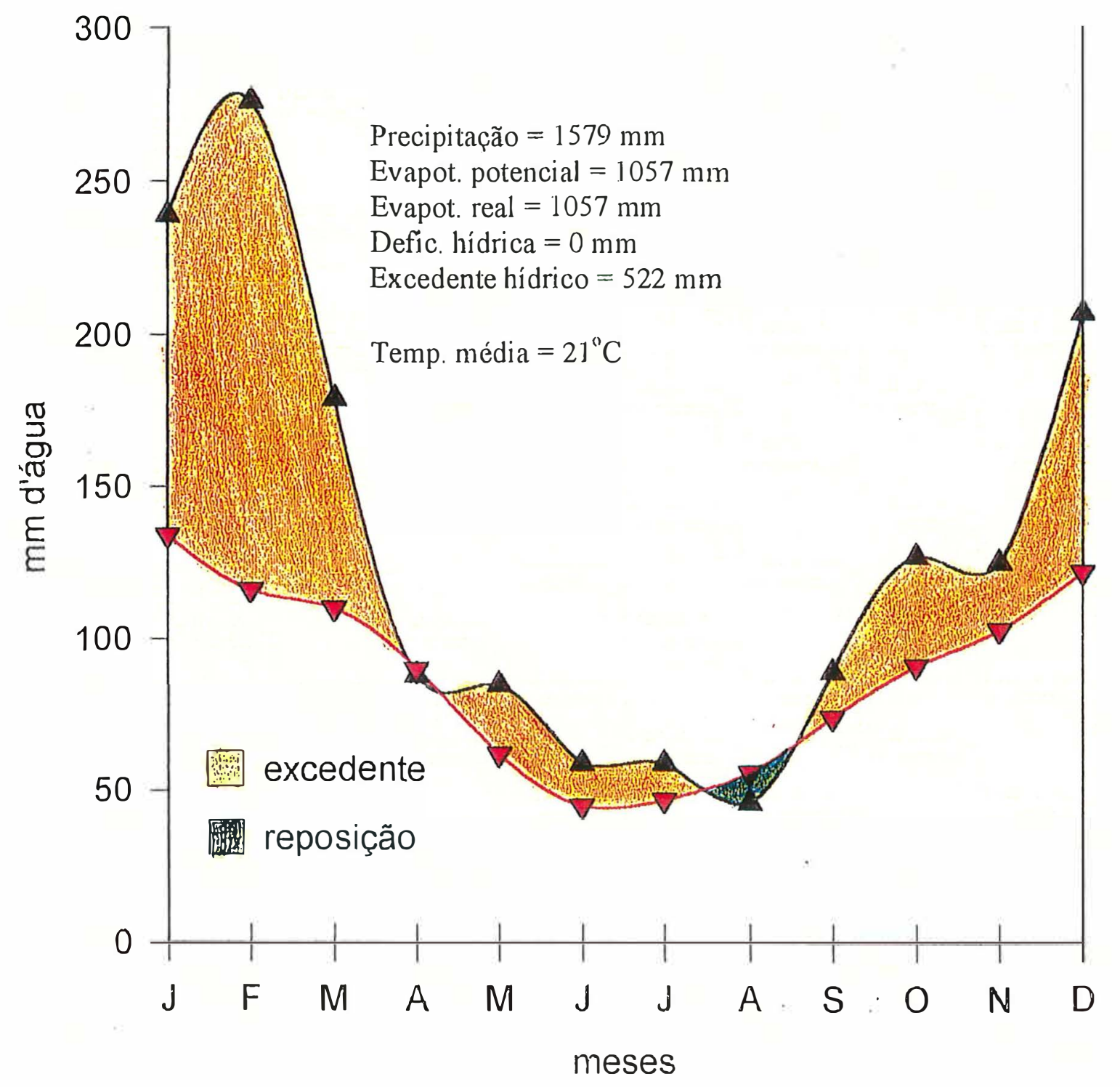

Figura 2.Balanço hídrico, segundo Thomthwaite \& Mather, 1955, considerando $125 \mathrm{~mm}$ de capacidade de armazenamento de água do solo. 


\subsection{Sistemas de preparo do solo}

Os tratamentos experimentais consistiram em práticas operacionais que contemplaram distúrbios de diferentes magnitudes do solo e dos resíduos culturais, a saber:

A. Manutenção do povoamento de Eucalyptus grandis intacto cobrindo o solo;

B. Corte raso do povoamento. Manutenção sobre o solo de todos os resíduos culturais: serapilheira e restos culturais (sobras da exploração: ponteiros, galhos e folhas, basicamente). Condução de um broto por cepa;

C. Corte raso do povoamento. Manutenção sobre o solo de todos os resíduos culturais;

D.Corte raso do povoamento. Manutenção da serapilheira sobre o solo. Remoção dos restos culturais;

E. Corte raso do povoamento. Remoção de todos os resíduos culturais;

F. Corte raso do povoamento. Incorporação ao solo de todos os resíduos culturais com uma grade pesada $16 \times 24$ ", sendo feitos dois repasses e,

G. Corte raso do povoamento. Distribuição de todos os resíduos culturais, os quais foram queimados. 
Nos tratamentos $C, D, E, F$ e G foi realizado, após o corte raso (11/07/95) e instalação dos tratamentos (02/08/95), o plantio de um novo povoamento de Eucalyptus grandis (procedente de Coff's Harbour), em 26/09/95, no espaçamento de 3,0 $\mathrm{m} \times 2,0 \mathrm{~m}$, utilizando-se mudas formadas a partir de sementes.

Para o plantio das mudas foi aberto um sulco de $30 \mathrm{~cm}$ de profundidade com um sulcador monohaste. A adubação de plantio (25/08/95) consistiu da aplicação de $150 \mathrm{~kg} \mathrm{ha}^{-1}$ da formulação NPK 10-20-10 e, a adubação de cobertura (08/05/96), da aplicação de $250 \mathrm{~kg} \mathrm{ha}^{-1}$ de KCl.

Foram realizadas duas capinas manuais, a primeira três meses após o plantio (27/12/95) e, a segunda, sete meses após o plantio (06/05/96). A desbrota foi realizada manualmente, tres meses após o plantio (01/96).

\subsection{Delineamento experimental}

Para a instalação das parcelas foi usado o delineamento experimental em blocos ao acaso com 7 tratamentos e 4 repetições, totalizando 28 parcelas. Cada parcela experimental foi composta por 121 plantas distribuídas, em 11 linhas com 11 plantas em cada uma. Considerando a área ocupada por cada árvore igual a $6,0 \mathrm{~m}^{2}$ (nos tratamentos em que foi realizado o corte raso e o plantio das mudas em espaçamento 3,0 $\mathrm{m} \times 2,0 \mathrm{~m}$ ), cada parcela experimental ocupou $726 \mathrm{~m}^{2}$, totalizando $17.424,0 \mathrm{~m}^{2}$. Nas 4 parcelas onde 0 povoamento com espaçamento $3,00 \mathrm{~m} \times 1,80 \mathrm{~m}$ foi mantido intacto, a área considerada como ocupada por cada árvore foi $5,4 \mathrm{~m}^{2}$, totalizando $2.613,6 \mathrm{~m}^{2}$ com povoamento intacto. Dessa forma, o experimento abrangeu $20.037,6 \mathrm{~m}^{2} \mathrm{de}$ área (Figura 3).

Os estudos sobre a mineralização, absorção e lixiviação de $N$ foram realizados apenas nos tratamentos $A, C, E, F$ e $G$, sendo todas as amostragens realizadas na área central das parcelas, ocupada por 49 plantas, resultando no estabelecimento de uma bordadura dupla. 


\subsection{Condições macrò e microclimáticas}

Os dados pluviométricos, as temperaturas máxima e mínima e a umidade relativa do ar foram medidos durante o período experimental em uma estação metereológica situada na sede da fazenda Entre-Rios.

Semanalmente foram medidas as temperaturas máximas e mínimas do solo, na profundidade de $2,5 \mathrm{~cm}$, de todos os tratamentos.

Os percentuais de umidade do solo e dos resíduos culturais foram estimados na ocasião da amostragem do solo para avaliação das quantidades de $\mathrm{N}$ mineralizadas, lixiviadas e absorvidas. 


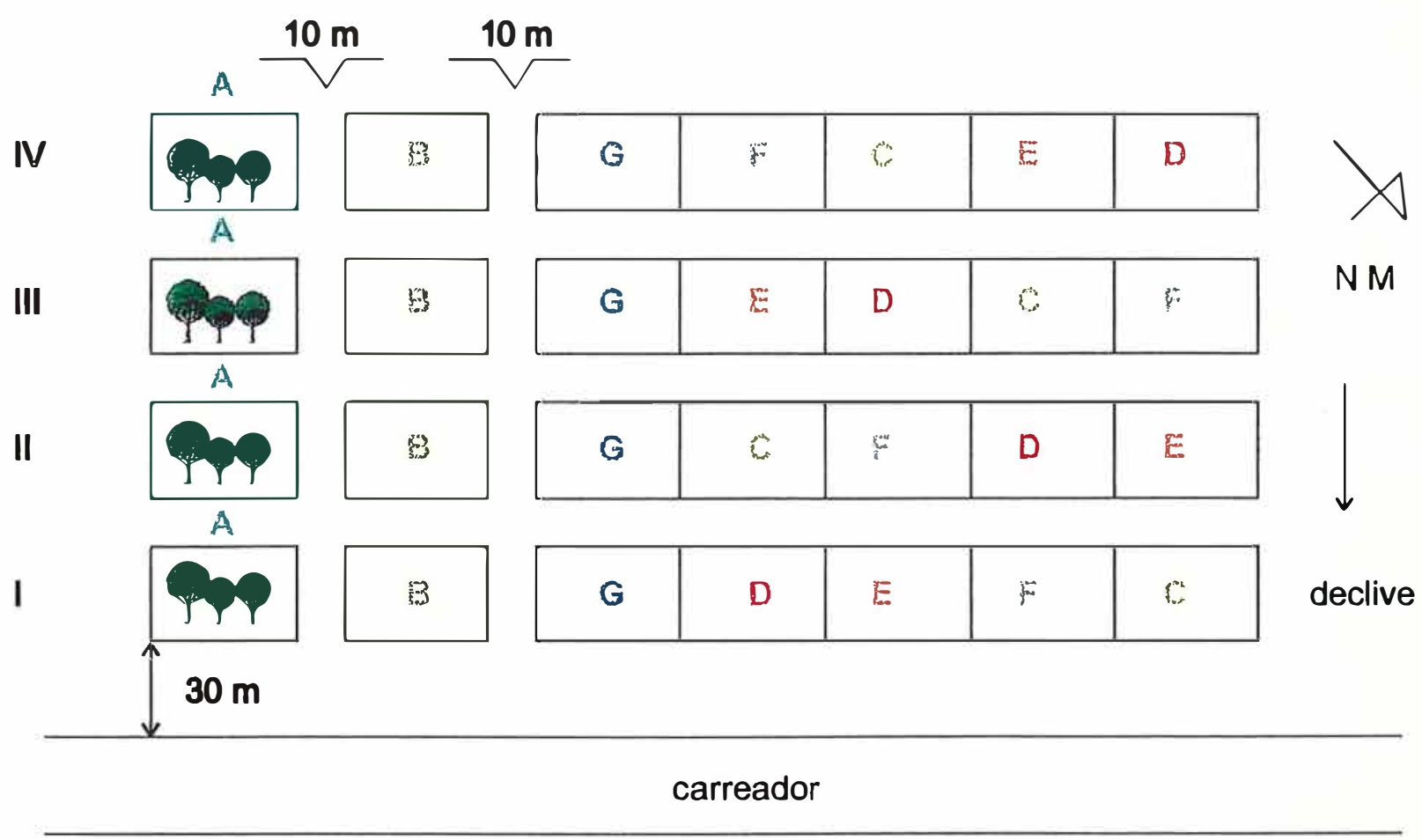

* Os termômetros de solo foram instalados ao lado da primeira árvore da área útil da parcela e na linha de plantio

$A=$ manutenção do povoamento intacto:

$B=$ manutençáo dos resíduos culturais a conducâo da rebruta;

C= manutenga de torks os residuos culuras sobre o solo;

$D=$ remoção dos restos culturais e manutenção da serapitheira;

E :- remoçäo doe restos culurais e serapitheira;

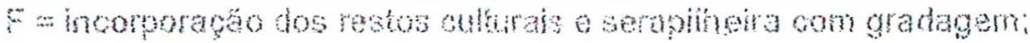

$G=$ queima dos residuos culturais.

Figura 3. Esquema da área experimental. 


\subsection{Inventário de fitomassa e do estoque de nutrientes nos diferentes compartimentos do povoamento de Eucalyptus grandis}

Em todas parcelas experimentais do tratamento $A$ foram realizadas avaliações do crescimento das árvores, para os seguintes parâmetros: altura, crescimento em diâmetro à altura do peito (d.a.p.), volume sólido de madeira, área basal, índice de sítio e ocorrência de falhas. Nos demais tratamentos, aos 6 meses de idade, foi avaliado o crescimento em altura.

Para estimar a biomassa e o estoque de nutrientes do povoamento, foi obtida uma distribuição diamétrica das árvores das 4 parcelas experimentais, em função de 5 classes, sendo abatida 1 árvore por parcela de cada uma dessas classes. Para as estimativas da massa seca e determinação da composição química dos diferentes componentes das árvores, as folhas, os galhos e os troncos foram separados no campo e, pesados logo após o corte.

As estimativas de massa seca e a determinação da composição química dos diferentes componentes das árvores foram feitas mediante amostragens. Cerca de $200 \mathrm{~g}$ de folhas por árvore, após homogeneização de toda copa, foram amostrados. Os galhos de cada árvore, incluindo a parte do caule com menos de $3,0 \mathrm{~cm}$ de diâmetro, foram agrupados num feixe e da parte intermediária foi obtida uma amostra (cerca de $500 \mathrm{~g}$ ) representativa do conjunto.

As amostras de folhas, galhos e cascas foram devidamente acondicionadas, identificadas e encaminhadas ao Laboratório de Ecologia Aplicada do Departamento de Ciências Florestais da ESALQ. As amostras foram pesadas, após 72 horas de secagem sob ventilação forçada a $65^{\circ} \mathrm{C}$ (até a obtenção da massa constante para a matéria seca). As composições químicas das amostras foram determinadas segundo as metodologias propostas por Sarruge \& Haag (1974). Uma vez conhecida a massa de material 
fresco total dos componentes folhas e galhos e, a massa de material fresco e seco das respectivas amostras, foi possivel estimar a massa seca total de cada componente para cada árvore abatida.

Para calcular a massa de casca e de lenho secos, foram tomados os diâmetros com e sem casca das árvores abatidas, em intervalos fixos de 2,0 $\mathrm{m}$ em 2,0 $\mathrm{m}$, da base até a altura em que o diâmetro fosse menor ou igual a $3,0 \mathrm{~cm}$. De posse destas medições, foram calculados os volumes do tronco com e sem casca e, pela diferença entre ambos, obteve-se o volume de casca de cada árvore. Para o cálculo dos volumes de madeira com e sem casca foi usada a fórmula de Smallian.

Para estimar a quantidade e composição química da serapilheira acumulada sobre o solo foram coletadas 5 amostras simples por parcela, que, após homogeneizadas, deram origem a uma amostra composta. As amostras foram retiradas com um aro de aço circular com $2 \mathrm{~mm}$ de espessura, $5 \mathrm{~cm}$ de altura e $30 \mathrm{~cm}$ de diâmetro. Uma das bordas do aro tem superfície cortante, para facilitar o corte do material depositado nas margens da área amostrada. As amostras foram secas e analisadas quimicamente conforme metodologias utilizadas para as amostras dos componentes das árvores.

Para estimar a massa seca das raízes grossas $(>3 \mathrm{~mm}$ de espessura), e determinar a sua composição química, três árvores médias quanto ao d.a.p.. foram removidas de três parcelas experimentais distintas. Para isso, foram escavadas trincheiras de $5,4 \mathrm{~m}^{2}$, ao redor das árvores. Depois da cuidadosa remoção do solo e exposição das raízes, os sistemas radiculares dessas árvores foram removidos e obteve-se as massas de todo o material fresco. Do material obtido, retirou-se amostras com aproximadamente $1 \mathrm{~kg}$ de cada parcela, as quais foram secas, sob ventilação forçada a $65^{\circ} \mathrm{C}$, até a obtenção das massas constantes. Uma vez conhecida a massa de material fresco total dos sistemas radiculares de cada parcela e, a massa de material fresco e seco das respectivas amostras, foi possivel estimar a massa seca total 
das raízes para cada árvore abatida (Mello, 1997). Nas amostras de raízes tambem foi realizada a determinação da composição química segundo metodologias propostas por Sarruge \& Haag (1974).

\subsection{Caracterização química e física do solo}

As características químicas do solo foram determinadas para as camadas $0-2,2-5,5-10$ e 10-20 cm de profundidade em todos os tratamentos onde foram realizados os estudos sobre a mineralização, absorção e lixiviação de $\mathrm{N}$ (Tratamentos $\mathrm{A}, \mathrm{C}, \mathrm{E}, \mathrm{F}$ e G). As características físicas do solo foram determinadas para as camadas de $0-10,10-20,20-30,30-50$ e 50-100 cm de profundidade no tratamento $A$

A composição granulométrica (método da pipeta), a densidade do solo e a densidade de partículas foram realizadas segundo a metodologia apresentada pela Empresa Brasileira de Pesquisa Agropecuária (EMBRAPA, 1979). As determinações de pH, carbono orgânico, fósforo disponivel, cálcio, magnésio, potássio e alumínio trocável, acidez potencial, hidrogênio titulável, capacidade de troca de cátions, saturação de bases e de alumínio foram feitas segundo RAlJ et al. (1987).

As determinações de $\mathrm{C}$ e $\mathrm{N}$ totais no solo foram realizadas em todos os tratamentos na primeira coleta (Setembro/95). Para isso, amostras de solo isentas de raízes foram moídas em gral e passadas em uma peneira de malha 100 mesh.

O Carbono total foi determinado através do método de via seca, utilizando-se o analisador de carbono LECO, modelo CR/ 412, no Laboratório de Química do Solo, do Centro de Energia Nuclear na Agricultura (CENAUSP). A deteção é feita por infravermelho e a conversão em percentagem de carbono total é fornecida diretamente pelo aparelho. $\mathrm{O}$ total foi determinado pelo método micro-Kjeldahl (Bremner, 1965) no Laboratório de Fertilidade do Solo do CENAIUSP. 


\subsection{Caracterização química da serapilheira acumulada}

Para a caracterização da composição química da serapilheira acumulada, amostras compostas de cada parcela experimental do tratamento $\mathrm{A}$ foram moídas em moinho tipo Wiley e passadas em peneira de malha 100 mesh. Nessas amostras foram determinados os teores de $\mathrm{C}$ e $\mathrm{N}$ totais pelos métodos de via seca e micro-Kjeldahl, respectivamente, conforme metologia já descrita. $O$ teor de lignina foi determinado segundo Soest (1963).

\subsection{Mineralização, absorção e lixiviação de N no solo}

No início de cada período de incubação, em todas as parcelas experimentais, foram instalados no solo, aleatoriamente, seis conjuntos de três tubos de PVC (40 cm de comprimento e $5 \mathrm{~cm}$ de diâmetro) para as determinações das quantidades de $\mathrm{N}$ mineralizadas, absorvidas e lixiviadas, nas camadas de 0-5, 5-15 e 15-30 cm do solo, segundo metodologia proposta por Raison et al. (1987). Seis tubos foram removidos e analisados imediatamente para as determinações das concentrações iniciais de $\mathrm{N}-\mathrm{NH}_{4}{ }^{+} \mathrm{e}$ de $\mathrm{N}-\mathrm{NO}_{3}{ }^{-}$. Com relação aos 12 tubos restantes, seis foram cobertos para evitar as lixiviações de $\mathrm{N}$ e seis foram deixados abertos. Esses tubos permaneceram incubados no campo por um período de 45 dias, após o qual foram removidos e substituídos imediatamente por um novo conjunto de tubos para uma nova fase de incubação das amostras de solo in situ (Figura 4).

O tempo de incubação (45 dias) foi definido em função de trabalhos, já existentes na literatura, utilizando a mesma metodologia e em solos de baixa fertilidade natural como o do presente estudo (Smethurst \& Nambiar, 1989; Smethurst \& Nambiar, 1990a, b). O estudo envolveu 4 períodos de incubação do solo no campo: $1^{9}$ ) 05/09/95 a 19/10/95; $2^{\circ}$ ) 19/10/95 a 05/12/95; $3^{\circ}$ ) 05/12/95 a 22/ 01/ 96 e 4º ) 22/01/96 a 05/ 03/96. 
Após a remoção do campo, os tubos foram encaminhados diretamente ao Laboratório de Ecologia Aplicada do Departamento de Ciências Florestais da ESALQ, onde foram mantidos sob refrigeração a $4^{\circ} \mathrm{C}$ e processados dentro de, no máximo, 4 dias.

Os cilindros de solo foram removidos dos tubos após a separação da serapilheira, e então, secionados nas profundidades de 0-5, 5-15 e $15-30 \mathrm{~cm}$. As seis amostras simples de serapilheira e de cada camada do solo foram reunidas e homogeneizadas, separadamente, dando origem as amostras compostas de serapilheira e das várias camadas de solo.

Para obtenção dos extratos foram tomadas $10 \mathrm{~g}$ de terra úmida $\mathrm{e}$ de serapilheira, as quais foram agitadas com $50 \mathrm{ml}$ de $\mathrm{KCl} 2 \mathrm{M}$ por uma hora à temperatura ambiente (Bremner, 1965). Os extratos foram centrifugados a 2000 rpm por 15 minutos e foram tomadas alíquotas de $20 \mathrm{ml}$ do sobrenadante que, após receberem $0,1 \mathrm{ml}$ do inibidor da atividade microbiológica, fenil acetato de mercúrio $\left(0,5 \mathrm{mg} \mathrm{L}^{-1}\right)$, foram submetidas aos procedimentos analíticos para a determinação de $\mathrm{N}_{-} \mathrm{NH}_{4}^{+}$e de $\mathrm{N}-\mathrm{NO}_{3}^{-}$. Paralelamente, foram tomadas subamostras de solo e de serapilheira, as quais foram submetidas à secagem a $105^{\circ} \mathrm{C}$ por 24 horas para a determinação do percentual de umidade das mesmas.

As determinações das concentrações de $\mathrm{N}-\mathrm{NH}_{4}{ }^{+}$e de $\mathrm{N}-\mathrm{NO}_{3}{ }^{-}$nos extratos foram realizadas com o emprego do Sistema de Análise por Injeção em Fluxo - FIA - (Ruzicka \& Hansen, 1975) na Seção de Química Analítica do CENA/USP. $\mathrm{O} \mathrm{N}-\mathrm{NH}_{4}{ }^{+}$foi determinado pelo método condutimétrico e $\circ \mathrm{N}-\mathrm{NO}_{3}{ }^{-}$ pelo método colorimétrico, sendo os limites de deteção obtidos de 0,25 e de $0,05 \mu \mathrm{g} \mathrm{ml}^{-1}$, respectivamente.

Para a obtenção das concentrações de $\mathrm{N}_{-} \mathrm{NH}_{4}{ }^{+}$e de $\mathrm{N}-\mathrm{NO}_{3}{ }^{-}$no solo, cada concentração obtida pelo sistema FIA foi multiplicada pelo volume do extrato acrescido do volume de água de cada amostra (calculado mediante a determinação do percentual de umidade de cada uma das mesmas por 
ocasião da preparação dos extratos) e então, dividida pela massa de terra seca da amostra. Portanto, as concentrações de $\mathrm{N}_{-} \mathrm{NH}_{4}{ }^{+}$e de $\mathrm{N}-\mathrm{NO}_{3}{ }^{-}$no solo foram expressas em $\mu \mathrm{g} \mathrm{g}^{-1}$ de terra seca. A densidade do solo foi utilizada para converter as concentrações de $\mathrm{N}$ mineral do solo $\left(\mathrm{N}^{-} \mathrm{NH}_{4}^{+}\right.$e $\left.\mathrm{N}-\mathrm{NO}_{3}{ }^{-}\right)$em conteúdo por área $\left(\mathrm{kg} \mathrm{ha}^{-1}\right)$.

\subsection{Demonstração dos cálculos para obtenção das quantidades de $\mathbf{N}$} mineralizadas, lixiviadas e absorvidas (Raison et al., 1987)

$$
\begin{aligned}
\Delta \mathrm{NH}_{4}^{+}-\mathrm{N} & =\text { AMONIFICAÇÃO LIQUIDA } \\
& =\mathrm{NH}_{4}^{+}-\mathrm{Ne}_{\mathrm{e}}(\mathrm{t}+1) \mathrm{c}-\mathrm{NH}_{4}^{+}-\mathrm{Nb}_{\mathrm{b}}(\mathrm{t}) \\
\Delta \mathrm{NO}_{3}^{-}-\mathrm{N} & =\text { NITRIFICAÇÃO LIQUIDA } \\
& =\mathrm{NO}_{3}^{-}-\mathrm{N} e(\mathrm{t}+1) \mathrm{c}-\mathrm{NO}_{3}^{-}-\mathrm{N} b(\mathrm{t}) \\
\mathrm{Nmin}^{-} & =\mathrm{MINERALIZAÇÃO} \mathrm{LIQUIDA}^{-} \\
& =\Delta \mathrm{N}-\mathrm{NH}_{4}^{+}+\Delta \mathrm{N}-\mathrm{NO}_{3}^{-}
\end{aligned}
$$

onde,

$$
\mathrm{NH}_{4}{ }^{+}-\mathrm{Nb}(\mathrm{t}) \text { e } \mathrm{NO}_{3}^{-}-\mathrm{Nb}(\mathrm{t}) \text { correspondem às concentrações de }
$$

$\mathrm{N}-\mathrm{NH}_{4}{ }^{+}$e N- $\mathrm{NO}_{3}{ }^{-}$do solo no início do período exposição;

$$
\mathrm{NH}_{4}{ }^{+}-\mathrm{Ne}(\mathrm{t}+1) \mathrm{c} \text { e } \mathrm{NO}_{3}^{-}-\mathrm{Ne}(\mathrm{t}+1) \mathrm{c} \text { correspondem às }
$$
concentrações de $\mathrm{N}^{-\mathrm{NH}_{4}}{ }^{+}$e $\mathrm{N}-\mathrm{NO}_{3}{ }^{-}$do solo após um determinado período (tempo $\mathrm{t}+1$ ) no solo dos tubos que apresentavam a extremidade superior coberta. 
Se as taxas de amonificação e nitrificação líquidas no interior e no exterior dos tubos corresponderem-se, a quantidade de $\mathrm{N}$ - mineral absorvida ( $\mathrm{Na}$ ) pela vegetação durante o período de exposição será dada por:

$$
\begin{aligned}
N a & =(N \text { min })-(\Delta N-\text { mineral natural do solo })-\text { (perdas) } \\
& =\left[N_{e}(t+1) c-N_{b(t)}\right]-\left[N_{b(t+1)}-N_{b}(t)\right]-(\text { perdas }) \\
& =N_{e}(t+1) c-N_{b}(t+1)-(\text { perdas }) .
\end{aligned}
$$

onde,

$\mathrm{N}$ e $(t+1) c$ é a concentração de $\mathrm{N}$ - mineral do solo contido no tubo coberto no final do período de exposição;

$N_{b}(t+1)$ é a concentração de $N$ - mineral no solo após um determinado período de tempo $(t+1)$.

As perdas constituem variações no conteúdo de $\mathrm{N}$-mineral $(\mathrm{Nm})$, resultantes da lixiviação e denitrificação. A denitrificação é tida como zero a menos que avaliações independentes indiquem o contrário. A lixiviação também é assumida como zero nos tubos cobertos (c), sendo máxima nos tubos abertos (a). Neste caso, a perda por lixiviação será dada por:

Perda lix. $=N_{e}(t+1) c-N_{b}(t+1) a$

Substituindo a eq. (5) na eq. (4), obteremos:

$$
\mathrm{Na}=\mathrm{N}_{e}(t+1) a-\mathrm{N}_{b}(t+1)
$$


onde,

$\mathrm{Ne}_{e}(t+1) a$ é a concentração de $\mathrm{N}$-mineral do solo no tubo exposto aberto no final do período;

$\mathrm{N}_{b}(t+1)$ é a concentração de $\mathrm{N}$-mineral do solo após um determinado período de tempo (tempo $t+1)$.

\subsection{Análises estatísticas}

Verificadas as condições para a análise de variância através da análise exploratória dos dados, evidenciou-se que as profundidades não poderiam ser estudadas conjuntamente. Dessa forma, cada variável $\left(\mathrm{N}-\mathrm{NH}_{4}{ }^{+}\right.$ mineralizado, lixiviado, absorvido e $\mathrm{N}-\mathrm{NO}_{3}^{-}$mineralizado, lixiviado e absorvido) foi analisada dentro de cada profundidade.

O modelo utilizado é baseado nas médias dos mínimos quadrados (LSMeans) para cada efeito a ser testado. A comparação linear das média foi realizada mediante a utilização do " Teste t " para o nível de significância de

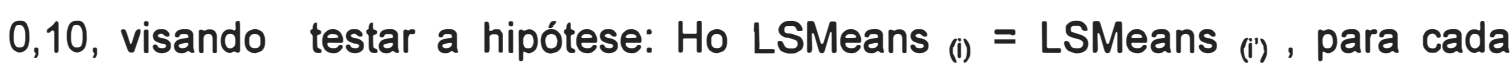
manejo testado, sendo o método recomendado para testar as médias de mínimos quadrados (SAS, 1990). 


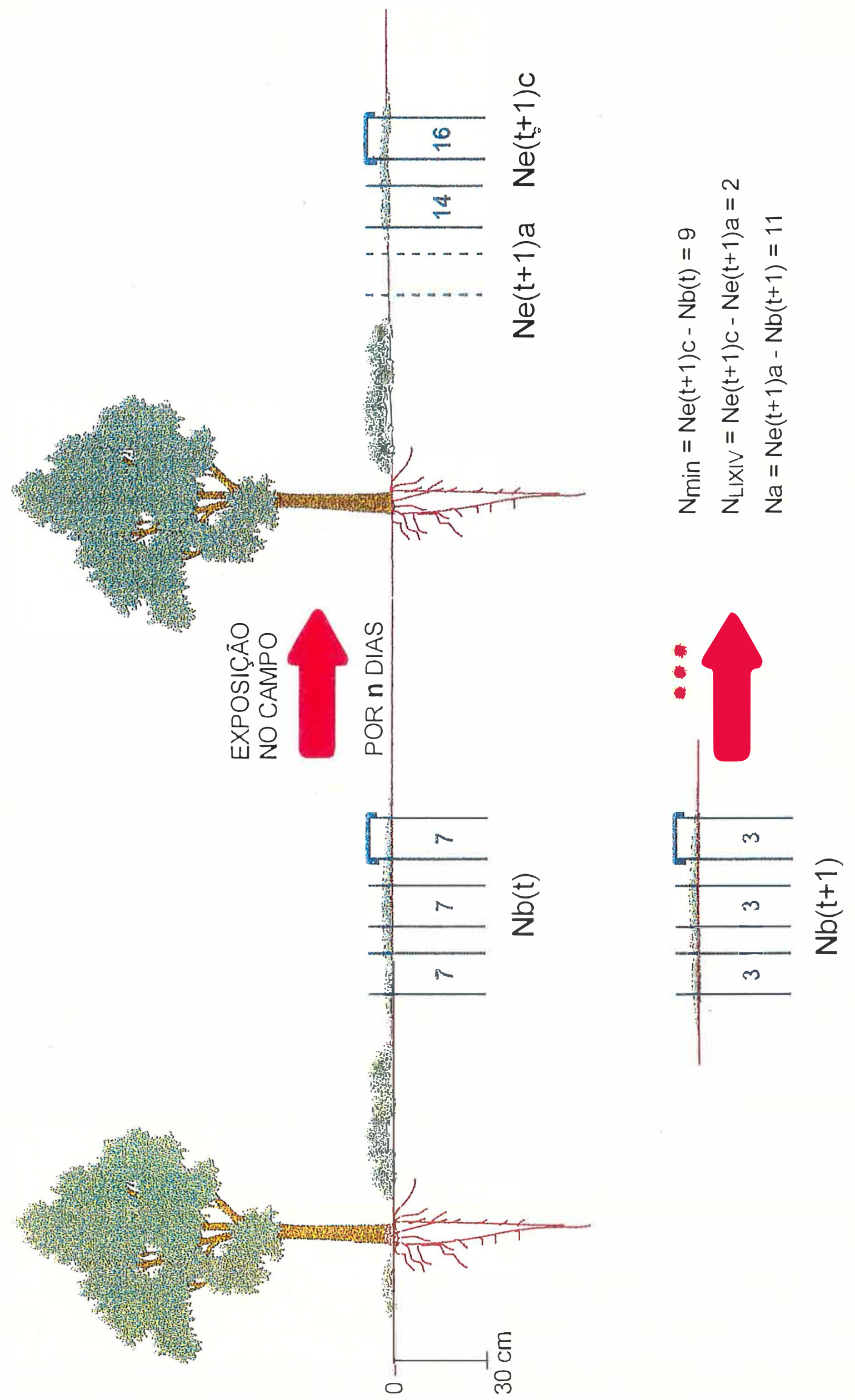

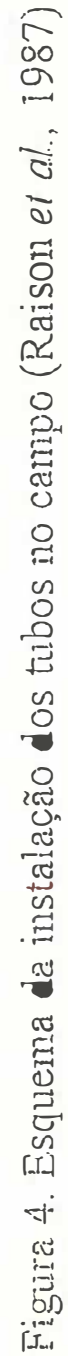




\section{RESULTADOS E DISCUSSÃO}

\subsection{Efeitos do preparo do solo em sua fertilidade}

A queima promoveu uma alteração considerável na distribuição dos nutrientes no sistema. A deposição das cinzas na superfície ocasionou modificações nas características químicas do solo, particularmente, na camada de $0-2 \mathrm{~cm}$ de profundidade.

$\mathrm{O}$ caráter básico das cinzas promoveu uma elevação do $\mathrm{pH}$ do solo bem como uma diminuição do $\mathrm{Al}$ trocável e de $\mathrm{H}+\mathrm{Al}$ nessa camada. Além disso, nesse tratamento, foram verificados aumentos nos teores de $\mathrm{Ca}, \mathrm{Mg}$ e $\mathrm{P}$ disponiveis. Provavelmente, o aumento nos teores desses elementos resultou da presença dos mesmos nas cinzas, em forma de óxidos e de sais, facilmente solubilizáveis (Tabela 1). Entretanto, comparando-se os dados das Tabelas $1 \mathrm{e}$ 2 observou-se uma redução dos teores de $\mathrm{P}$ e de bases trocáveis no solo do tratamento $\mathrm{G}$, em relação ao observado logo após a queima dos resíduos. 
Tabela 1. Características químicas do solo, 34 dias após a aplicação dos tratamentos experimentais.

\begin{tabular}{|c|c|c|c|c|c|c|c|c|c|c|c|c|c|c|}
\hline Prof. & C & $\mathbf{N}$ & $\mathrm{C} / \mathrm{N}$ & $\begin{array}{c}\mathrm{pH} \\
\left(\mathrm{CaCl}_{2}\right)\end{array}$ & Presina & $K$ & $\mathrm{Ca}$ & $\mathrm{Mg}$ & $\mathrm{H}+\mathrm{Al}$ & Al & $S$ & $T$ & V & $\mathrm{m}$ \\
\hline$(\mathrm{cm})$ & \multicolumn{2}{|c|}{$-\mathrm{g} \mathrm{kg}^{\prime}-$} & & & $\mathrm{mgdm}^{-3}$ & \multicolumn{7}{|c|}{$-\mathrm{mmol}_{c} \mathrm{dm}^{-3}$} & $\%$ & $\%$ \\
\hline \multicolumn{15}{|c|}{ Tratamento A } \\
\hline $0-2$ & 8,8 & 0,4 & 22,0 & 3,4 & 4,0 & 0,5 & 4,0 & 1,1 & 38,0 & 12,6 & 5,6 & 43,6 & 12,8 & 69,2 \\
\hline $2-5$ & 6,3 & 0,3 & 21,0 & 3,5 & 5,0 & 0,4 & 4,3 & 1,1 & 36,3 & 12,2 & 5,8 & 42,1 & 13,8 & 67,8 \\
\hline $5-10$ & 5,6 & 0,3 & 18,7 & 3,7 & 3,0 & 0,3 & 3,0 & 0,7 & 34,3 & 11,2 & 4,0 & 38,3 & 10,4 & 73,7 \\
\hline $10-20$ & 3,6 & 0,2 & 18,0 & 3,6 & 5,0 & 0,2 & 4,7 & 1,8 & 30,0 & 10,1 & 6,7 & 36,7 & 18,2 & 60,1 \\
\hline \multicolumn{15}{|c|}{ Tratamento C } \\
\hline $0-2$ & 10,6 & 0.5 & 21.2 & 3,5 & 4,0 & 0,8 & 3,0 & 1,2 & 45,0 & 13,5 & 4,5 & 53,2 & 8,5 & 68,5 \\
\hline $2-5$ & 8,4 & 0.4 & 21.0 & 3,6 & 3,0 & 0,6 & 3,0 & 0,5 & 40,3 & 12,4 & 4,1 & 44,4 & 9,2 & 75,2 \\
\hline $5-10$ & 4,7 & 0.3 & 15.7 & 3,8 & 5,0 & 0,4 & 2,0 & 0,2 & 32,5 & 11,9 & 2,6 & 35,1 & 7,4 & 82,1 \\
\hline $10-20$ & 3,4 & 0.2 & 17.0 & 3,8 & 5,0 & 0,2 & 3,0 & 0,2 & 28,0 & 9,5 & 3,5 & 31,5 & 11,1 & 73,1 \\
\hline \multicolumn{15}{|c|}{ Tratamento $\mathrm{E}$} \\
\hline $0-2$ & 6,1 & 0.5 & 12.2 & 3,6 & 3,0 & 0,7 & 3,5 & 0,5 & 38,3 & 12,5 & 4,7 & 43,0 & 10,9 & 72,7 \\
\hline $2-5$ & 4,4 & 0.3 & 14.7 & 3,7 & 5,0 & 0,4 & 2,3 & 0,3 & 33,0 & 12,4 & 3,0 & 36,0 & 8,3 & 80,5 \\
\hline $5-10$ & 5,3 & 0.3 & 17.7 & 3,8 & 3,0 & 0,3 & 3,3 & 0,2 & 32,0 & 11,1 & 3,8 & 35,8 & 10,6 & 74,5 \\
\hline $10-20$ & 3,4 & 0.2 & 17.0 & 3,9 & 4,0 & 0,2 & 2,8 & 0,2 & 27,0 & 9,2 & 1,7 & 28,7 & 5,9 & 81,3 \\
\hline \multicolumn{15}{|c|}{ Tratamento F } \\
\hline $0-2$ & 7,2 & 0,4 & 18,0 & 3,5 & 6,0 & 0,7 & 3,3 & 1,4 & 37,5 & 12,7 & 5,4 & 42,9 & 12,6 & 70,2 \\
\hline $2-5$ & 8,5 & 0,4 & 21,2 & 3,5 & 7,0 & 0,7 & 4,0 & 0,8 & 42,0 & 12,9 & 5,5 & 47,5 & 11,6 & 70,5 \\
\hline $5-10$ & 8,4 & 0,4 & 21,0 & 3,6 & 4,0 & 0,6 & 2,7 & 0,6 & 45,0 & 12,5 & 3,9 & 48,9 & 8,0 & 76,2 \\
\hline $10-20$ & 4,3 & 0,2 & 21,5 & 3,8 & 3,0 & 0,4 & 3,0 & 0,2 & 28,0 & 10,0 & 3,6 & 31,6 & 11,4 & 73,5 \\
\hline \multicolumn{15}{|c|}{ Tratamento G } \\
\hline $0-2$ & 6,5 & 0,3 & 21,7 & 4,3 & 14,0 & 3,3 & 11,3 & 6,1 & 31,3 & 4,3 & 20,7 & 52,0 & 39,8 & 17,3 \\
\hline $2-5$ & 6,4 & 0,3 & 21,3 & 4,2 & 8,0 & 2,3 & 7,5 & 3,4 & 37,0 & 7,2 & 13,2 & 50,2 & 26,3 & 35,3 \\
\hline $5-10$ & 4,4 & 0,3 & 14,7 & 3,7 & 6,0 & 0,3 & 3,8 & 0,6 & 38,0 & 11,5 & 4,7 & 42,7 & 11,0 & 71,0 \\
\hline $10-20$ & 3,4 & 0,2 & 17,0 & 3,8 & 8,0 & 0,2 & 4,3 & 0,6 & 28,0 & 9,1 & 5,1 & 33,1 & 15,4 & 64,5 \\
\hline
\end{tabular}


Tabela 2. Características químicas do solo, nos tratamentos A, F e G, 173 dias após a aplicação dos tratamentos experimentais e, após 216 dias para os tratamentos C e E.

\begin{tabular}{|c|c|c|c|c|c|c|c|c|c|c|c|}
\hline Prof & $\mathrm{pH}$ & $P$ resina & $\mathrm{K}$ & $\mathrm{Ca}$ & $\mathrm{Mg}$ & $\mathrm{H}+\mathrm{Al}$ & Al & $S$ & $\mathrm{~T}$ & v & $\mathrm{m}$ \\
\hline$(\mathrm{cm})$ & & $\dot{\mathrm{m} g} \mathrm{dm}^{-3}$ & \multicolumn{7}{|c|}{$-\mathrm{mmol}_{\mathrm{c}} \mathrm{dm}^{-3}$} & $\%$ & $\%$ \\
\hline \multicolumn{12}{|c|}{ Tratamento A } \\
\hline $0-2$ & 3,6 & 7,0 & 0,8 & 1,7 & 1,4 & 48,7 & 12,0 & 3,9 & 52,6 & 7,4 & 75,5 \\
\hline $2-5$ & 3,7 & 5,0 & 0,6 & 1,4 & 0,7 & 36,7 & 9,6 & 2,7 & 39,4 & 6,9 & 78,0 \\
\hline $5-10$ & 3,9 & 5,0 & 0,4 & 1,2 & 0,6 & 36,7 & 9,2 & 2,2 & 38,9 & 5,7 & 80,7 \\
\hline $10-20$ & 4,0 & 4,0 & 0,5 & 2,2 & 0,8 & 30,0 & 6,9 & 3,5 & 33,5 & 10,4 & 66,3 \\
\hline \multicolumn{12}{|c|}{ Tratamento C } \\
\hline $0-2$ & 3,6 & 9,0 & 1,0 & 5,0 & 3,6 & 31,7 & 10,4 & 9,6 & 41,3 & 23,2 & 52,0 \\
\hline $2-5$ & 3,8 & 9,0 & 0,6 & 2,5 & 1,5 & 45,3 & 10,3 & 4,6 & 49,9 & 9,2 & 69,1 \\
\hline $5-10$ & 4,0 & 7,0 & 0,7 & 2,7 & 1,2 & 42,3 & 11,1 & 4,6 & 46,9 & 9,8 & 70,7 \\
\hline $10-20$ & 4,0 & 4,0 & 0,8 & 2,2 & 0,6 & 32,0 & 8,5 & 3,6 & 35,6 & 10,1 & 70,2 \\
\hline \multicolumn{12}{|c|}{ Tratamento $\mathrm{E}$} \\
\hline $0-2$ & 3,9 & 3,0 & 0,5 & 3,4 & 1,5 & 39,3 & 11,9 & 5,4 & 44,7 & 12,1 & 68,8 \\
\hline $2-5$ & 3,9 & 4,0 & 0,7 & 1,8 & 1,1 & 38,0 & 13,0 & 3,6 & 41,6 & 8,7 & 78,3 \\
\hline $5-10$ & 4,0 & 4,0 & 0,6 & 1,9 & 0,7 & 36,7 & 13,1 & 3,2 & 39,9 & 8,0 & 80,4 \\
\hline $10-20$ & 4,0 & 3,0 & 0,4 & 1,5 & 0,3 & 28,8 & 10,7 & 2,2 & 31,0 & 7,1 & 82,9 \\
\hline \multicolumn{12}{|c|}{ Tratamento F } \\
\hline $0-2$ & 3,8 & 8,0 & 1,0 & 3,6 & 2,0 & 37,3 & 7,4 & 6,6 & 43,9 & 15,0 & 52,9 \\
\hline $2-5$ & 3,8 & 11,0 & 0,6 & 2,7 & 1,6 & 38,0 & 8,5 & 4,9 & 42,9 & 11,4 & 63,4 \\
\hline $5-10$ & 3,8 & 7,0 & 0,8 & 2,7 & 1,4 & 39,0 & 8,9 & 4,9 & 43,9 & 11,2 & 64,5 \\
\hline $10-20$ & 4,0 & 3,0 & 0,6 & 2,2 & 0,6 & 31,0 & 7,0 & 3,4 & 34,4 & 9,9 & 67,3 \\
\hline \multicolumn{12}{|c|}{ Tratamento $\mathbf{G}$} \\
\hline $0-2$ & 4,2 & 9,0 & 1,3 & 8,3 & 3,6 & 33,0 & 4,5 & 13,2 & 46,2 & 28,6 & 25,4 \\
\hline $2-5$ & 3,9 & 7,0 & 0,9 & 2,1 & 0,9 & 35,7 & 8,8 & 3,9 & 39,6 & 9,8 & 69,3 \\
\hline $5-10$ & - & - & - & - & - & - & - & - & - & - & - \\
\hline $10-20$ & 4,0 & 6,0 & 0,7 & 2,7 & 0,7 & 28,0 & 6,9 & 4,1 & 32,1 & 12,8 & 62,7 \\
\hline
\end{tabular}


Tabela 3. Características físicas do solo sob povoamento de E. grandis com 7 anos de idade (Tratamento $\mathrm{A}$ ).

\begin{tabular}{|c|c|c|c|c|c|}
\hline Prof. & Areia & Silte & Argila & Dens. Solo & Dens. Part. \\
\hline (cm) & 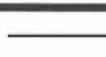 & $\mathrm{g} \mathrm{kg}^{-1}$ & $\overline{ }$ & $\longrightarrow$ & \\
\hline $0-10$ & 770 & 30 & 200 & 1,25 & 2,22 \\
\hline $10-20$ & 770 & 30 & 200 & 1,25 & 2,22 \\
\hline $20-30$ & 760 & 20 & 220 & 1,30 & 2,25 \\
\hline $30-50$ & 760 & 20 & 220 & 1,30 & 2,25 \\
\hline $50-100$ & 740 & 20 & 240 & 1,31 & 2,25 \\
\hline
\end{tabular}

A serapilheira acumulada no piso florestal do povoamento de $E$. grandis apresentou uma relação C:N de 67,8. Essa relação é alta e, provavelmente promove uma imobilização inicial do nitrogênio. O solo sob o povoamento apresentou uma relação $\mathrm{C}: \mathrm{N}$ bem inferior àquela verificada na serapilheira, variando de 22,0 na profundidade de $0-2 \mathrm{~cm}$ a 18,0 na de $10-20 \mathrm{~cm}$ (Tabela 1). Essa relação $\mathrm{C}: \mathrm{N}$ foi um pouco superior à encontrada por Fialho et al. (1991) também em um latossolo vermelho-amarelo, distrófico e sob povoamento de eucalipto. O autores verificaram que a relação C:N do solo variava de 19,5 na profundidade de 0-2 a 15,5 na camada de 10 a $20 \mathrm{~cm}$. A análise de lignina na serapilheira acumulada revelou a presença de um alto conteúdo, 40,1\% (Tabela 4).

Tabela 4. Composição química da serapilheira acumulada amostrada no tratamento A.

\begin{tabular}{|c|c|c|c|c|c|c|c|}
\hline C & $\mathrm{N}$ & $\mathrm{C} / \mathrm{N}$ & Lignina & $\mathrm{P}$ & $\mathrm{K}$ & $\mathrm{Ca}$ & $\mathrm{Mg}$ \\
\hline$\longrightarrow$ & - & & - & - & $\mathrm{kg}^{-1}$ & & - - \\
\hline \multirow[t]{2}{*}{536,0} & 7,9 & 67,8 & 401,0 & 0,4 & 1,5 & 8,8 & 1,0 \\
\hline & & & & & & & \\
\hline
\end{tabular}


4.2 Índices de crescimento e estoque de biomassa e nutrientes no povoamento de Eucalyptus grandis

Os índices de crescimento de E. grandis nos diferentes tratamentos são apresentados nas Tabelas 5 e 6.

As avaliações de crescimento em altura $(m)$ das árvores foram realizadas aos 6 meses de idade. As árvores do tratamento onde foi conduzida a rebrota (Tratamento $B$ ) apresentaram a maior média em altura $(P=0,01)$, evidenciando a importância da presença de um sistema radicular já estabelecido para o crescimento inicial das mudas. As árvores do tratamento $G$, onde foi realizada a queima, apresentaram a segunda maior média em altura, a qual também foi significativamente maior do que as médias obtidas para os demais tratamentos. Isto provavelmente se deve ao arranque inicial promovido pela disponibilidade inicial de nutrientes, em função da rápida mineralização promovida pela queima. Os tratamentos $C, D$ e $F$ (cultivo mínimo, manutenção apenas da serapilheira e incorporação de todos os resíduos, respectivamente) não foram estatisticamente diferentes, assim como, também não o foram, os tratamentos $D$ e $E$ (manutenção apenas da serapilheira $e$ remoção de todos os resíduos), onde foram observadas as menores médias.

Não foi possivel estabalecer nenhuma relação entre as quantidades de $\mathrm{N}$ mineralizadas e o crescimento inicial das árvores, sendo consideráveis as quantidades de $\mathrm{N}$ lixiviadas nos primeiros meses de estudo naqueles tratamentos sem plantas invasoras ou com pequena infestação pelas mesmas. 
Tabela 5. Avaliações de crescimento das árvores do povoamento de Eucalyptus grandis (7 anos de idade).

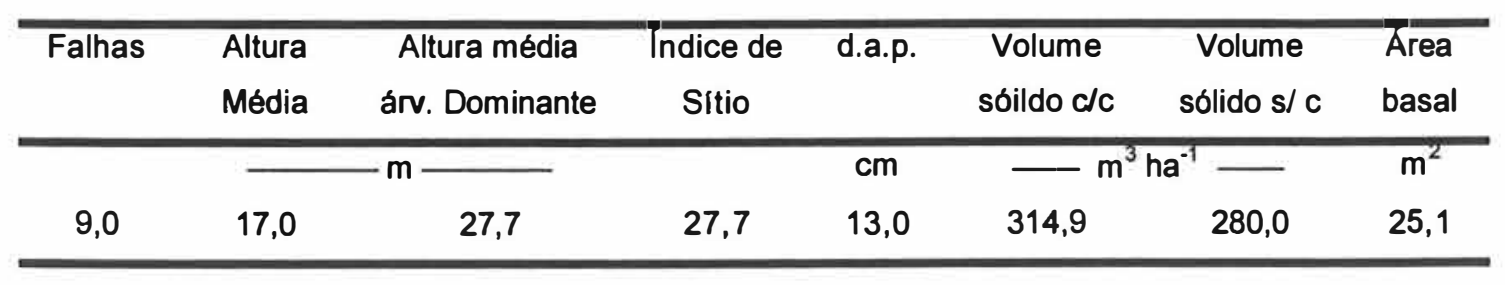

Tabela 6. Altura média das árvores e ocorrência de falhas, aos 6 meses de idade ${ }^{(1)}$, nos diferentes tratamentos.

\begin{tabular}{ccc}
\hline Tratamento & $\begin{array}{r}\text { Altura Média } \\
\text { (seis meses) }\end{array}$ & Falhas \\
\hline B & $-m-$ & $-\%-$ \\
C & $4,4 a$ & 4,6 \\
D & $2,8 b$ & 0,0 \\
E & $2,6 \mathrm{bc}$ & 2,5 \\
F & $2,3 \mathrm{c}$ & 1,0 \\
G & $2,8 \mathrm{~b}$ & 0,5 \\
\hline
\end{tabular}

(1) Médias com letras iguais, na vertical, nåo diferem estatisticamente pelo teste de Tukey $(P=0,01)$. 
A composição química e as quantidades de biomassa e nutrientes nos diferentes componentes do povoamento de Eucalyptus grandis, tratamento A, são apresentadas nas Tabelas 7 e 8 . Constata-se que os componentes dos resíduos culturais (folha, galho, casca e serapilheira) correspondem a $38,9 \mathrm{t} \mathrm{ha}^{-1}$, ou seja, a $28 \%$ do total da biomassa aérea.

Nos resíduos culturais estão contidos $48,56,45,71$ e $66 \%$ do $\mathrm{N}$, $\mathrm{P}, \mathrm{K}, \mathrm{Ca}$ e $\mathrm{Mg}$ do estoque de nutrientes, respectivamente. Nas cascas e serapilheira podem estar presentes mais de $30 \%$ do estoque desses nutrientes. A serapilheira, os restos culturais e os $20 \mathrm{~cm}$ superiores do solo continham $1225,5 \mathrm{~kg} \mathrm{ha}^{-1}$ de $\mathrm{N}$, dos quais os restos culturais e a serapilheira continham 108,5 e $187,2 \mathrm{~kg} \mathrm{ha}^{-1}$, respectivamente. Dessa forma, a serapilheira e os restos culturais combinados continham $24,1 \%$ da reserva de $\mathrm{N}$ do sítio, considerando apenas os $20 \mathrm{~cm}$ superiores do solo. 
Tabela 7. Composição química dos diferentes compartimentos das árvores do povoamento de E. grandis (7 anos).

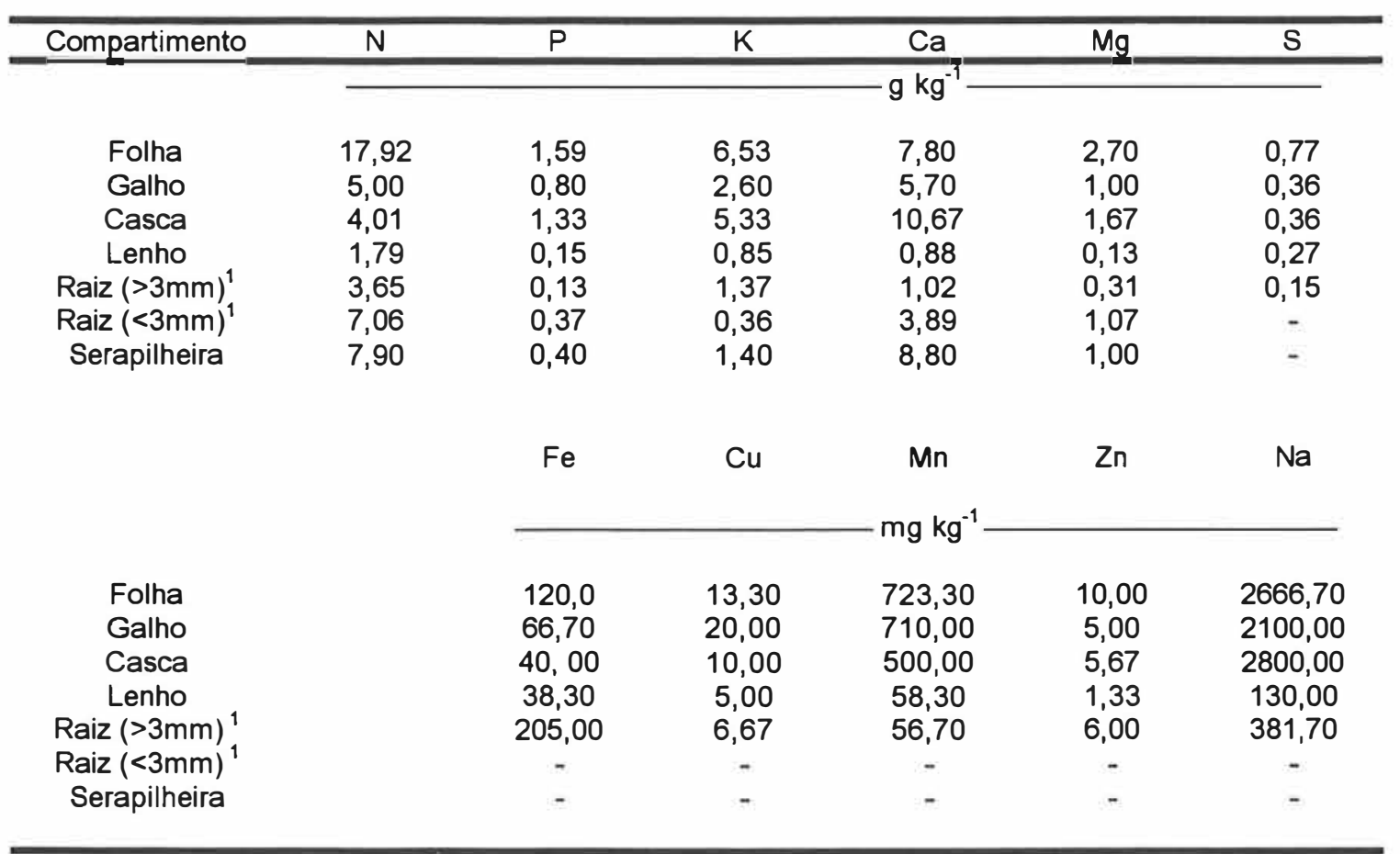

${ }^{1}$ MELLO, S. L. DE MIRANDA. Caracteristicas do sistema radicular de povoamentos de eucaliptos propagados por sementes e estacas. Piracicaba, 1997. 71p. Dissertação (M. S.) - Escola Superior de Agricultura "Luiz de Queiroz" Universidade de São Paulo. 
Tabela 8. Estoque de biomassa e nutrientes nos diferentes compartimentos do povoamento de Eucalyptus grandis.

\begin{tabular}{|c|c|c|c|c|c|c|c|}
\hline Compartimento & Biomasssa & $\mathrm{N}$ & $P$ & $\mathrm{~K}$ & $\mathrm{Ca}$ & $\mathrm{Mg}$ & s \\
\hline & $-\mathrm{tha}^{-1}-$ & $\longrightarrow$ & 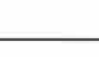 & 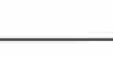 & $\mathrm{ha}^{-1}$ & & \\
\hline Folha & 3,2 & 57,3 & 5,1 & 20,9 & 25,0 & 8,6 & 2,5 \\
\hline Galho & 3,1 & 15,5 & 2,5 & 8,1 & 17,7 & 3,1 & 1,1 \\
\hline Casca & 8,9 & 35,7 & 11,8 & 47,4 & 95,0 & 14,9 & 3,2 \\
\hline Lenho & 125,1 & 223,9 & 18,8 & 106,3 & 110,1 & 16,3 & 26,3 \\
\hline Raiz $(>3 \mathrm{~mm})^{1}$ & 20,6 & 75,2 & 2,7 & 28,2 & 21,0 & 6,4 & 3,1 \\
\hline Raiz (<3mm) & 3,6 & 22,4 & 1,2 & 1,0 & 11,9 & 3,1 & - \\
\hline Serapilheira & 23,7 & 187,2 & 9,5 & 35,5 & 208,6 & 23,7 & - \\
\hline \multirow[t]{2}{*}{ Total } & 188,2 & 617,2 & 51,6 & 247,4 & 489,3 & 76,1 & 36,2 \\
\hline & & $\mathrm{Fe}$ & $\mathrm{Cu}$ & $M n$ & $\mathrm{Zn}$ & $\mathrm{Na}$ & \\
\hline Folha & & 0,38 & 0,04 & 2,31 & 0,03 & 8,5 & \\
\hline Galho & & 0,21 & 0,06 & 2,20 & 0,02 & 6,5 & \\
\hline Casca & & 0,36 & 0,09 & 4,45 & 0,05 & 24,9 & \\
\hline Lenho & & 4,79 & 0,62 & 7,29 & 0,17 & 16,3 & \\
\hline Raiz (>3mm) & & 4,22 & 0,14 & 1,17 & 0,12 & 7,9 & \\
\hline Raiz (<3mm) & & - & - & - & - & - & \\
\hline Serapilheira & & - & - & - & - & - & \\
\hline Total & & 9,96 & 0,95 & 17,42 & 0,39 & 64,1 & \\
\hline
\end{tabular}

${ }^{1}$ MELLO, S. L. DE MIRANDA. Características do sistema radicular de povoamentos de eucaliptos propagados por sementes e estacas. Piracicaba, 1997. 71p. Dissertação (M. S.) - Escola Superior de Agricultura "Luiz de Queiroz " Universidade de São Paulo. 


\subsection{Efeitos das práticas de manejo sobre a temperatura e umidade do solo}

A temperatura máxima do solo oscilou entre 29,9 e $46,6^{\circ} \mathrm{C}$ e a mínima entre 5,3 e 17,6 $6^{\circ}$ entre setembro de 1995 e março de 1996 (Tabela 9). As menores amplitudes térmicas foram observadas no tratamento $A$ e as maiores no tratamento $E$, evidenciando a importância do papel da cobertura florestal e da presença de resíduos sobre a variação da temperatura do solo (Figura 5). A remoção dos restos culturais e da serapilheira (Tratamento E), resultou em um acréscimo de $2,7^{\circ} \mathrm{C}$ na temperatura máxima do solo quando comparada com a verificada no tratamento onde os resíduos foram mantidos (Tratamento C). O manejo dos resíduos culturais teve maior influência sobre as temperaturas máximas do solo do que sobre as mínimas. Resultados similares foram obtidos por Smethurst \& Nambiar (1990b), ao estudarem os efeitos do manejo dos restos culturais e da serapilheira sobre os fluxos de $\mathrm{N}$ e crescimento de Pinus radiata em solos arenosos no sudeste da Austrália.

Com relação ao teor de umidade do solo, foram verificadas diferenças entre os tratamentos apenas para a camada de 0-5 cm (Figura 7). O comportamento da umidade da serapilheira do tratamento cultivo mínimo foi semelhante ao verificado para a serapilheira do povoamento mantido intacto. Nos tratamentos onde após o corte raso, os resíduos foram mantidos sobre a serapilheira (Tratamento $\mathrm{C}$ ), os niveis de umidade do solo foram maiores que nos demais tratamentos, durante todo o período experimental, mostrando a importância da manutenção dos resíduos na conservação da umidade do solo (Figura 7). Farrel et al. ${ }^{1}$, citados por Smethurst \& Nambiar (1990b) também verificaram que a manutenção dos restos da cultura sobre o solo

\footnotetext{
${ }^{1}$ FARREL,P.W.; FLINN, D.W. SQUIRE, R.O.; CRAIG,F.G. On the maintenance of productivity radiata pine monocultures on sandy soils in south-east Australia. IIn: Proccedings on the IUFRO World Congress, 17, Kyoto, 1981. Division 1: Forest Environment and Silviculture, 1981. p.117-128.
} 
formando uma manta, conservou a temperatura mais estável para o crescimento das raízes. Segundo Gonçalves (1995c), a presença de serapilheira e dos restos culturais reduz as perdas de água por evaporação devido à insolação direta do solo, reduzindo também, as perdas por transpiração ao suprimir o desenvolvimento de plantas invasoras. Silva et al. (1997), estudando o desenvolvimento de plantas invasoras nos diferentes tipos de manejo dos resíduos, na mesma área experimental do presente trabalho, verificaram menor produção de biomassa dessas, onde os resíduos culturais foram mantidos, corroborando a afirmativa Gonçalves (1995c) e Squire et al. (1979). 


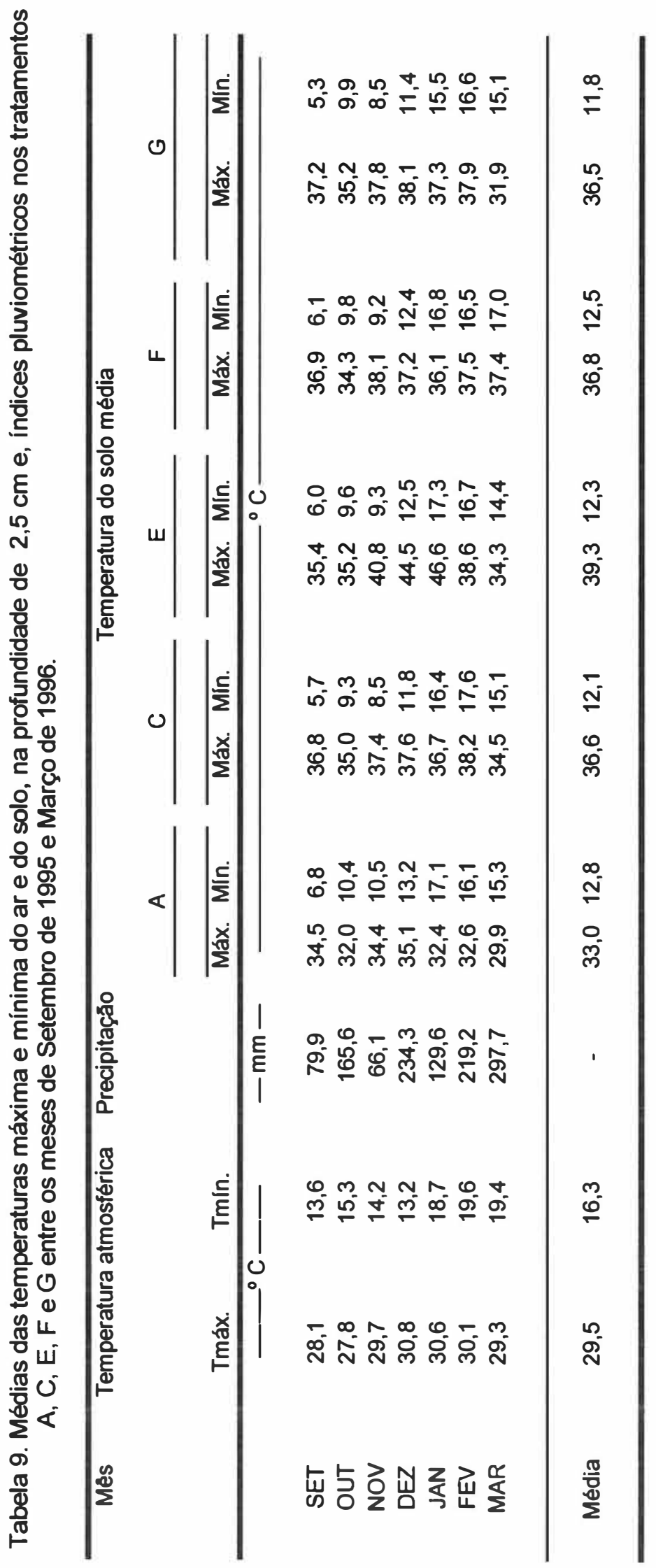




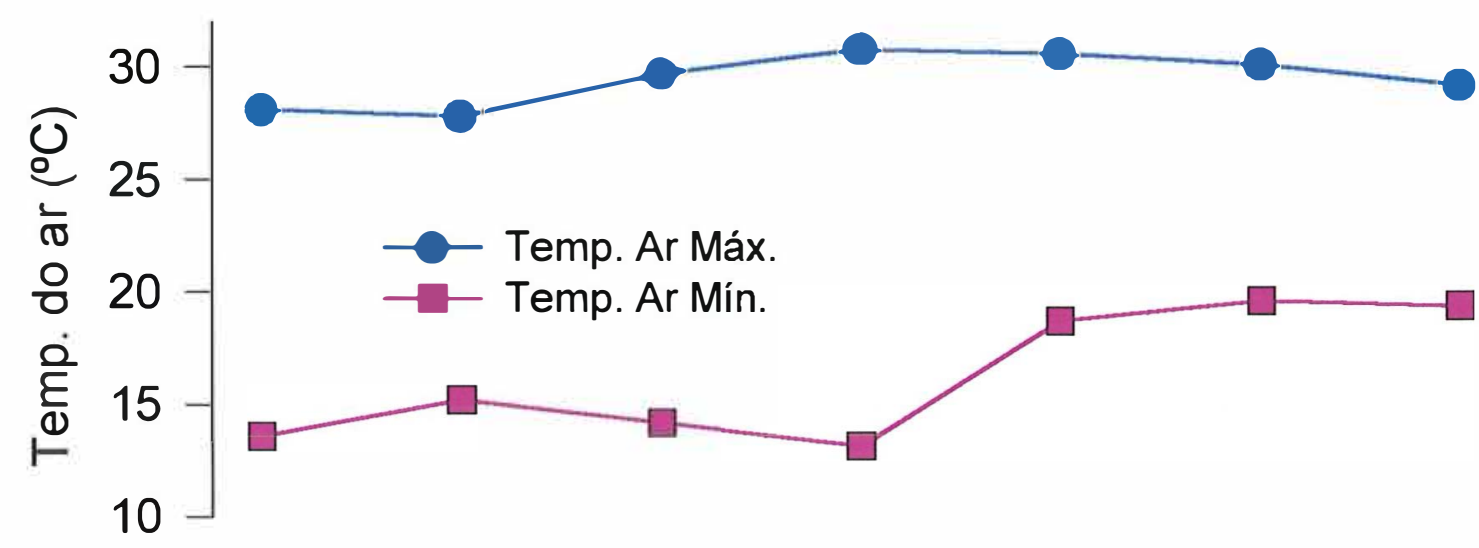

- Trat. A $\square \quad$ Trat. C $\triangle$ Trat. $E$ $\checkmark$ Trat. F Trat. G
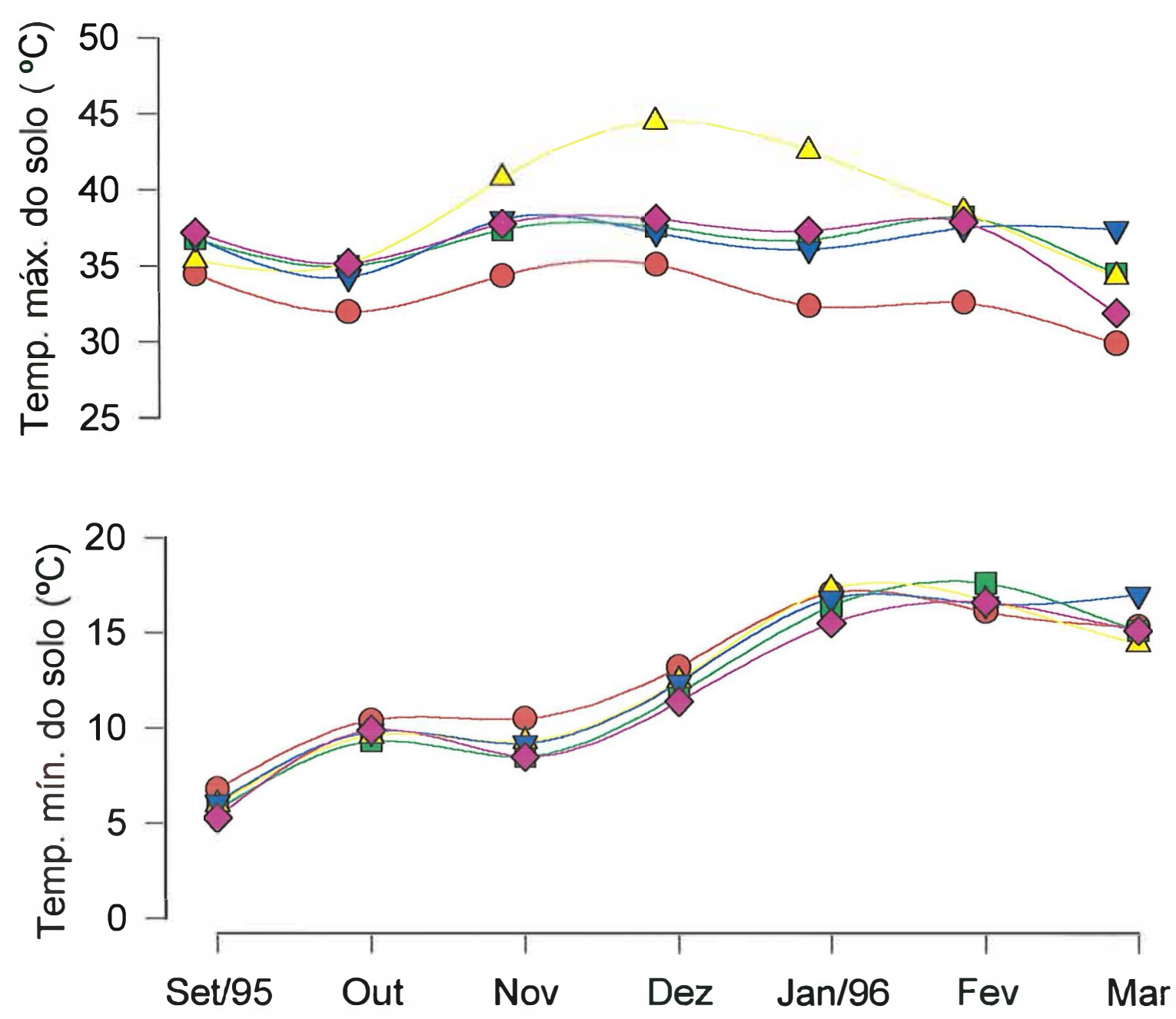

Figura 5. Variação das temperaturas máximas e mínimas do ar e do solo na profundidade $2,5 \mathrm{~cm}$. 


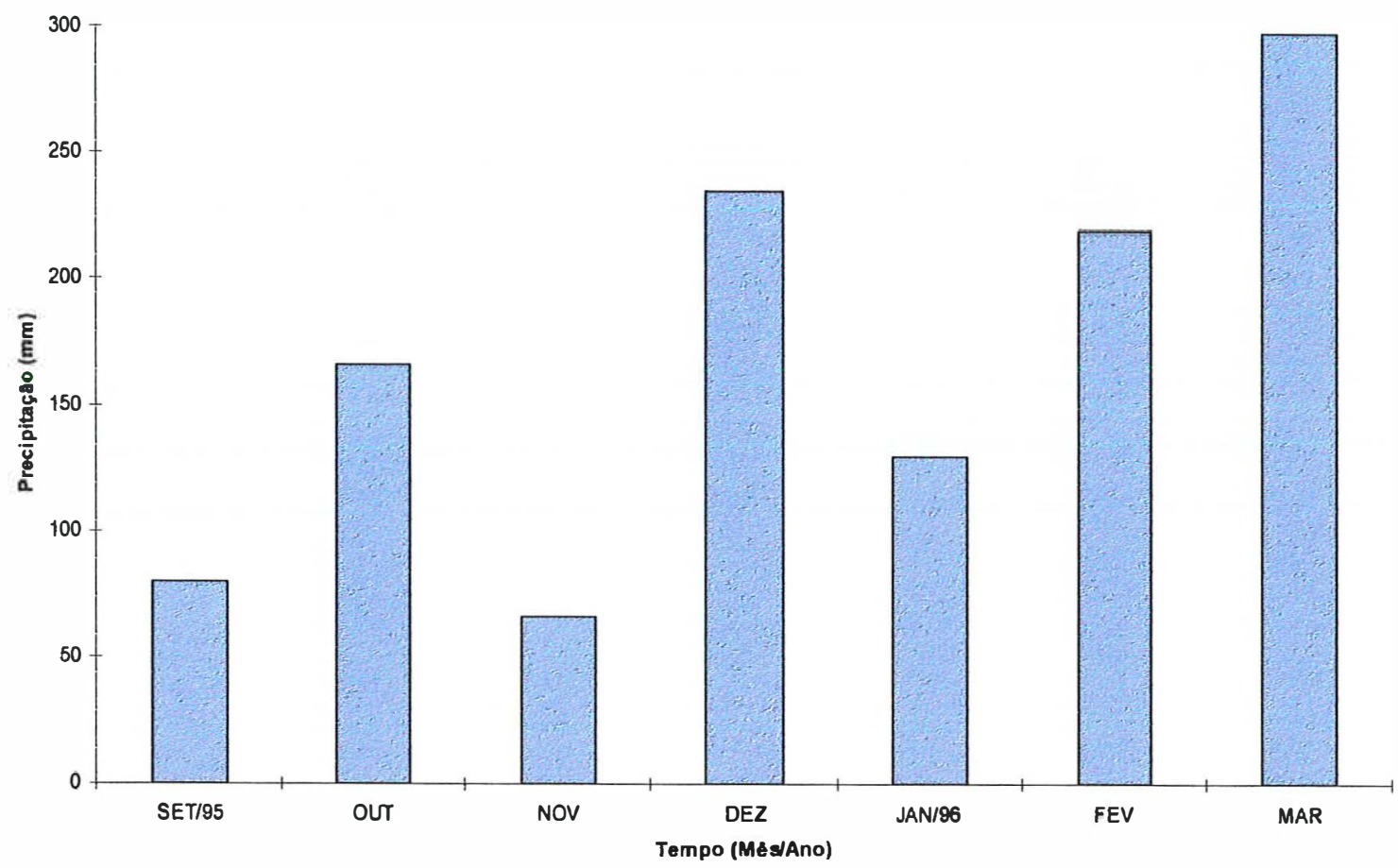

Figura 6. Precipitação média mensal $(\mathrm{mm})$ entre os meses de setembro de 1995 e março de 1996 


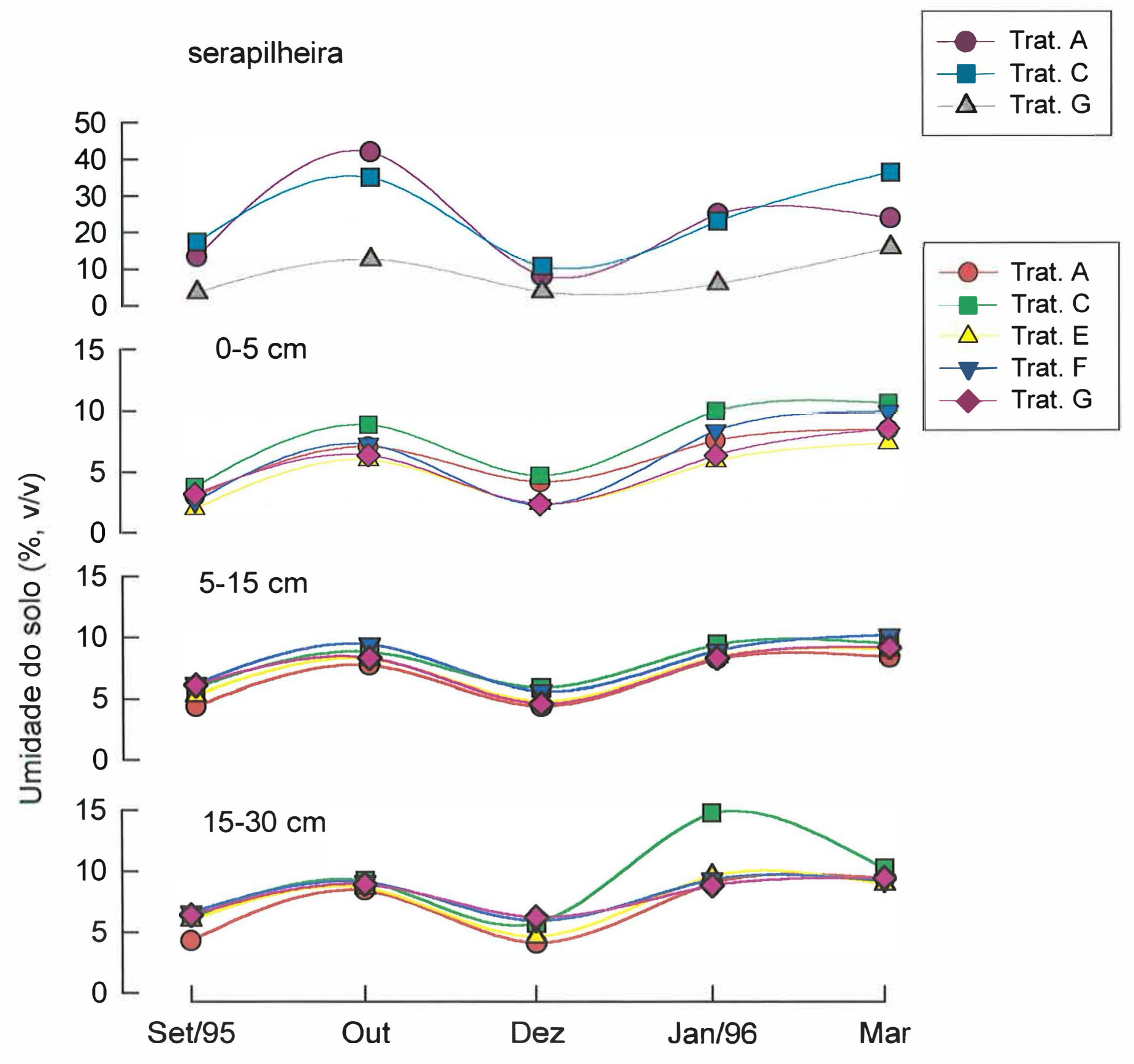

Figura 7. Umidade média da serapilheira e do solo entre os meses de setembro de 1995 e março de 1996. 


\subsection{Concentrações de $\mathrm{N}-\mathrm{NH}_{4}{ }^{+}$e $\mathrm{N}-\mathrm{NO}_{3}{ }^{-}$na serapilheira e no solo}

As maiores concentrações de $\mathrm{N}_{-} \mathrm{NH}_{4}{ }^{+}$e de $\mathrm{N}-\mathrm{NO}_{3}{ }^{-}$no solo, bem como suas maiores oscilações, foram verificadas na profundidade de $0-5 \mathrm{~cm}$, camada do solo mais rica em matéria orgânica e com maior atividade biológica. No tratamento $A$, independente das oscilações verificadas nas taxas líquidas de mineralização de $\mathrm{N}_{-} \mathrm{NH}_{4}^{+}$e de $\mathrm{N}^{+} \mathrm{NO}_{3}{ }^{-}$, suas concentrações no solo permaneceram praticamente constantes, principalmente com relação ao nitrato, indicando que as quantidades de $\mathrm{N}_{-} \mathrm{NH}_{4}{ }^{+}$e $\mathrm{N}^{-} \mathrm{NO}_{3}{ }^{-}$produzidas via mineralização, foram contrabalanceadas pelos processos de lixiviação e de absorção (Figuras 8 e 9).

As diferenças entre as concentrações de $\mathrm{N}^{-\mathrm{NH}_{4}}{ }^{+}$no solo nos diversos tratamentos foram observadas apenas para a camada de $0-5 \mathrm{~cm}$, diferentemente do observado por Smethurst \& Nambiar (1990b). Os autores verificaram que as mesmas relações observadas entre os tratamentos na superfície também ocorreram na camada de $15-30 \mathrm{~cm}$ do solo apenas com concentrações muito mais baixas.

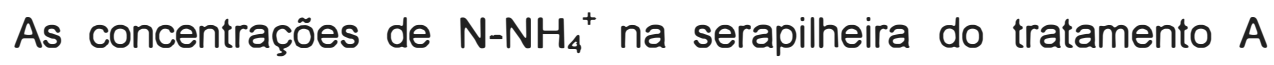
variaram de 4,6 a $28,5 \mu \mathrm{g} / \mathrm{gTFSA}$. No solo foi verificada uma variação de 1,3 a $2,6 \mu \mathrm{g} / \mathrm{gTFSA}$. Na serapilheira do tratamento $\mathrm{C}$, as concentrações variaram de 14,8 a $41,3 \mu \mathrm{g} / \mathrm{gTFSA}$ e no solo de 1,0 a $4,3 \mu \mathrm{g} / \mathrm{gTFSA}$. No tratamento $G$ foram observadas as maiores variações nas concentrações de $\mathrm{N}^{-} \mathrm{NH}_{4}{ }^{+}$e N-NO${ }_{3}^{-}$, de 1,2 a 10,8 $\mu \mathrm{g} / \mathrm{gTFSA}$ e, 0,4 a $3,3 \mu \mathrm{g} / \mathrm{gTFSA}$, respectivamente.

As concentrações de $\mathrm{N}_{-} \mathrm{NO}_{3}{ }^{-}$na serapilheira do tratamento $A$ praticamente não variaram, enquanto que no tratamento $C$, houve uma variação de 0,3 a 1,7 $\mu \mathrm{g} / \mathrm{gTFSA}$. No solo do tratamento $A$, as concentrações de $\mathrm{N}-\mathrm{NO}_{3}{ }^{-}$foram muito baixas (menores que $0,5 \mu \mathrm{g} \mathrm{g}^{-1}$ ), indicando que o processo de nitrificação foi pouco intenso. 
A concentração média de nitrogênio inorgânico verificada na camada superficial do solo do povoamento de Eucalyptus grandis foi de $1,7 \mu \mathrm{g} / \mathrm{gTFSA}$. Esse resultado é considerado baixo quando comparado com outros dados encontrados para povoamentos de eucaliptos (Adams \& Attiwill,1986b). 


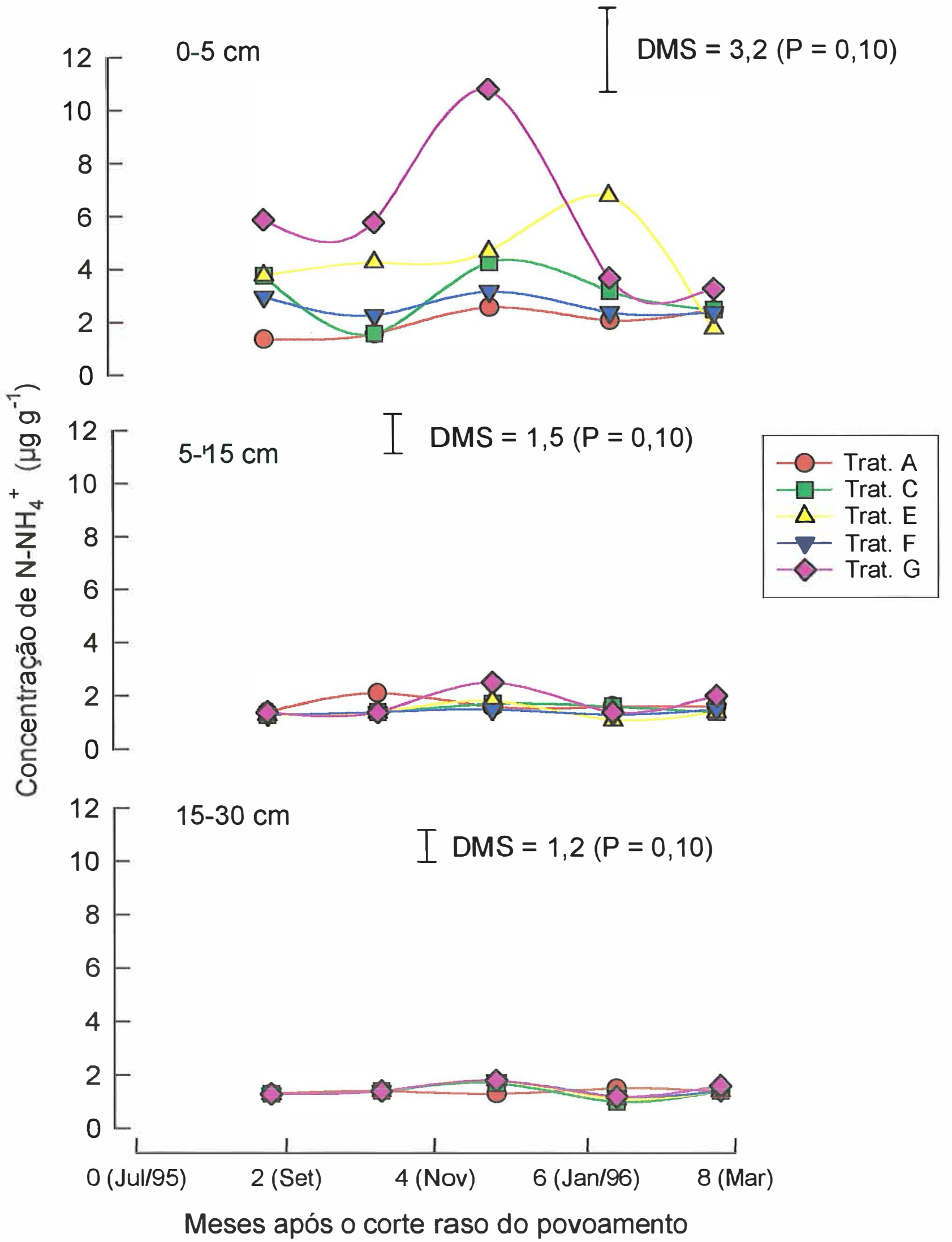

Figura 8. Concentração de $\mathrm{N}-\mathrm{NH}_{4}{ }^{+}$no solo. 

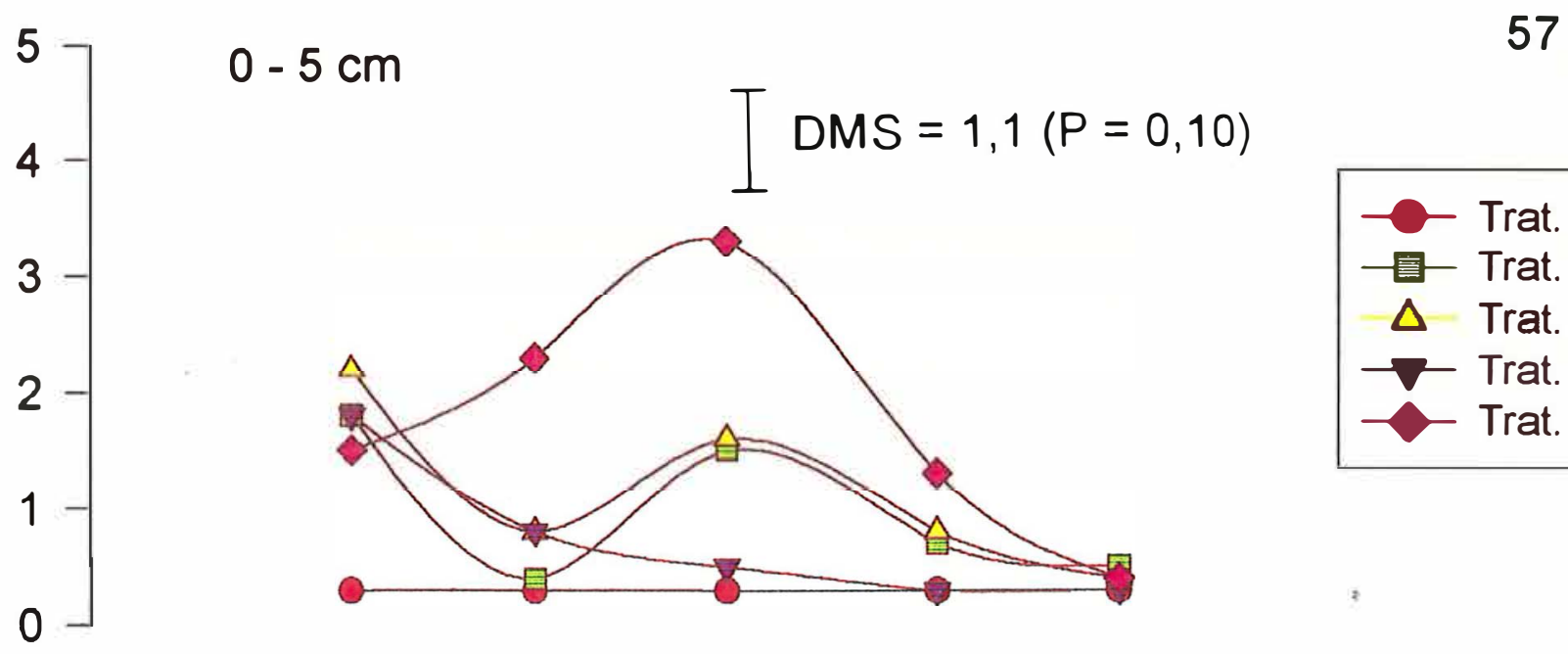

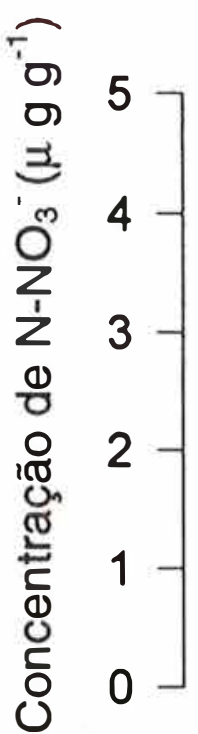

$5-15 \mathrm{~cm}$

I DMS $=0,5(P=0,10)$

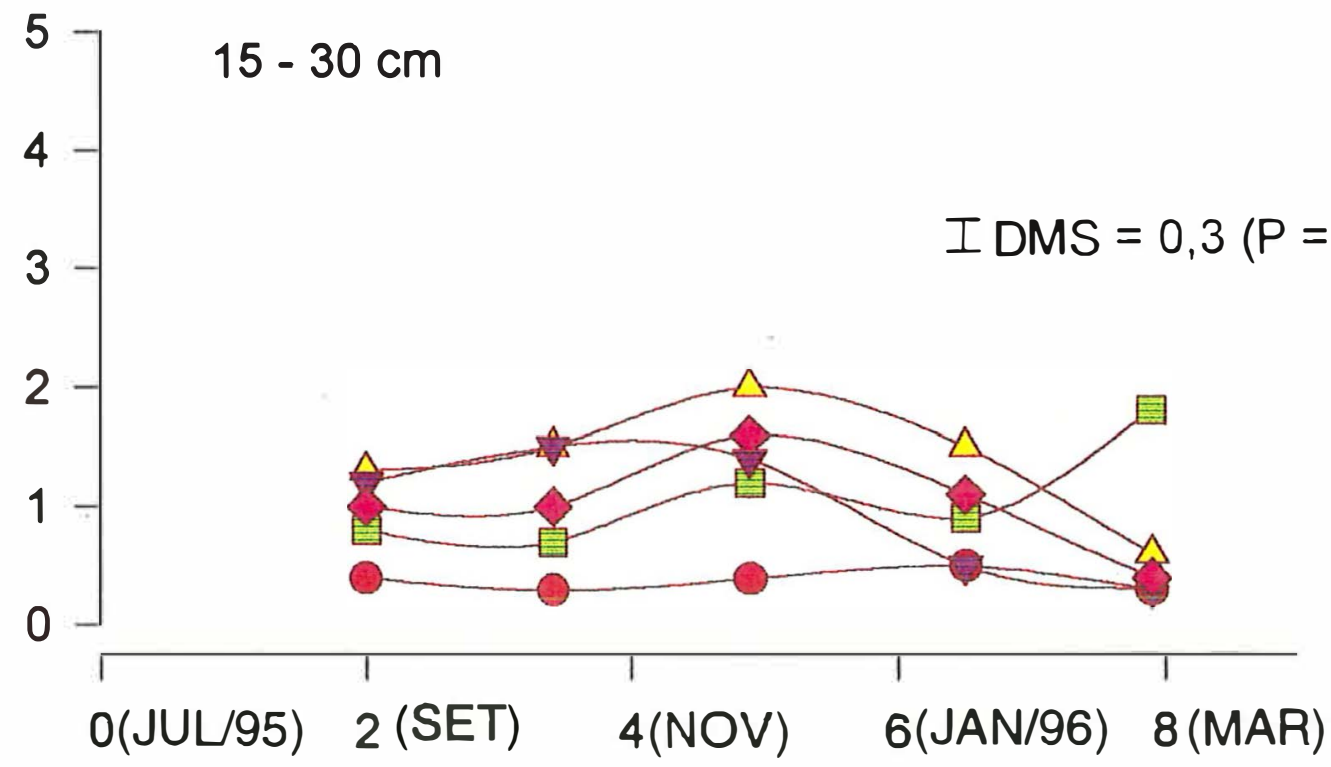

Meses após o corte raso do povoamento

Figura 9. Concentração de $\mathrm{N}-\mathrm{NO}_{3}{ }^{-}$no solo 


\subsection{Mineralização de N}

De modo geral, as maiores taxas líquidas de amonificação e nitrificação foram verificadas na camada de $0-5 \mathrm{~cm}$ do solo, indicando a maior atividade dos organismos mineralizadores da matéria orgânica nesta camada. Entretanto, no tratamento onde os resíduos foram incorporados (Tratamento F) foram verificadas as maiores taxas de amonificação e nitrificação nas camadas subsuperficiais do solo, evidenciando a efetiva incorporação dos resíduos e inoculação dos microrganismos nessas camadas. As quantidades de $\mathrm{N}_{-} \mathrm{NH}_{4}{ }^{+} \mathrm{e}$ de $\mathrm{N}^{-} \mathrm{NO}_{3}{ }^{-}$mineralizadas nas camadas subsuperficiais do tratamento $\mathrm{F}$ foram estatisticamente maiores das observadas no povoamento $(P=0,10)$ no segundo período de incubação (Figuras 10 e 11).

Entre todos os tratamentos avaliados foi constatada uma nítida e consistente superioridade das taxas de amonificação sobre as de nitrificação apenas no tratamento A (Figuras 10 e 11, Tabela 10). Na camada superficial do solo, as médias de $\mathrm{N}^{-\mathrm{NH}_{4}}{ }^{+}$mineralizadas diferenciaram-se significativamente das observadas onde foi realizado o corte raso $(P=0,0001)$. No período de setembro a dezembro de 1995, as taxas de amonificação foram superiores a $8 \mathrm{Kg} \mathrm{ha}^{-1} \mathrm{mês}^{-1}$, enquanto que as taxas de nitrificação foram inferiores a 2,0 Kg ha $\mathrm{Kês}^{-1}$. Segundo Carlyle (1986), a magnitude do processo de nitrificação em povoamentos florestais é pequena em função da grande

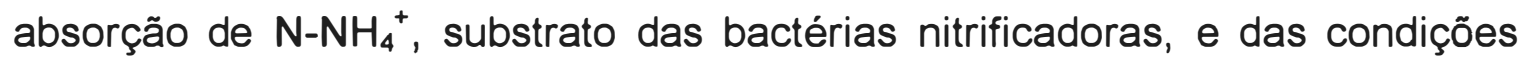
adversas dos vários solos usados para fins florestais, tais como a baixa fertilidade natural e elevada acidez. Adams \& Attiwill (1982) consideram a baixa disponibilidade do substrato $\mathrm{N}_{-} \mathrm{NH}_{4}{ }^{+}$, absorvido pelas árvores, plantas invasoras e imobilizado pela microflora heterotrófica, como o principal fator responsável pelas baixas taxas de nitrificação em solos sob florestas. 
Nesse mesmo período (setembro a dezembro de 95), as maiores taxas de mineralização de $\mathrm{N}-\mathrm{NH}_{4}{ }^{+}$foram observadas na camada superficial do solo, $0-5 \mathrm{~cm}$, do tratamento $A$, indicando os efeitos positivos da cobertura florestal sobre a microbiota, tais como a menor amplitude de variação da temperatura e menor exposição do solo à radiação solar (Figuras 5 e 10). A partir de janeiro de 1996, as taxas de mineralização de $\mathrm{N}_{-} \mathrm{NH}_{4}{ }^{+}$decresceram consideravelmente, em todos os tratamentos, sendo esse decréscimo atribuído a um período de estiagem. Daí por diante, (no último período de incubação, compreendido entre 22/01 e 05/03/96) houve uma tendência de estabilização das taxas líquidas de amonificação.

As taxas líquidas de nitrificação foram superiores às taxas de amonificação em todos os tratamentos em que o povoamento florestal foi removido e os resíduos culturais foram queimados, removidos ou incorporados (Figuras 10 e 11). De modo geral, na camada superficial do solo do tratamento $A$, as quantidades de $\mathrm{N}^{-N_{3}}{ }_{3}^{-}$mineralizadas foram significativamente menores do que as observadas nos demais tratamentos onde foi realizado o corte raso do povoamento $(P<0,0004)$.

A queima de resíduos vegetais e a deposição das cinzas na superfície do solo (Tratamento $G$ ) estimulou a atividade das bactérias nitrificadoras, provavelmente em função da elevação do $\mathrm{pH}$ e da fertilidade do solo (Tabela 1), fatores que elevam suas capacidades competitivas com outros microrganismos. Entretanto, o aumento na mineralização do $\mathrm{N}^{-\mathrm{NO}_{3}{ }^{-} \text {não }}$ resultou em diferenças significativas $(P=0,10)$ entre o tratamento $G$ (Queima) e outros tratamentos onde foi realizado o corte raso ( $E$ e $C)$. 
O efeito da queima sobre a mineralização do nitrato foi verificado basicamente na camada de $0-5 \mathrm{~cm}$ do solo. Resultados similares foram encontrados por Theodorou \& Bowen (1982), os quais estudando os efeitos do fogo sobre a microbiologia de um planossolo distrófico sob florestas de eucalipto, verificaram que as maiores mudanças ocorreram na camada de 0-2 $\mathrm{cm}$ do solo, sendo percebidas até cerca de 2 meses após a queima. 


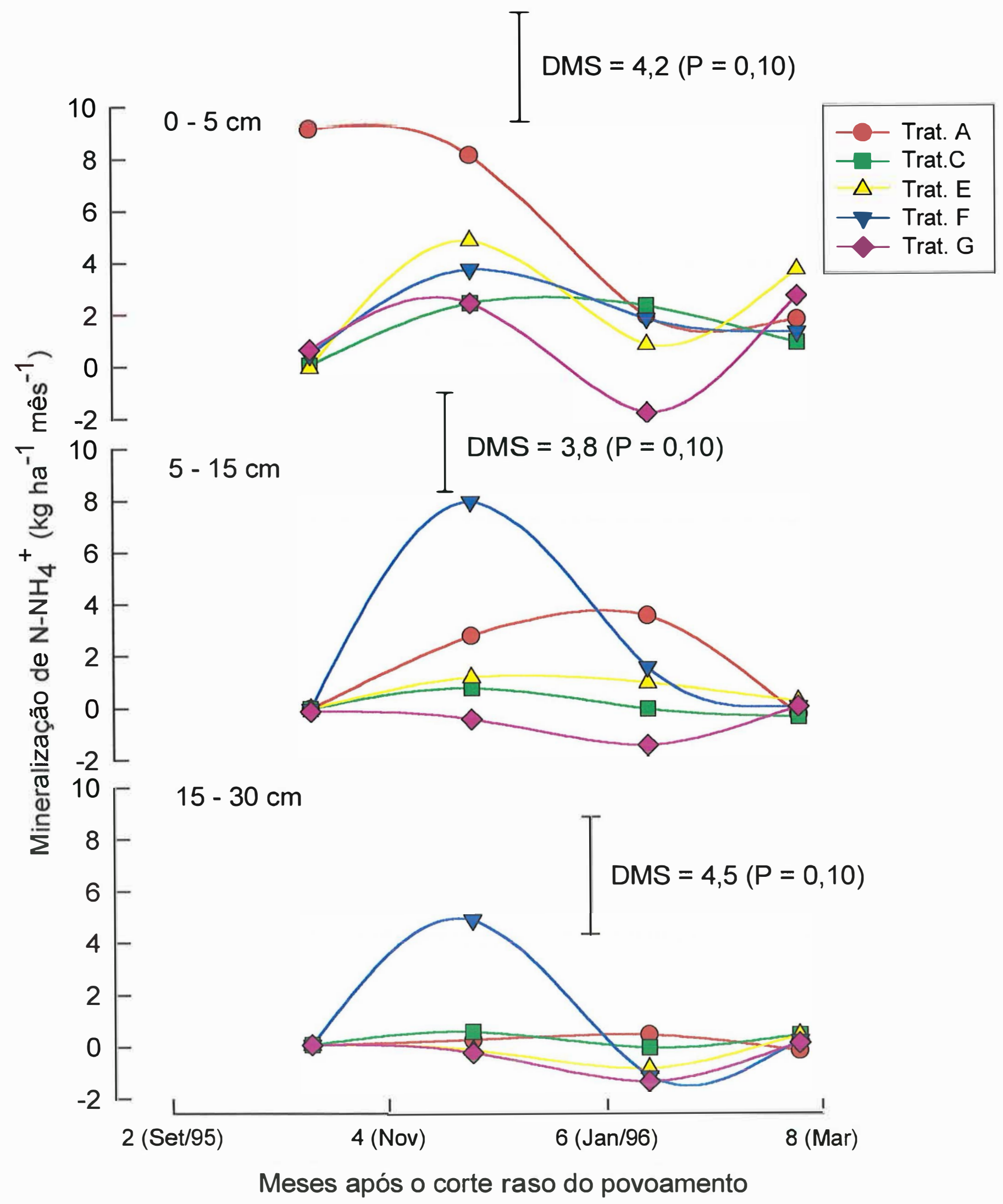

Figura 10. Taxas líquidas de mineralização de $\mathrm{N}^{-\mathrm{NH}_{4}}{ }^{+}$no solo. 


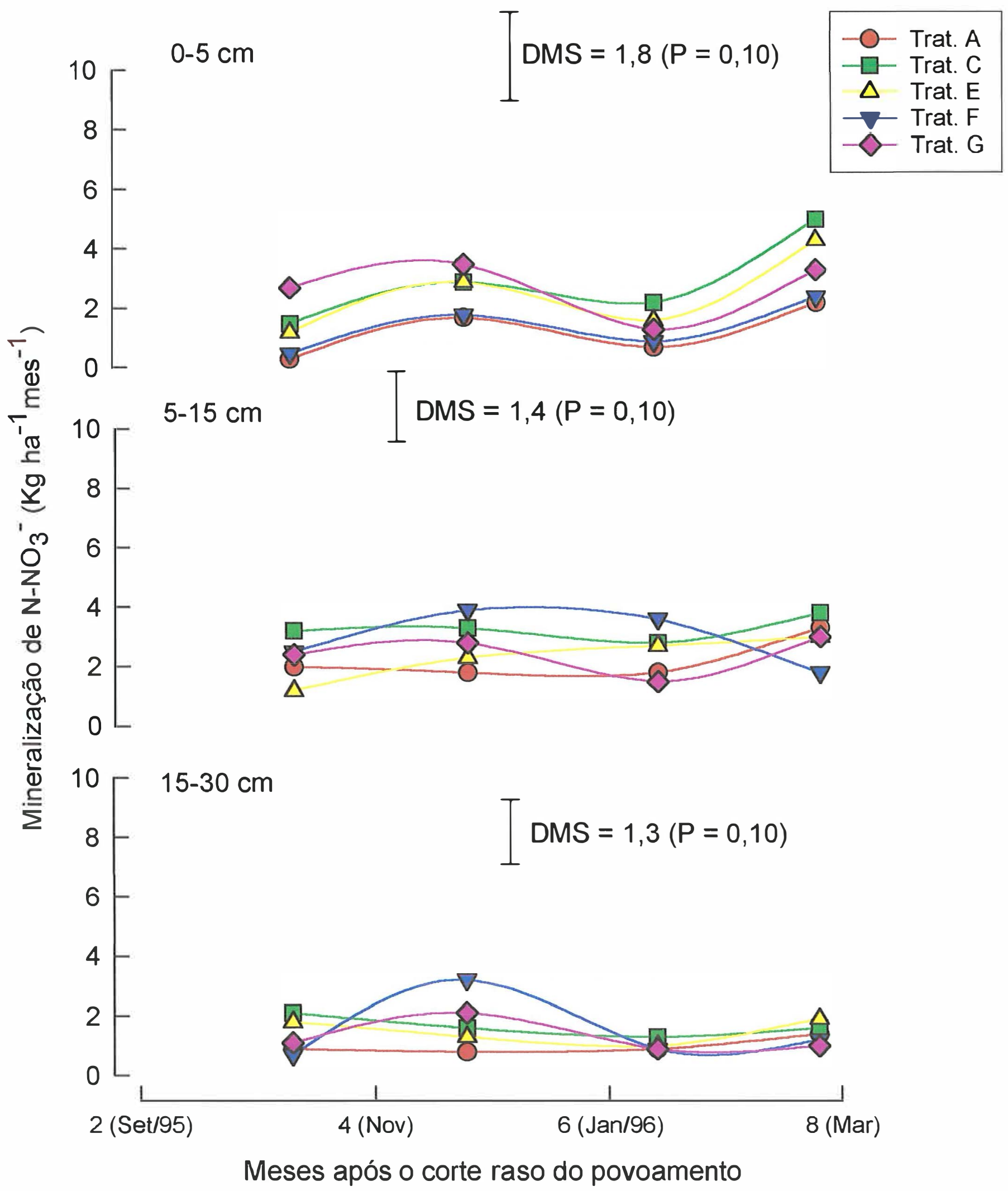

Figura 11. Taxas líquidas de mineralização de $\mathrm{N}^{-\mathrm{NO}_{3}}{ }^{-}$no solo. 


\subsection{Lixiviação e absorção de $\mathrm{N}$}

No tratamento $A$ foram observadas as menores taxas de lixiviação de $\mathrm{N}$ (principalmente $\mathrm{N}-\mathrm{NO}_{3}{ }^{-}$), em todas as profundidades, refletindo o elevado potencial de absorção das árvores (Figuras 12, 13, 14 e 15). De modo geral, nos tratamentos onde foram verificadas as maiores taxas de absorção de $\mathrm{N}$, foram observadas as menores taxas de lixiviação.

As taxas de absorção de $\mathrm{N}^{-\mathrm{NH}_{4}}{ }^{+}$no povoamento florestal variaram de menos de 0,2 $\mathrm{Kg} \mathrm{ha}{ }^{-1} \mathrm{mês}^{-1}$, na camada de $15-30 \mathrm{~cm}$, a 6,8 $\mathrm{Kg} \mathrm{ha}^{-1} \mathrm{mês}^{-1}$, na camada de $0-5 \mathrm{~cm}$ (Figura 14). A maior absorção na camada superficial é esperada, desde que a maioria das raízes finas se encontra nessa camada (Gonçalves, 1995b). As taxas de absorção de nitrato (Figura 15) foram bem inferiores as de amônio, variando de 0,3 a $1,7 \mathrm{Kg} \mathrm{ha}^{-1} \mathrm{mês}^{-1}$, indicando uma preferência das árvores pela forma amoniacal.

Dentre as formas de $\mathrm{N}$ mineral, o $\mathrm{N}^{-\mathrm{NO}_{3}}{ }^{-}$foi a forma mais lixiviada (forma mais móvel no solo), com destaque para os tratamentos onde os processos de nitrificação foram favorecidos (Figura 13). As maiores taxas de lixiviação ocorreram nos tratamentos onde havia a menor cobertura vegetal, isto é, menor crescimento da brotação das cepas das árvores cortadas e/ou plantas invasoras, tratamentos C, E e F. As menores taxas de lixiviação de N$\mathrm{NO}_{3}{ }^{-}$foram verificadas no tratamento $\mathrm{G}$ (Queima). Segundo estudo realizado por Silva et al. (1997), esse foi o tratamento que apresentou o maior grau de infestação por plantas invasoras.

O tratamento onde realizou-se a queima (Tratamento $G$ ) foi 0 único entre os tratamentos, onde o povoamento foi removido, a apresentar altas taxas de absorção de $\mathrm{N}_{-} \mathrm{NH}_{4}^{+}$na camada superficial, não diferindo estatisticamente das quantidades de $\mathrm{N}_{-} \mathrm{NH}_{4}{ }^{+}$absorvidas pelo povoamento intacto (Tratamento A). $O$ tratamento $G$ foi o que apresentou o maior grau de infestação por plantas invasoras e crescimento da brotação das cepas do 
plantio anterior, entre os meses de dezembro de 1995 a março de 1996 (Silva et al., 1997), podendo então, explicar esses resultados. Isto destaca a importância do crescimento das plantas invasoras e brotação de eucaliptos em evitar perdas de nutrientes por lixiviação em áreas onde a plantação florestal não se encontra plenamente estabelecida, o que também foi constatado por Woods et al. (1992). 


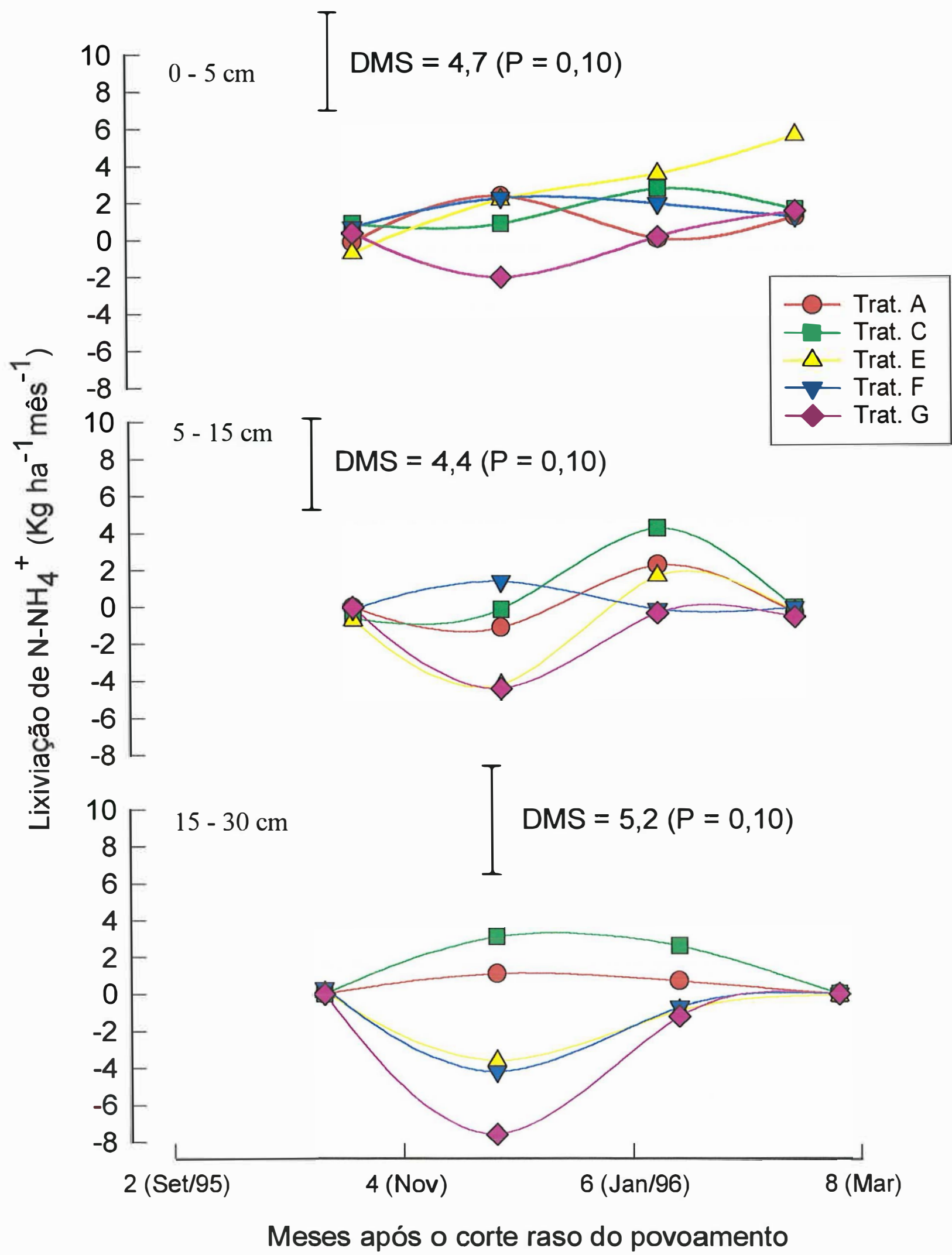

Figura 12. Taxas líquidas de lixiviação de $\mathrm{N}^{-\mathrm{NH}_{4}}{ }^{+}$no solo. 


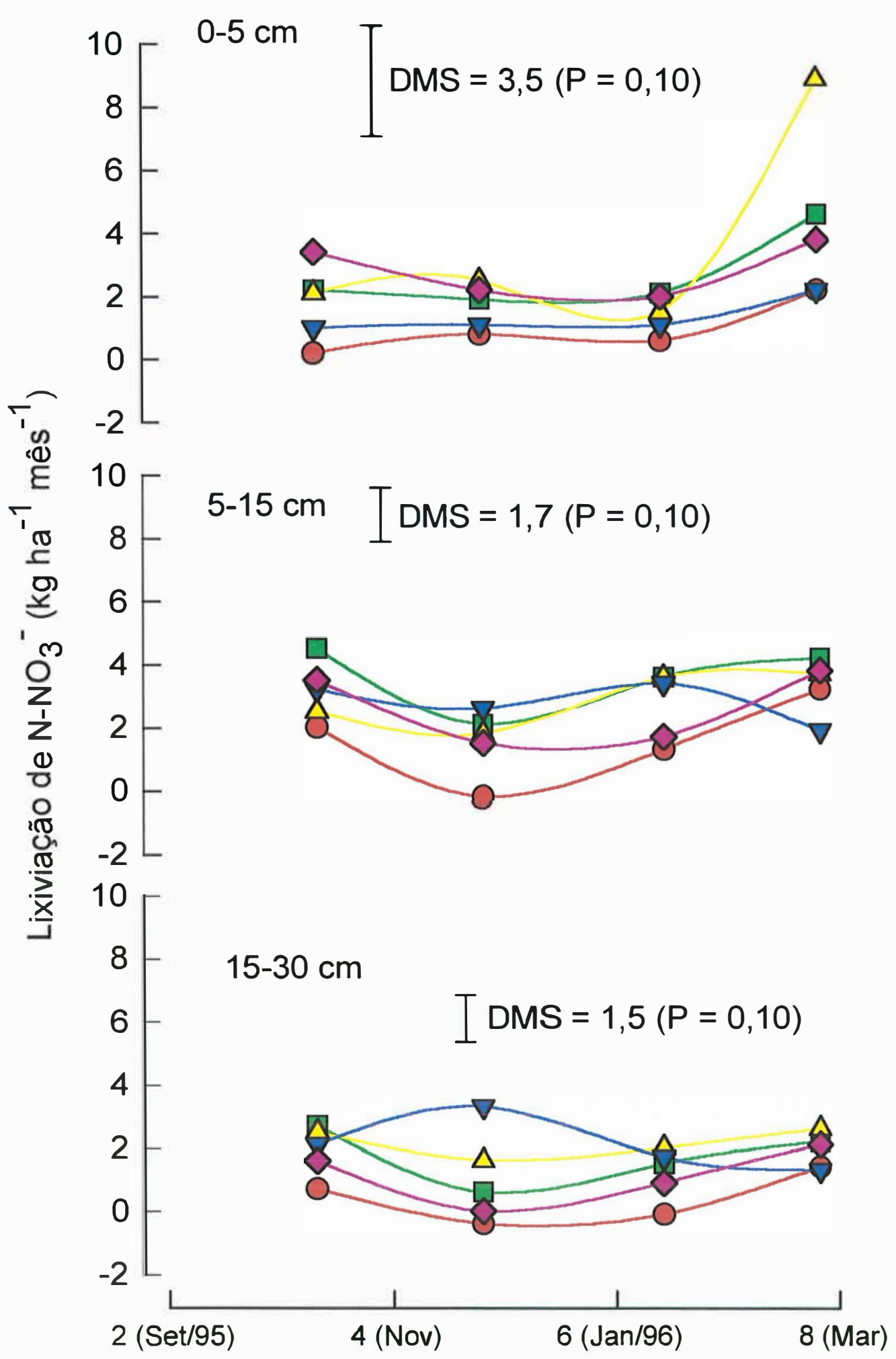

Meses após o corte raso do povoamento

Figura 13. Taxas líquidas de lixiviação de $\mathrm{N}^{-\mathrm{NO}_{3}}{ }^{-}$no solo. 


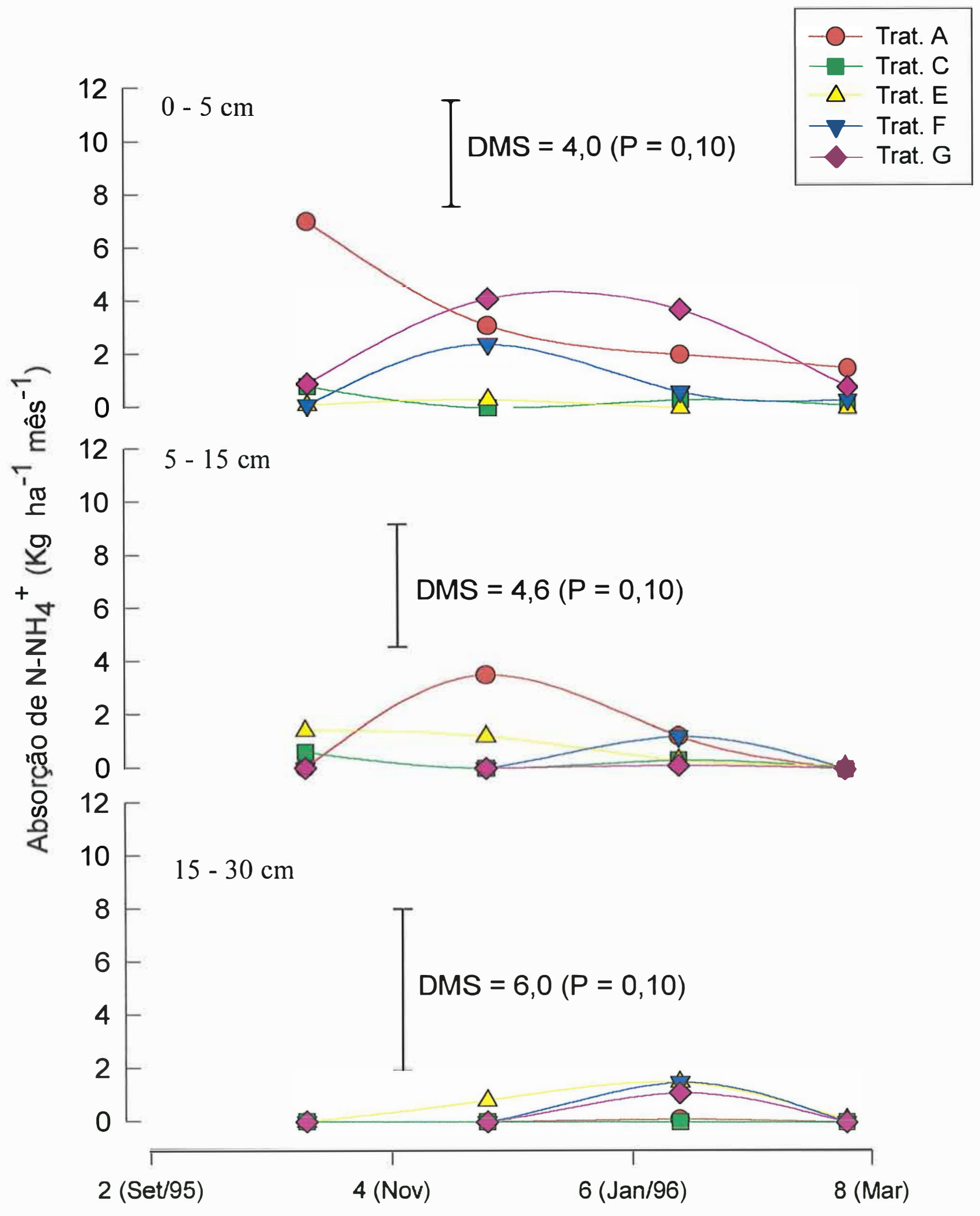

Meses após o corte raso do povoamento

Figura 14. Taxas líquidas de absorção de $\mathrm{N}-\mathrm{NH}_{4}{ }^{+}$no solo. 


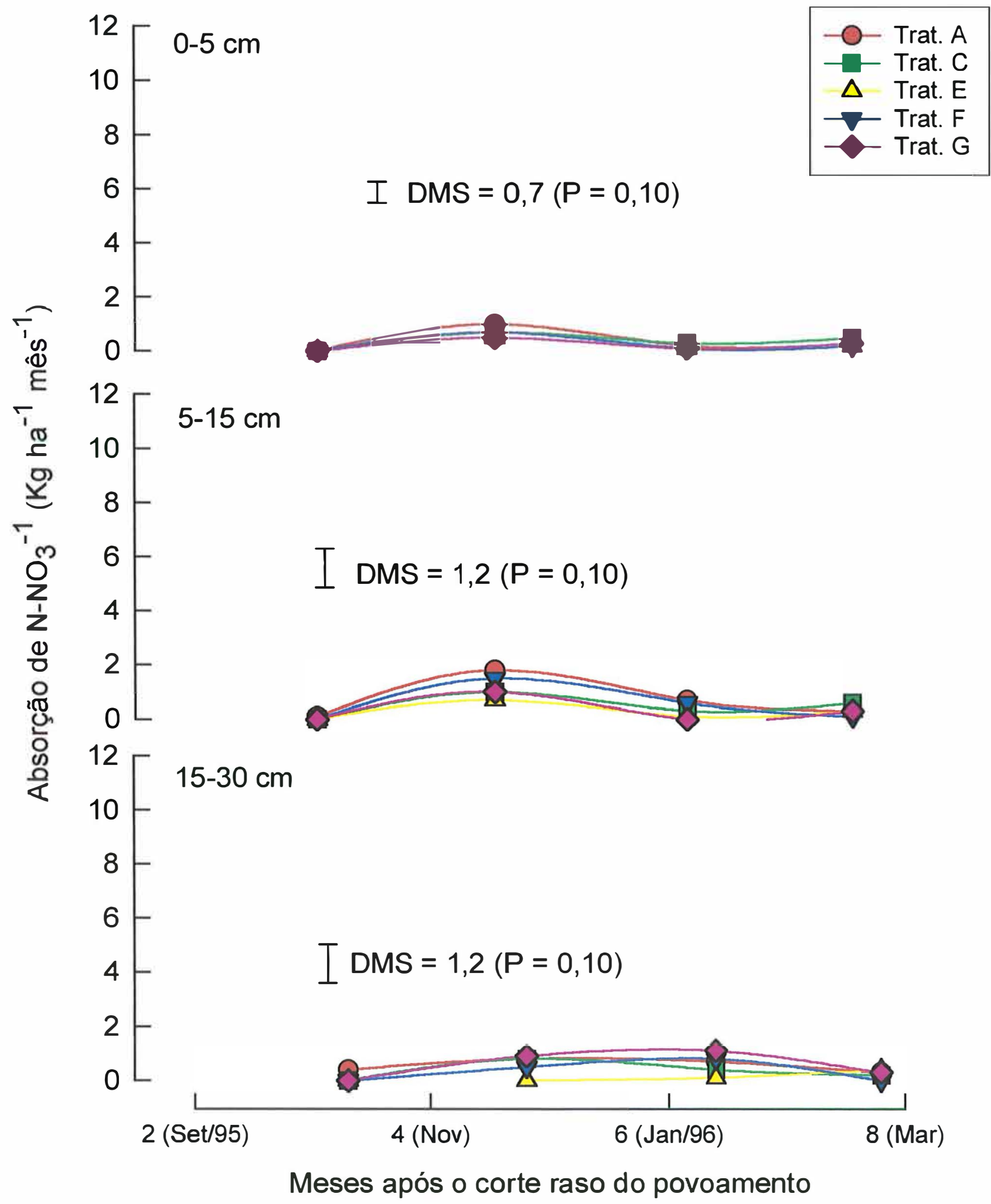

Figura 15. Taxas líquidas de absorção de $\mathrm{N}-\mathrm{NO}_{3}{ }^{-}$do solo. 


\subsection{Balanço das quantidades de $\mathrm{N}$ mineralizadas, absorvidas e lixiviadas}

Nos povoamento adulto de Eucalyptus grandis a forma mais mineralizada e absorvida de $\mathrm{N}$ foi a amoniacal. (Tabela 10).

De modo geral, com exceção do tratamento $\mathrm{A}, \circ \mathrm{N}-\mathrm{NO}_{3}{ }^{-}$foi a forma de $\mathrm{N}$ mais mineralizada e lixiviada em todos tratamentos. A remoção, queima ou incorporação dos residuos favoreceram os microrganismos nitrificadores, reduzindo, consideravelmente, a relação $\mathrm{N}_{-} \mathrm{NH}_{4}^{+}: \mathrm{N}-\mathrm{NO}_{3}{ }^{-}$, particularmente quando a queima foi realizada.

Transformando as quantidades de $\mathrm{N}_{-} \mathrm{NH}_{4}^{+}$e de $\mathrm{N}-\mathrm{NO}_{3}{ }^{-}$ mineralizadas, lixiviadas e absorvidas entre os meses de setembro de 1995 a março de 1996, em quantidades de $\mathbf{N}$, em cada uma das camadas do solo, verifica-se que a mineralização de $\mathrm{N}$, basicamente, restringiu-se às camadas superficiais do solo, bem como a absorção das formas inorgânicas de $\mathrm{N}$, sendo mínimo o potencial de absorção na camada de $15-30 \mathrm{~cm}$ (Tabela 11).

As maiores quantidades de $\mathrm{N}$ mineralizadas foram observadas nos tratamentos $A, F, C$, e $E$, ou seja, onde os organismos do solo tiveram mais substrato para processar. Cerca de 25 a $40 \mathrm{~kg} \mathrm{ha}^{-1}$ de $\mathrm{N}$ foram mineralizados (Tabela 12), o que justifica a falta ou pequena ocorrência de resposta à adubação nitrogenada observada em povoamentos florestais de eucaliptos (Barros et al., 1990 e Gonçalves, 1995a), uma vez que a demanda média anual de $\mathrm{N}$ em florestas de eucaliptos varia de 20 a $40 \mathrm{~kg} \mathrm{ha}^{-1} \mathrm{ano}^{-1}$ (Bellote et al., 1980; Reis et al. ,1987 e Poggiani \& Schumacher, 1997).

As entradas de nitrogênio resultantes da decomposição da matéria orgânica e mineralização do N, observadas nesses 6 meses de estudo, foram muito maiores que do que as entradas anuais via precipitação. Segundo Poggiani \& Schumacher (1997), a entrada anual de $N$ via precipitação pluviométrica é cerca de 6,5 a $7,3 \mathrm{~kg} \mathrm{ha}^{-1}$ ano $^{-1}$.

No tratamento G (Queima) foram verificadas as menores quantidades de $\mathrm{N}$ mineralizadas $\left(16,4 \mathrm{~kg} \mathrm{ha}^{-1}\right)$. É sabido que as quantidades 
perdidas de $\mathrm{N}$, por volatilização, durante a queima são apreciáveis (Maluf, 1991). Segundo este pesquisador, $88 \%$ do $N$ contido nos resíduos é perdido, por volatilização e por movimento de partículas, com a queima. No presente estudo, isto corresponderia a perdas de $260,0 \mathrm{~kg} \mathrm{ha}^{-1}$ de $\mathrm{N}$, o que reduz consideravelmente as quantidades de $\mathrm{N}$ potencialmente mineralizáveis.

As quantidades de $\mathrm{N}$ absorvidas nos tratamentos $\mathrm{C}, \mathrm{E}, \mathrm{F}$ e $G$, onde foi feito o corte raso do povoamento, são atribuídas, preferencialmente, à brotação das cepas das árvores abatidas e às plantas invasoras. As maiores quantidades absorvidas foram verificadas no tratamento $G$, onde houve a maior infestação por plantas invasoras. A presença de resíduos sobre o solo inibiu a infestação por plantas invasoras no tratamento $C$ (Silva et al., 1997). 
Tabela 10. Quantidades de $\mathrm{N}-\mathrm{NH}_{4}{ }^{+}$e de $\mathrm{N}-\mathrm{NO}_{3}{ }^{-}$mineralizadas, lixiviadas e absorvidas na profundidade de $0-30 \mathrm{~cm}$ do solo $\left(\mathrm{kg} \mathrm{ha}^{-1}\right)$, nos 4 períodos de incubação compreendidos entre os meses de Setembro de 1995 e Março de 1996.

\begin{tabular}{|c|c|c|c|c|c|c|c|c|c|c|}
\hline \multirow[t]{2}{*}{ Tratamento } & \multicolumn{5}{|c|}{$\mathrm{N}-\mathrm{NH}_{4}{ }^{+}$Mineralizado } & \multicolumn{5}{|c|}{$\mathrm{N}-\mathrm{NO}_{3}{ }^{-}$Mineralizado } \\
\hline & $1^{0}$ & $2^{\circ}$ & $3^{\circ}$ & $4^{\circ}$ & Total & $1^{0}$ & $2^{\circ}$ & $3^{\circ}$ & $4^{\circ}$ & Total \\
\hline $\begin{array}{l}A \\
C \\
E \\
F \\
G\end{array}$ & $\begin{array}{c}14,0 \\
0,2 \\
0,2 \\
0,7 \\
1,1\end{array}$ & $\begin{array}{c}18,1 \\
6,3 \\
9,7 \\
26,7 \\
3,9\end{array}$ & $\begin{array}{c}9,9 \\
11,9 \\
3,2 \\
5,7 \\
<0,2\end{array}$ & $\begin{array}{l}2,8 \\
2,2 \\
6,7 \\
2,7 \\
4,4\end{array}$ & $\begin{array}{c}44,8 \\
20,6 \\
19,8 \\
35,8 \\
9,4\end{array}$ & $\begin{array}{c}4,7 \\
10,2 \\
6,3 \\
5,6 \\
9,4\end{array}$ & $\begin{array}{c}6,9 \\
12,4 \\
10,4 \\
14,3 \\
13,5\end{array}$ & $\begin{array}{c}5,6 \\
10,3 \\
8,6 \\
8,9 \\
6,1\end{array}$ & $\begin{array}{c}10,2 \\
15,2 \\
13,5 \\
7,9 \\
10,7\end{array}$ & $\begin{array}{l}27,4 \\
48,1 \\
38,8 \\
36,7 \\
39,7\end{array}$ \\
\hline & \multicolumn{5}{|c|}{$\mathrm{N}-\mathrm{NH}_{4}{ }^{+}$Lixiviado } & \multicolumn{5}{|c|}{$\mathrm{N}-\mathrm{NO}_{3}{ }^{-}$Lixiviado } \\
\hline $\begin{array}{l}A \\
C \\
E \\
F \\
G\end{array}$ & $\begin{array}{c}<0,2 \\
1,4 \\
0,2 \\
1,5 \\
0,6\end{array}$ & $\begin{array}{c}5,5 \\
6,4 \\
3,5 \\
5,9 \\
<0,2\end{array}$ & $\begin{array}{c}5,0 \\
15,8 \\
8,7 \\
3,3 \\
0,3\end{array}$ & $\begin{array}{l}1,9 \\
2,5 \\
8,3 \\
1,9 \\
2,4\end{array}$ & $\begin{array}{c}12,4 \\
26,1 \\
20,7 \\
12,6 \\
3,3\end{array}$ & $\begin{array}{c}4,4 \\
14,2 \\
10,7 \\
9,4 \\
12,7\end{array}$ & $\begin{array}{c}1,2 \\
7,3 \\
9,3 \\
11,2 \\
5,9\end{array}$ & $\begin{array}{c}3,1 \\
11,8 \\
11,2 \\
10,1 \\
7,4\end{array}$ & $\begin{array}{c}9,9 \\
16,1 \\
22,2 \\
7,9 \\
14,2\end{array}$ & $\begin{array}{l}18,6 \\
49,4 \\
53,4 \\
38,6 \\
40,2\end{array}$ \\
\hline & \multicolumn{5}{|c|}{$\mathrm{N}-\mathrm{NH}_{4}{ }^{+}$Absorvido } & \multicolumn{5}{|c|}{$\mathrm{N}-\mathrm{NO}_{3}{ }^{-}$Absorvido } \\
\hline $\begin{array}{l}A \\
C \\
E \\
F \\
G\end{array}$ & $\begin{array}{c}10,2 \\
2,1 \\
2,3 \\
<0,2 \\
1,3\end{array}$ & $\begin{array}{l}10,1 \\
<0,2 \\
3,4 \\
3,7 \\
6,3\end{array}$ & $\begin{array}{l}5,2 \\
0,9 \\
2,8 \\
5,3 \\
7,5\end{array}$ & $\begin{array}{c}2,2 \\
<0,2 \\
0,2 \\
<0,2 \\
1,1\end{array}$ & $\begin{array}{c}27,7 \\
3,0 \\
8,7 \\
9,0 \\
16,2\end{array}$ & $\begin{array}{l}0,7 \\
<0,2 \\
<0,2 \\
<0,2 \\
<0,2\end{array}$ & $\begin{array}{l}5,5 \\
3,8 \\
1,9 \\
4,0 \\
3,7\end{array}$ & $\begin{array}{l}2,5 \\
1,5 \\
0,6 \\
2,2 \\
1,8\end{array}$ & $\begin{array}{l}1,4 \\
1,8 \\
1,3 \\
0,5 \\
1,4\end{array}$ & $\begin{array}{l}10,1 \\
7,1 \\
3,8 \\
6,7 \\
6,9\end{array}$ \\
\hline
\end{tabular}


Tabela 11. Quantidades de $N$ mineralizadas, lixiviadas e absorvidas ( $\mathrm{kg} \mathrm{ha}^{-1}$ ), no solo sob povoamento de Eucalyptus grandis, entre os meses de Setembro de 1995 e Março de 1996, nas profundidades de $0-5,5-15,15-30 \mathrm{~cm}$.

\begin{tabular}{cccc}
\hline Profundidade & N-Mineralizado & N-Lixiviado & N-Absorvido \\
\cline { 2 - 4 } cm & $27,5(67 \%)^{1}$ & $5,9(42 \%)$ & $16,3(68 \%)$ \\
$0-5$ & $11,2(27 \%)$ & $5,2(37 \%)$ & $6,7(28 \%)$ \\
$5-15$ & $2,6(6,0 \%)$ & $2,9(21 \%)$ & $0,9(4 \%)$ \\
$15-30$ & 41,3 & 14,0 & 23,9 \\
Total & & $\mathrm{ha}^{-1}$ & \\
\hline
\end{tabular}

'Percentual em relação ao total.

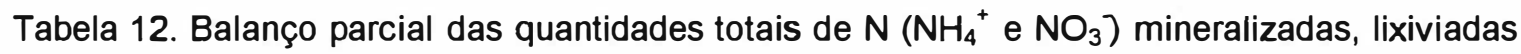
e absorvidas $\left(\mathrm{kg} \mathrm{ha}^{-1}\right)$, na profundidade de $0-30 \mathrm{~cm}$, para os diferentes tratamentos entre os meses de Setembro de 1995 e Março de 1996.

\begin{tabular}{crrrrr}
\hline & \multicolumn{4}{c}{ Tratamentos } \\
Nitrogênio & A & C & E & F & G \\
\cline { 2 - 6 } & & & $\mathrm{kg} \mathrm{ha}^{-1}$ & & \\
Mineralizado & 41,2 & 27,2 & 24,3 & 36,3 & 16,4 \\
Lixiviado & 14,0 & 31,7 & 28,4 & 18,7 & 11,8 \\
Absorvido & 23,9 & 3,9 & 7,7 & 8,5 & 14,3 \\
\hline
\end{tabular}




\section{CONCLUSÕES}

1. O corte raso favoreceu a nitrificação independente do manejo dado aos resíduos e do preparo do solo;

2. As maiores quantidades de $\mathrm{N}$ lixiviadas foram na forma nítrica (forma mais móvel no perfil de solo);

3. No povoamento de Eucalyptus grandis a forma predominante e mais absorvida de $\mathrm{N}$ foi a amoniacal;

4. A manutencão dos resíduos sobre o solo, após o corte raso do povoamento reduziu as oscilações térmicas e hídricas do solo em relação às observadas nos tratamentos onde os resíduos foram queimados, removidos ou incorporados;

5. As menores oscilações térmicas e hídricas do solo observadas no tratamento onde os resíduos foram mantidos sobre o solo (cultivo mínimo) afetaram positivamente a mineralização da matéria orgânica; 


\section{APLICAÇÕES PRÁTICAS}

1. Considerando que a forma de $\mathrm{N}$ preferencialmente absorvida pelas árvores foi $\circ \mathrm{NH}_{4}^{+}$e que o pH desse solo encontra-se na faixa de 3,5 a 4,5 , recomenda-se utilizar fontes de adubo contendo o $\mathrm{NH}_{4}^{+}$;

2. Em virtude das altas taxas de mineralização de $\mathrm{N}$, após o corte raso do povoamento, a adubação nitrogenada de base deve limitar-se às quantidades mínimas necessárias para o arranque das mudas $\left(\leq 20 \mathrm{~kg} \mathrm{ha}^{-1}\right)$;

3. As menores quantidades de $\mathrm{N}$ lixiviadas no tratamento com maior infestação por plantas invasoras (Tratamento G), evidencia a importância de um bom manejo dessas plantas visando a retenção de nutrientes no sítio. 


\section{REFERÊNCIAS BIBLIOGRÁFICAS}

ADAMS, M.A.; ATTIWILL, P.M. Nitrogen mineralization and nitrate reduction in forests soils. Biology and Biochemistry, v.14, p.197-202, 1982.

ADAMS, M.A.; ATTIWILL, P.M. Nutrient cycling and nitrogen mineralization in eucalypt forests of souther-eastern Australia- I. Nutrient cycling and nitrogen turnover, Plant and Soil, v.92, p.319-339, 1986a.

ADAMS, M.A.; ATTIWILL, P.M. Nutrient cycling and nitrogen mineralization in eucalypt forests of souther-eastern Australia- II. Indices of nitrogen mineralization, Plant and Soil, v.92, p.341-362, 1986b.

ADAMS, M.A.; ATTIWILL, P.M. Nutrient balance in forests of northern Tasmania. II-Alteration of nutrient avaialability and soil-water chemistry as a result of logging, slashburning and fertilizer application. Forest Ecology and Management, v.44, p.115-131, 1991.

ALEXANDER, M. Introduction to soil microbiology. New York: John Wiley, 1977. 467p.

ALISSON, F.E. Soil organic matter and its role in crop production. Amsterdam: Elsevier, 1973. 637p.(Developments in Soil Science, v.3) 
ALVES, J.B.R. Avaliação da mineralização do $\mathbf{N}$ do solo in situ. Itaguaí, 1992. 177p. Dissertação (M. S.) - Instituto de Agronomia, Universidade Federal Rural do Rio de Janeiro.

BARROS, N.F.; NOVAIS, R.F.; NEVES, J.C.L. Fertilização e correção do solo para o plantio de eucalipto. In: BARROS, N.F.; NOVAIS, R.F. (Eds.). Relação Solo-Eucalipto. Viçosa: Folha de Viçosa, p.127-186, 1990.

BELLOTE, A.F.J.; SARRUGE, J.R.; HAAG, P.H.; OLIVEIRA, G.D. Extração e exportação de nutrientes pelo Eucalyptus grandis Hill, exMaiden em função de idade: 1 - Macronutrientes. IPEF, v.20, p.1-23, 1980.

BINKLEY, D. Ion exchange resin bags: Fattors affecting estimates of nitrogen availability. Soil Science Society of America Journal., v.48, p.1181-1184, 1984.

BINKLEY, D.; MATSON, P.lon exchange resin bag method for assessing forest soil nitrogen availability. Soil Science Society of America Journal, v.47, p.1050-1052, 1983.

BINKLEY, D.; HART, S.C. The components of Nitrogen Availability Assessments in forests soils. Advances in Soil Science, v.10, p.57-112, 1989.

BIRCH, H. F. Nitrification in soils after different periods of dryness. Plant and Soil, v.12, p.81-96, 1960. 
BORMANN, F.H.; LIKENS, G.E.; FISHER, D.W.; PIERCE, R.S. Nutrient loss accelerated by clear-cutting of a forest ecosystem. Science, v. 159, p. $882-884,1968$.

BREMNER, J.M. Organic nitrogen in soils. In: BARTHOLOMEW, W.V.\& CLARK, F.E. (Eds.) Soil nitrogen.Madson:American Society of Agronomy, 1965. p.93-149. (Agronomy, v.10).

BURGER, J.; PRITCHETT, W. Effects of clearfelling and site preparation on nitrogen mineralization in a Southern pine stand. Soil Science Society of America Journal, v.48, p.1432-1437, 1984.

CAMERON, D.R.; KOWALENKO, C.G. Moddelling nitrogen processes in soil: mathematical development and relations. Canadian Journal of Soil Science, v.56, p.71-78, 1976

CAMPBELL, C.A. Soil organic carbon, nitrogen and fertility. In: SCHNITZER, M. \& KHAN, S.U. (Eds.) Soil Organic Matter, p.173-272. Amsterdam. Elsevier, 1978.

CARLYLE, J.C. Nitrogen cycling in forested ecosystems. Forest Abstract., v.47, p.307-336, 1986.

CARLYLE, J.C. Nutrient management in a Pinus radiata plantation after thinning: the effect of thinning and residues on nutrient distribuition, mineral nitrogen fluxes, and extractable phosphorus. Canadian Journal Forestry Research. v.25, p.1278-1291, 1995. 
CERRI, C.C.; VOLKOFF, B.; ANDREAUX, F. Nature and behaviour of organic matter in soils under natural forest, and after deforestation, burning and cultivation, near Manaus. Forest Ecology and Management, v.38, p.247257, 1991.

Di STEFANO, J.; GHOLZ, H. A proposed of ion exchange resin to measure nitrogen mineralization and nitrification in intact soil cores. Communications in Soil Science and Plant Analysis, v.17, p.989-998, 1986.

ELLIS, R.C. The sazonal pattern of nitrogen and carbon mineralization in forest and pasture soils in southern Ontario. Canadian Journal of Soil Science, v.54, p.15-28, 1974.

EMPRESA BRASILEIRA DE PESQUISA AGROPECUÁRIA. Manual de métodos de análise do solo. Rio de Janeiro. SNLCS, 1979. (s.n.p.)

FASSBENDER, H.W.; BORNEMISZA, E. Química de suelos: con énfasis en suelos de America Latina. San José: IICA,1987. cap.7, p. 199-253.

FEIGGL, B.J.; SPARLING, G.P.; ROSS, D.J.; CERRI, C.C. Soil microbial biomass in Amazonian soils: evaluation of methods and estimates of pool sizes. Soil Biology Biochemistry, v.27, p.1467-1472, 1995.

FIALHO, J.F.; BORGES, AC.; BARROS,N.F. Cobertura vegetal e as carcterísticas químicas e físicas e atividade da microbiota de um latossolo vermelho-amarelo distrófico. Revista Brasileira de Ciência do Solo, v.15, p.21-28 
FLINN, D.W.; HOPMANS, P.; FARREL, P.W.; JAMES, J.M. Nutrient losses from the burning of Pinus radiata logging residue. Autralian Forestry Research., v.9, p.17-23, 1979.

FLINN, D. W.; SQUIRE, R.O.; FARREL, P.W. The role of organic matter in the maintenance of productivity on sandy soils. New Zealand Journal of Forest Science, v.25, p.229-236, 1980.

GONÇALVES, J.L.M. Recomendações de adubação para Eucalyptus, Pinus e espécies típicas da Mata Atlântica. Documentos Florestais, n.15, p.1-23, 1995a.

GONÇALVES, J.L.M. Sistema radicular de absorção do Eucalyptus grandis sob diferentes condições edáficas. Silvicultura, n. 61, p.8-10, 1995b.

GONÇALVES, J.L.M. SEMINÁRIO SOBRE CULTIVO MÍNIMO DO SOLO EM FLORESTAS, 1, Curitiba, 1995. Anais.Piracicaba, CNPFloresta / IPEF / UNESP / SIF / FUPEF, 1995c. 162p.

HALL, M. Establishment of radiata pine on a high altitude second rotation site. I. Effect of site preparation on nutrient capital. Australian Forestry, v.47, p.194-198, 1984.

HART, S.C.; BINKLEY, D. Correlations among indices of forest soil nutrient availability in fertilized and unfertilized loblolly pine plantations. Plant and Soil, v.85, p.11-21, 1985. 
HART, S.C. \& FIRESTONE, M.K. Evaluation of three in situ soil nitrogen availability assays. Canadian Journal Forest Research, v.19, n.2, p.185-191, 1989.

HOPMANS, P.; FLINN, D.W.; FARREL, P.W. Nitrogen mineralization in a sandy soil under native eucalypt forest and exotic pine plantations in relation to moisture content. Communications in Soil Science and Plant Analysis, v.11, n.1, p.71-79, 1980.

KEENEY, D.; BREMNER, J. A chemical index of soil nitogen availability. Nature, v.211, p.892-893, 1966.

LAMB, D. Soil nitrogen mineralization in a secundary rainforest sucession. Oecologia, v.47, p.257-263, 1980.

LUIZÃO, R.C.C.; BONDE, T.A.; ROSSWALL, T. Seasonal variation of soil microbial biomass - The effects of clearfelling a tropical rainforest and establisment of pasture in the Central Amazon. Soil Biology Biochemistry, v.24, p.805-813, 1992.

MALUF, J.P.L. Efeito da queima, métodos, do preparo do solo e da adubação no crescimento de Eucalyptus camaldulensis em areia quartzosa. Viçosa, 1991.78p. Dissertação (M.S.) Universidade Federal de Viçosa.

MARKS, P.L.; BORMANN, F. H. Revegetation following forest cutting: mechanisms for return to steady - state nutrient cycling. Science, v.176, p.914-915, 1972. 
MARTINS, P.F. da S.; CERRI, C.C.; VOLKOFF,B.; ANDREUX, F.; CHAUVEL, A. Consequences of clearing and tillage on the soil of a natural Amazonian ecosystem. Forest Ecology and Management, v.38, p.273-282, 1991.

MATSON, P.A.; VITOUSEK, P.M. Nitrogen mineralization and nitrification potencials following clearcutting in the Hoosier National Forest, Indiana. Forest Science, v.27, p.781-791, 1981.

MELLILO, J.M. Nitrogen cycling in deciduous forests. In: CLARK, F.E.; ROSWALL, T. (Ed.). Terrrestrial nitrogen cycle: processes, ecosystem strategies and management impacts. Stockholm, 1981, p.631-642 (Ecological Bulletins, v.33).

MELLO, S.L. de M. Características do sistema radicular de povoamentos de eucaliptos propagados por sementes e estacas. Piracicaba, 1997. 71p.Dissertação (M.S.) - Escola Superior de Agricultura "Luiz de Queiroz", Universidade de São Paulo.

NADELHOFFER, K.J.; ABER, J.D.; MELLILO, J.M. Leaf litter production and soil organic matter dynamics along a nitrogen availability gradient in Southern Wisconsin (USA), Canadian Journal of Forest Research, v.13, p.12-21, 1983.

NADELHOFFER, K.J. \& ABER, J.D. Seasonal patterns of amonium and nitrate uptake in pine temperate forest ecosystems. Plant and Soil, v.80, p.321$335,1984$.

NEILL, C.; PICCOLO, M.C. STEUDLER, P.A.; MELLILO, J.M.; FEIGL, B.J.; CERRI, C.C. Nitrogen dynamics in soils of forests and active pastures in the 
western Brazilian Amazon Basin. Soil Biology Biochemistry, v.27, p.1167$1175,1995$.

NEILL, C.; PICCOLO, M.C.; CERRI, C.C.; STEUDLER, P.A.; MELLILO, J.M.; BRITO, M. de M. P.Net mineraliation and net nitrification rates in soils following deforestation for pasture across the southwestern Brazilian Amazon Basin landscape. Oecologia, v.110, p.243-252, 1997.

PICCOLO, M.C. Comportamento do nitrogênio do solo em cronosseqüências de floresta-pastagem em Rondônia. Piracicaba, 1994. 69p. Tese (Doutorado) - Centro de Energia Nuclear na Agricultura, Universidade de São Paulo.

PICCOLO, M.C.; NEILL, C.; CERRI, C. Net mineralization and net nitrification along a tropical forest -to-pasture chronosequence. Plant and Soil, v.162, p.61-70, 1994.

POGGIANI, F.; SHUMACHER, M.V.Atmospheric inputs compared with nutrient removed by harvesting from Eucalyptus plantation: implications for sustainability. In: Conferência IUFRO sobre silvicultura e melhoramento de Eucaliptos, Salvador, 1997. Anais. Colombo: EMBRAPA,1997. p.68-74.

POWERS, F. P.Mineralizable soil nitrogen as an index of nitrogen availability to forest trees. Soil Science Society of America Journal, v.44, p.1314-1320, 1980.

RAIJ, B.van; QUAGGIO, J.A.; CANTARELLA, H.; FERREIRA, M.E.; LOPES, A.S.; BATAGLIA, O.C. Análise química de solo para fins de fertilidade. Campinas: Fundação Cargill, 1987. 170p. 
RAISON, R. J. Modification on the soil environment by vegetation fires, with particular reference to nitrogen transformations: a review. Plant and Soil, v.51, p.73-108, 1979.

RAISON, R. J.; CONNEL, M. J.; KHANNA, P.K. Methodology for studyng fluxes of soil mineral in situ. Soil Biology Biochemistry, v.19, n. 5, 521-530, 1987.

RAISON, R.J.; KHANNA, P.K.; CONNELL, M.J.; FAULKINER, R.A. Effects of water availability and nitrogen fertilization on nitrogen cycling in a stand of Pinus radiata. Forest Ecology and Management, v.3, p.31-43, 1990.

REIS, M.G.F.; BARROS, N.F. AND KIMMINS, J.P.Acúmulo de nutrientes em uma seqüência de idade de Eucalyptus grandis W. Hill (ex Maiden) plantado no cerrado, em duas áreas com diferentes produtividades, em Minas Gerais. Revista Árvore, v.11, p.1-15, 1987.

RUZICKA, J.; HANSEN, E.H. Flow injection anaysis. Part I. The concept of a new, simple, ultrafast continuous flow analyser. Analitica Chimica Acta, v.78, p.145-157, 1975.

SANCHES, P.A. Properties and management of soils in the tropics. New York: john Wiley \& Sons, 1976. 618p.

SARRUGE, J.R.; HAAG, P.H. Análise química em plantas, Piracicaba: ESALQ, 1974. 56p. 
SAS Institute Inc. SAS, STAT User's Guide, version 6, fourth Edition, v.2, 1990.

SILVA, C.R. da; GONÇALVES, J.L. de M.; FOLEGATTI, B. da S.; STAPE, J.L.; GAVA, J.L. Infestação de plantas invasoras em povoamentos de eucalipto estabelecidos nos sistemas de cultivo mínimo e intensivo do solo. In: Conferência IUFRO sobre silvicultura e melhoramento de Eucaliptos, Salvador, 1997. Anais. Colombo: EMBRAPA, 1997.p.234-241.

SMETHURST, P.J.; NAMBIAR, E. K. An appraisal of the in situ soil-core technique for measuring nitrogen uptake by a yong Pinus radiata plantation. Soil Biology Biochemistry, v.21, p.939-942, 1989.

SMETHURST, P.J.; NAMBIAR, E. K. Distribution of carbon and nutrients and fluxes of mineral nitrogen after-clearfelling a Pinus radiata plantation. Canadian Journal Forestry Research, v.20, p.1490-1497, 1990a.

SMETHURST, P.J.; NAMBIAR, E. K. Effects os slash and litter management on fluxes of nitrogen and tree growth in a young Pinus radiata planntation. Canadian Journal Forestry Research, v.20, p.1498-1507, 1990b.

SOCIEDADE BRASILEIRA SILVICULTURA. A sociedade brasileira e seu patrimonio florestal, São Paulo, 1990. 20p.

SOEST, P.J.van. Use of detergents in the analysis of fibrous II. A rapid method for the determination of fiber and lignin. Official Agr. Chem., v.46, n.5, p.829-835, 1963. 
SQUIRE, R.O.; FLINN, D.W.; FARREL, P.W. Productivity of first and second rotation stands of radiata pine on sandy soils. I - site factors affecting early growth. Australian Forestry, v.42, p.226-235, 1979.

STANFORD, G.; SMITH, S. J. Nitrogen mineralization potencials of soils. Soil Science Society of America Proceedings, v.36, p.465-472, 1972.

STANFORD, G.; FRERE, M.H.; SCHWANINGER, D.E. Temperature coefficient of soil nitrogen mineralization. Soil Science, v.115, p.321-323, 1973.

STANFORD, G.; EPSTEIN, L. Nitrogen mineralization - water relations in soils. Soil Science Society of America Proceedings., v.38, p.103-106, 1974.

STEVENSON, F.J. Cycles of Soil: carbon, nitrogen, phosphorus, sulfur, micronutrients. New York: John Wiley \& Sons, 1986. Cap.4, p.155-215.

THEODOROU, C.; BOWEN, G. D. Microbiological studies of first and second rotation pine foest Soils in south Australia. Autralian Forest Research, v.11, p.129-139, 1981.

THEODOROU, C.; BOWEN, G. D. Effects of a bushfire on the microbiology of a south australian low open (dry sclerophyll) forest soil. Australian Forestry Research, v.12, p.317-327, 1982.

THEODOROU, C.; BOWEN, G. D. Effects of temperature, moisture and litter on nitrogen mineralization in Pinus radiata forest soils. Australian Forestry Research, v.13, p. 113-119, 1983. 
THORNTHWAITE, C.W. ; MATHER, J.R. The water balance. 1955. 104p. (Publications in Climatology, v.8).

VITOUSEK, P.M.; MATSON, P.A. Disturbance, nitrogen availability, and nitrogen losses in an intensively managed loblolly pine plantation. Ecology, v.66, p.1360-1376, 1985.

WAGLE, R.F.; KITCHEN, J.H. Influence of fire on soil nutrients in a Ponderosa pine type. Ecology, v.53, p.118-125, 1972.

WARING, S.A.; BREMNER, J.M. Amonium production in soil under waterlogged conditions as an index of nitrogen availability. Nature, v.201, p.951-952, 1964.

WESTERMANN, D.T.; CROTHERS, S.E. Measuring soil nitrogen mineralization under field conditions. Agronomy Joumal, v.72, p.1009-1012, 1980.

WHYNOT, T. W.; WEETMAN, G. F. Repeated fertilization effects on nitrogen fluxes measured by sequencial coring. Soil Science Society of American Journal, v.55, p.1101-1111, 1991.

WOODS, P.V., NAMBIAR, E.K.S.; SMETHURST, P.J. Effect of annual weeds on water and nitrogen availability to Pinus radiata trees in a young plantations. Forestry Ecology and Management, v.48, p.145163, 1992. 